\title{
PERCEPTIONS AND EVALUATION OF AN URBAN ENVIRONMENT FOR PEDESTRIAN FRIENDLINESS: A CASE STUDY
}

\author{
A Thesis \\ Presented to \\ the Faculty of California Polytechnic State University, \\ San Luis Obispo
}

\author{
In Partial Fulfillment \\ of the Requirements for the Degree
}

Master of City and Regional Planning in College of Architecture \& Environmental Design

By

Elizabeth Han Lee

October 2010 
(C) 2010

Elizabeth Han Lee

ALL RIGHTS RESERVED 
TITLE:

AUTHOR:

DATE SUBMITTED:

COMMITTEE CHAIR:

COMMITTEE MEMBER:

COMMITTEE MEMBER:
Perceptions and Evaluation of an Urban

Environment for Pedestrian Friendliness:

A Case Study

Elizabeth Han Lee

October 15, 2010
Chris Clark J.D., Lecturer

Joseph Ragsdale MLA, Associate Professor 


\begin{abstract}
Perceptions and Evaluation of an Urban Environment for Pedestrian Friendliness: A Case Study

Elizabeth Han Lee
\end{abstract}

Public health is an increasingly important issue addressed from both environmental and public health sectors for the future development of urban environments. From a planning perspective, one possible solution is to increase walkability throughout the cities. Many assessment methods are being developed and administered to evaluate the quality of existing urban environments to promote walkable cities/communities. The results from using these methods provide policymakers and stakeholders with valuable information regarding the existing physical conditions of the environment. Although several US cities started to develop and refocus plans toward pedestrian-oriented policies approaches, results from this particular study determined that the quality of pedestrian environments cannot solely be determined by using available assessment tools and recommend additional analytical methods used in conjunction with source data to provide a complete perspective to successfully increase the quality of life. The condition of the physical environment - high, average, and low quality - are important contributing factors to increase walkability, yet, it is equally important to understand and consider the needs, preferences and perceptions of end users when public officials are charged with the task of developing plan proposals for pedestrian neighborhoods. This study addresses these issues through a case study examining the quality of pedestrian environment and how people perceive those surroundings of downtown San Luis Obispo. Keywords: Pedestrian Environment, People's Perception, Pedestrian Activity, Health Assessment Tool, Pedestrian Behavior/Attitude, Case Study 


\section{ACKNOWLEDGEMENTS}

This study could not have been accomplished without the utmost help and support from the members of my thesis committee who have been tremendously inspiring as role models and advisors while I pursued my education at Cal Poly. I cannot express enough gratitude for the guidance and kindness from my thesis committee members, as they gave me confidence in what I was doing. I am sincerely thankful to my committee chair, Dr. Umut Toker, for his unfailing encouragements, challenges, and guidance. Because of his heart and passion for his students and the field of planning and design, I had more joy and motivation to continue with this study and to, once again, embrace the field of design. I am very thankful for my committee members, Professor Chris Clark and Professor Joseph Ragsdale, for their endless support, extensive advice, and other contributions to this study.

I am very grateful to have attended California Polytechnic State University, San Luis Obispo for the past seven years. Cal Poly never held back or limited my learning capability but expanded my parameters, providing me with countless opportunities and experiences.

Furthermore, I am very blessed to have met all of my friends at Cal Poly from the Landscape Architecture, City and Regional Planning, and Public Policy Departments. I am also extremely grateful for the long-lasting friendships I made from Asian American Christian Fellowship and Journey Christian Fellowship. The past seven years at Cal Poly have been a challenge but also the highlight of my life. The days I've spent and the conversations I've had with every one of you in classes, fellowship, church, 
dorms/apartments, and restaurants have placed a huge, permanent mark in my heart. I will never forget your faces, smiles, prayers and constant support. You all had such open hearts to understand me, and never ceased to pray with me and for me through times of trials. You always kept me informed of events and gatherings, oftentimes staying up with me as I finished working on projects and research papers. Because of your love, I have never felt alone but was always at home wherever I went. Thank you.

I greatly appreciate and express endless thanks to my two friends and editors of this thesis, Ricky Ng and Winston Ho. Your commitment and loyalty have truly helped me realize that I am blessed with a great community, who is sacrificially loving and caring. Your constant encouragement kept me going, to persevere and finish strong with this research study. I can always count on you, not only with editing my thesis, but also with life's experiences by taking care of me, helping me move, helping me cook, listening to me, laughing with me, worrying with me and the list goes on and on.

I am extremely blessed to have my family. Your unceasing prayers, love and support truly allowed me to become who I am today. No matter the circumstances, you have always supported and trusted me. This trust has surely helped me become responsible and loyal to the things I commit to doing. You endured through all the hardships and suffering, praised with me in times of joy and happiness, exhorted me to become a child of God, and encouraged me to press on. Thank you for constantly reaffirming that you will be there for me no matter what happens. Each one of you - Dad, Mom, Hanna and Jennifer - is undoubtedly my worthy role model and I strive to love you and give you more for I know the depth and length of how much you have sacrificed for me. Although we may not always be together and I often fail to express my endearing 
love for you, I love you and miss you more and more, each day. I can only love more because I am loved by each of you first and you are inevitably with me each step I take and turn I make in my life.

Lastly and most importantly, I praise my God - the Lord of hosts. I thank You for Your unceasing love and because of Your grace and mercy, I am here today, living this life that I do not deserve. You have blessed me unconditionally since my birth and constantly reaffirm me of your promise. You carried me through each step and protected me from all harm. My life alone is a living testimony of Your grace and I shall continue to live for Your kingdom and glory in everything I do until the day I see You, my Jesus, face to face. You are my Ultimate and in everything I do and as long as I live, may You be glorified.

Truly, "being confident of this, that He who began a good work in [me] will carry it on to completion until the day of Christ Jesus." -Philippians 1:6 - 


\section{TABLE OF CONTENTS}

Page

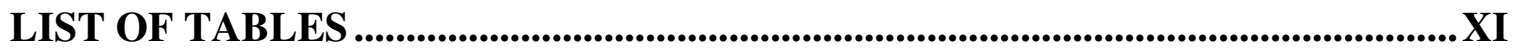

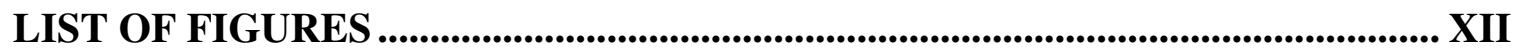

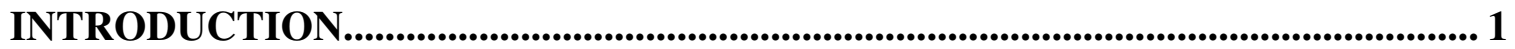

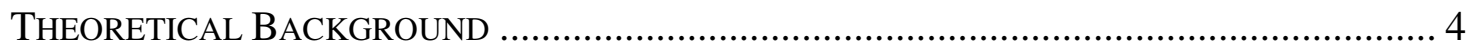

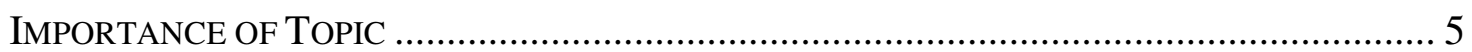

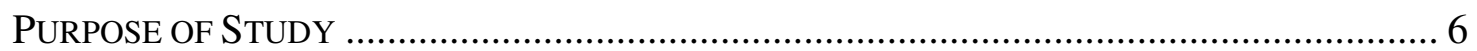

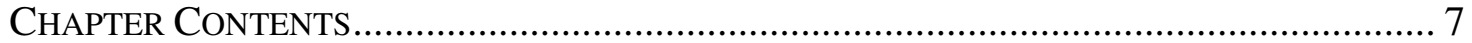

LITERATURE REVIEW ...................................................................................................... 8

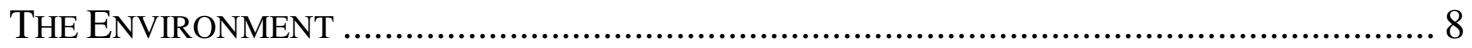

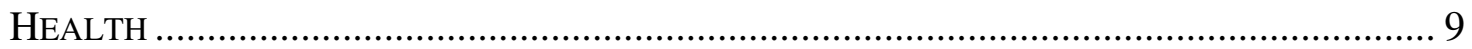

Lack of Physical Activity ............................................................................ 10

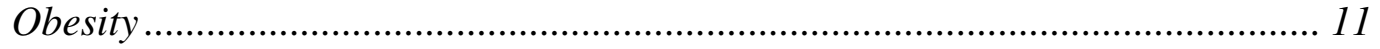

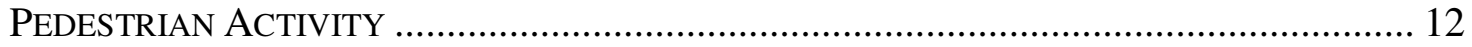

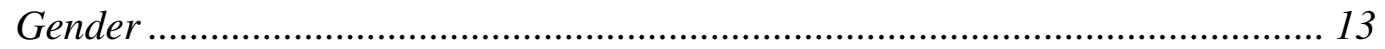

Age

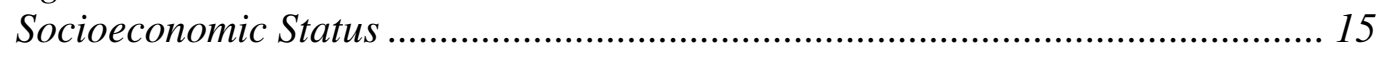

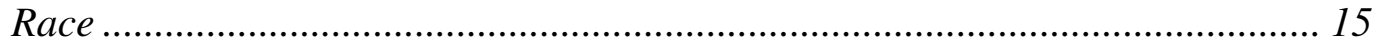

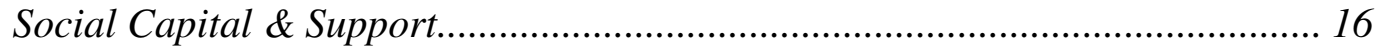

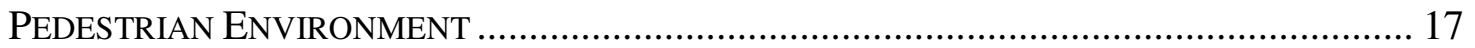

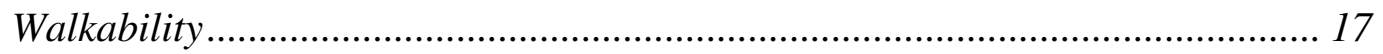

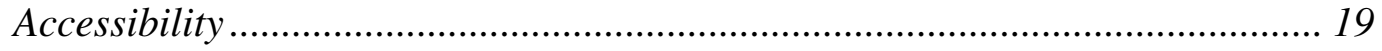

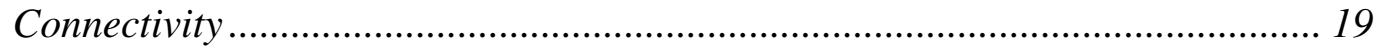

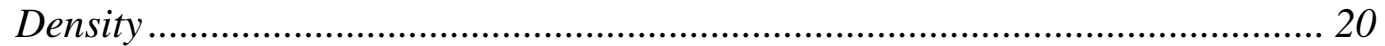

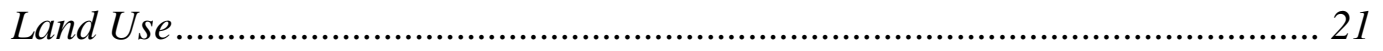

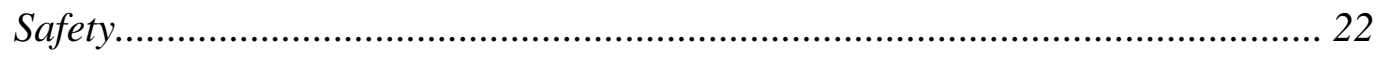

Aesthetical Quality ………………………………....................................... 23

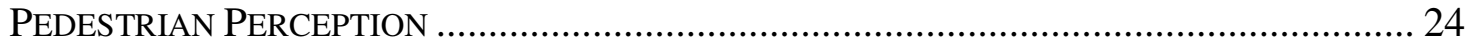

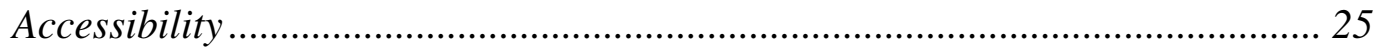

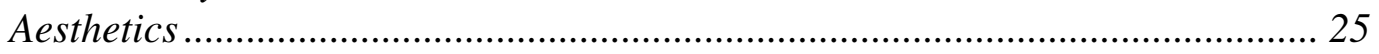

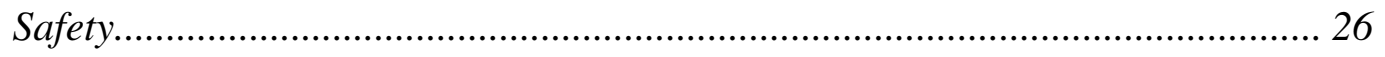

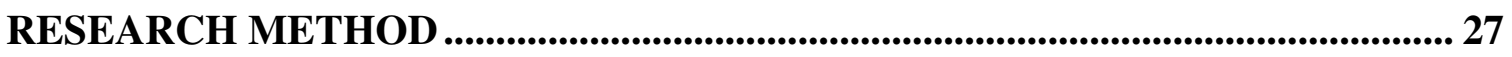

SUBJECTS AND SUBJECT SELECTION PROCEDURES ………...................................... 27

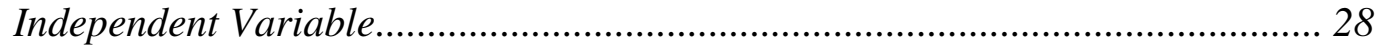

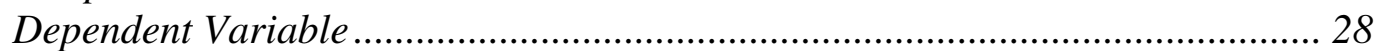

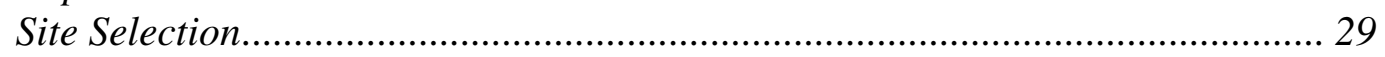

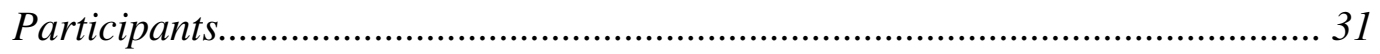

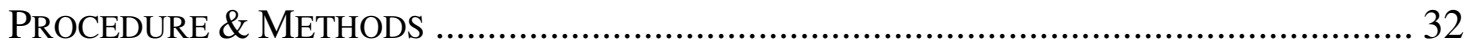

Pedestrian Environmental Quality Index (PEQI)........................................... 32

Pedestrian Perception Survey........................................................................ 33

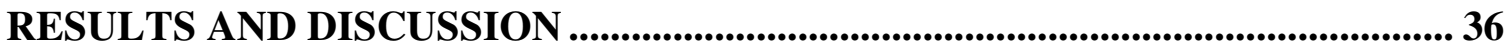

4.1 RESUltS OF PEDESTRIAN ENVIRONMENTAL QUALITY INDEX TOOL.......................... 36 
4.2 Results of Pedestrian PeRCEPTION SURVeY................................................... 38

4.2.1 ConTRIBUTING FACTORS TO STREET/INTERSECTION USE ……............................ 39

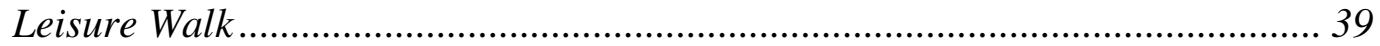

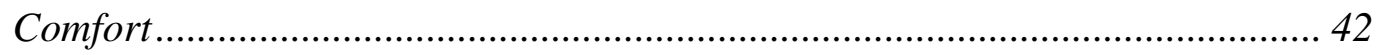

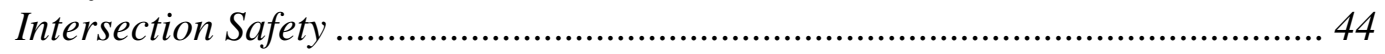

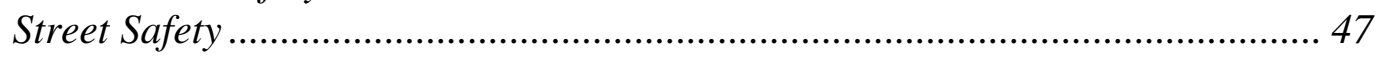

Perceived Street Usage.................................................................................. 49

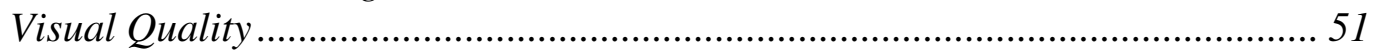

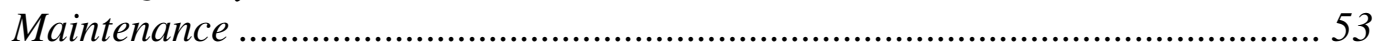

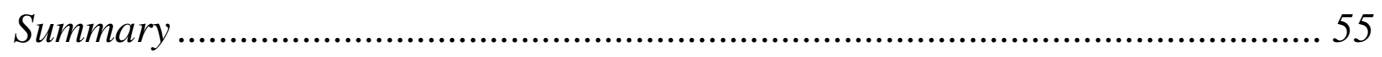

4.3 COMPARISON BETWEEN RESUlTS OF PEQI AND PEDESTRIAN PERCEPTION

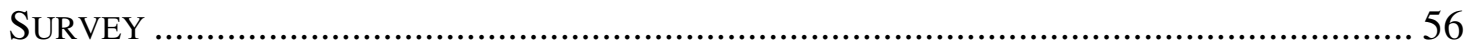

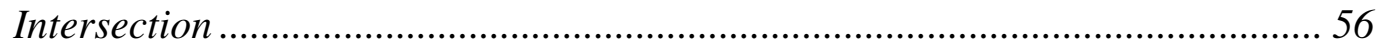

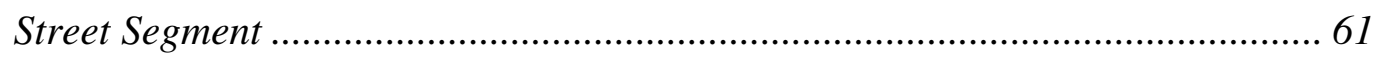

Summary for Intersection \& Street Segment ...................................................... 68

4.4 APPLICABILITY AND USABILITY OF THE PEQI TOOL FOR SMALLER URBAN

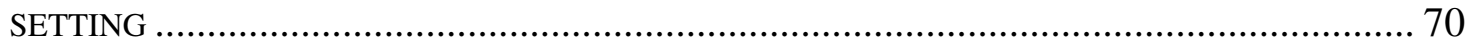

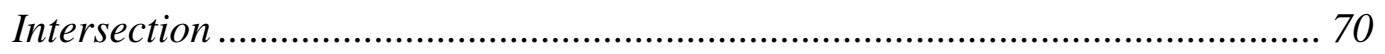

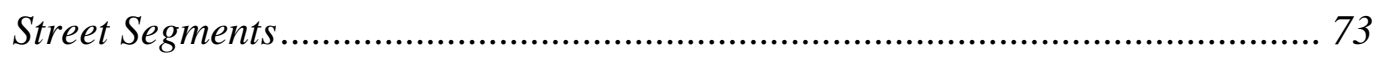

CONCLUSION, RECOMMENDATIONS, AND FUTURE STUDY ......................... 80

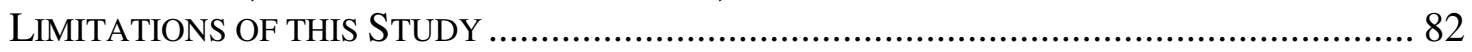

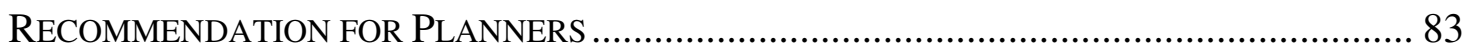

For TCFs specifically for intersections -.................................................... 84

For presence of buffer - ............................................................................... 85

Creating Walkable Environments and Problem with Connecting Streets........... 86

FUTURE DIRECTIONS FOR THIS STUDY ………….............................................. 88

APPENDICES .................................................................................................................90

APPENDIX A: PEDESTRIAN ENVIRONMENTAL QUALITY INDEX (PEQI) AsSESSMENT

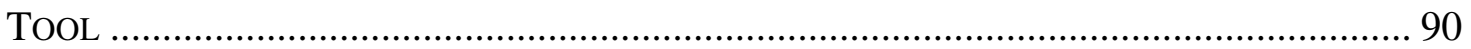

PEQI Assessment Tool, Page 1 .................................................................... 91

PEQI Assessment Tool, Page 2 ……............................................................. 92

APPENDIX B: PEDESTRIAN PERCEPTION SURVEY …………........................................ 93

Pedestrian Perception Survey - Page 1 to 2 ………….................................... 94

Pedestrian Perception Survey - Page 3 to 4 ....................................................... 95

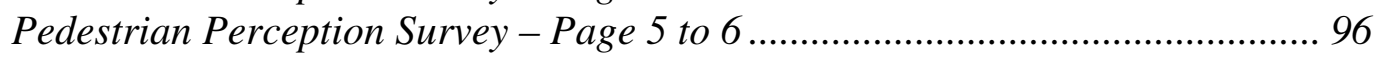

Pedestrian Perception Survey - Page 7 .......................................................... 97

APPENDIX C: Pedestrian PERCEPTION SURVEY MAP RESUlTS FOR MOST AND

LEAST PREFERRED AREAS FOR EACH CATEGORY …………...................................... 98

Pedestrian Perception Survey Map Results of most preferred areas for

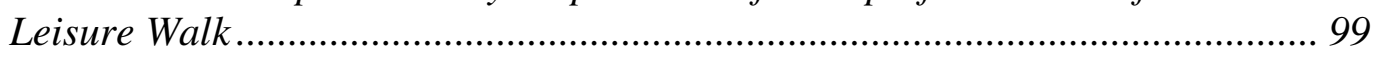

Pedestrian Perception Survey Map Results of least preferred areas for

Leisure Walk ............................................................................................ 100

Pedestrian Perception Survey Map Results of most preferred areas for

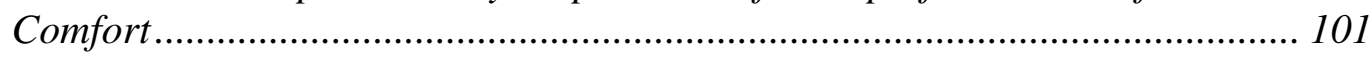

Pedestrian Perception Survey Map Results of least preferred areas for

Comfort. 102 
Pedestrian Perception Survey Map Results of most preferred areas for

Intersection Safety 103

Pedestrian Perception Survey Map Results of least preferred areas for

Intersection Safety 104

Pedestrian Perception Survey Map Results of most preferred areas for

Street Safety.... 105

Pedestrian Perception Survey Map Results of least preferred areas for

Street Safety. 106

Pedestrian Perception Survey Map Results of most preferred areas for

Perceived Street Usage. 107

Pedestrian Perception Survey Map Results of least preferred areas for

Perceived Street Usage. 108

Pedestrian Perception Survey Map Results of most preferred areas for Visual Quality. 109

Pedestrian Perception Survey Map Results of least preferred areas for

Visual Quality.... 110

Pedestrian Perception Survey Map Results of most preferred areas for

Maintenance 111

Pedestrian Perception Survey Map Results of least preferred areas for

Maintenance 112

APPENDIX D: PEQI INDICATORS VERSUS SURVEY RESPONDENTS' IDENTIFIED INDICATORS FOR EACH CATEGORY

PEQI indicators versus Survey respondents' identified indicators for

Intersection Safety

PEQI indicators versus Survey respondents' identified indicators for

Leisure Walk

PEQI indicators versus Survey respondents' identified indicators for

Comfort.

PEQI indicators versus Survey respondents' identified indicators for Street

Safety.....

PEQI indicators versus Survey respondents' identified indicators for

Perceived Street Usage.

PEQI indicators versus Survey respondents' identified indicators for Visual

Quality 119

PEQI indicators versus Survey respondents' identified indicators for

Maintenance 120

APPENDIX E: AGGREGATED DATA FROM PEQI INDICATORS VERSUS SURVEY RESPONDENTS' IDENTIFIED INDICATORS FOR EACH CATEGORY TABLE 121

Leisure Walk Table 121

Comfort Table 121

Intersection Saftey Table 121

Street Safety Table 122

Perceived Street Usage Table. 122

Visual Quality Table. 122

Maintenance Table 122 


\section{LIST OF TABLES}

TABLE 4. 1 PEQI INTERSECTION SCORING OF HIGUERA AND OSOS STREET

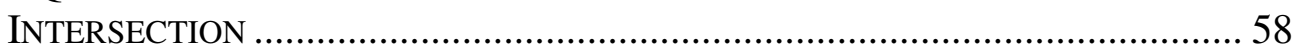

TABLE 4. 2 PEQI INTERSECTION SCORING OF SANTA ROSA AND HigUERA STREET

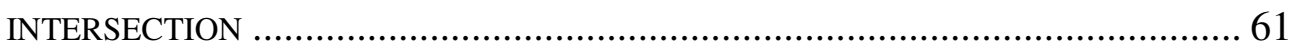

TABLE 4. 3 PEQI STREET SEGMENT SCORING FOR Higuera StREET BETWEen MORRO

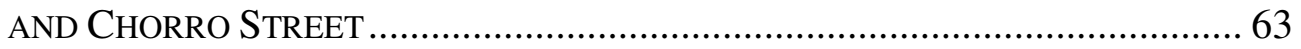

TABLE 4. 4 PEQI STREET SEGMENT SCORING OF SANTA ROSA STREET BETWEEN

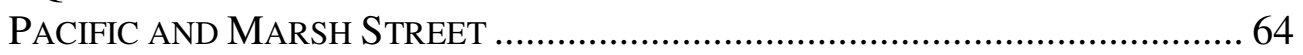

TABLE 4. 5 PEQI STREET SEGMENT SCORING OF SANTA ROSA STREET BETWEEN

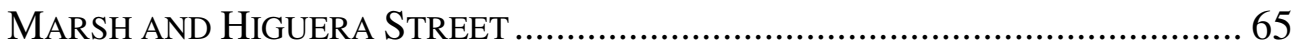

TABLE 4. 6 PEQI STREET SEGMENT SCORING OF SOUTHWEST SIDE OF NIPOMO STREET BETWEEN MARSH AND PACIFIC STREET ………………………………......... 67

TABLE 4. 7 PEQI STREET SEGMENT SCORING OF SOUTHEAST SIDE OF NIPOMO STREET BETWEEN PACIFIC AND MARSH STREET 


\section{LIST OF FIGURES}

Page

Figure 3. 1 DownTown SAN LuIS OBISPo Boundary MAP ....................................... 29

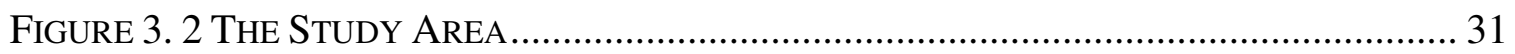

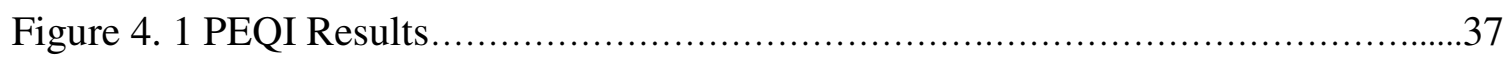

Figure 4. 2 COMMERCIAL AREA ALONG HigUERA STREET ........................................... 41

FIGURE 4. 3 STOREFRONTS WITH WINDOW-SHOPPING ALONG HIGUERA STREET............... 41

Figure 4. 4 POST OFFICE ALONG MARSH STREET ......................................................... 41

FIGURE 4. 5 LARGE GATHERING SPACE WITH GOOD STREET DESIGN ELEMENTS ................ 41

FIGURE 4. 6 LACK OF ACTIVITIES ALONG MORRo STREET ............................................ 42

FIGURE 4. 7 LACK OF SHADING ALONG MARSH STREET ............................................... 42

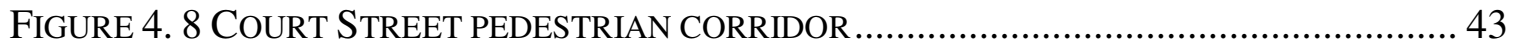

Figure 4. 9 Pedestrian CorRidor IN BETweEn MARSH ANd Higuera StreET............. 43

Figure 4. 10 LACK OF BUILDING AND ABANDONED AREA ALONG PALM STREET .............. 44

FIGURE 4. 11 UNATTRACTIVE WITH LACK OF SHADING, PEOPLE, AMENITIES ALONG

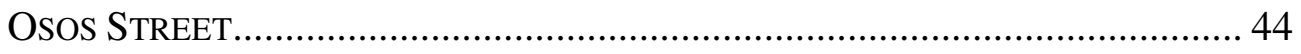

FIGURE 4. 12 TYPICAL TRAFFIC AND PEDESTRIAN SIGNALS AROUND THE STUDY AREA

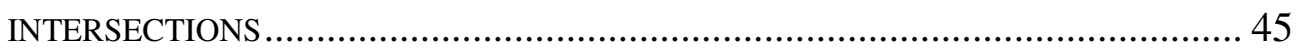

FIGURE 4. 13 CURB EXTENSION AS TRAFFIC-CALMING FEATURES ON GARDEN STREET

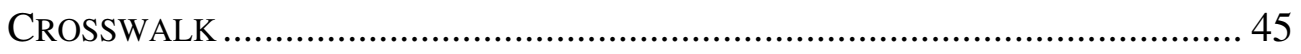

FIGURE 4. 14 POORLY MARKED PEDESTRIAN CROSSWALK ON SANTA ROSA AND HIGUERA STREET INTERSECTION ......................................................... 46

FIGURE 4. 15 No PEDESTRIAN CROSSWALK MARKING ON MARSH AND NIPOMO STREET

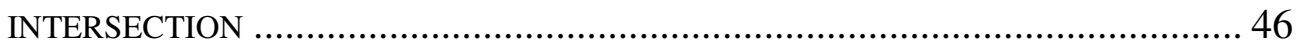

FigURE 4. 16 GOVERNMENT BUILDINGS ALONG MONTEREY STREET............................... 47

FIGURE 4. 17 NARROW SIDEWALK DUE TO PERMANENT SIDEWALK OBSTRUCTIONS TREES, LIGHTING, SIGNAGE............................................................ 48

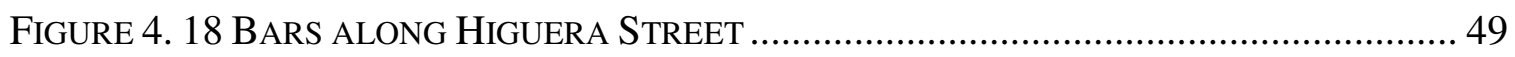

Figure 4. 19 Good ACCESSibILITy to other AMENities ALONG Monterey StReEt ..... 49 xii 
Figure 4. 20 SAN LUIS OBISPO Mission ON CHORRo STREET 50

FIGURE 4. 21 LACK OF AMENITIES AND ACTIVITIES AND POOR STREET DESIGN ALONG NIPOMO STREET

FIGURE 4. 22 LACK OF PEDESTRIAN-FRIENDLY FEATURES SUCH AS LIGHTING, SEATING, BUILDING..... 51

Figure 4. 23 StREet LIGHTING AND TREES ALONG HigUERA STREET .............................. 52

FIGURE 4. 24 SEATING ALONG MARSH STREET............................................................. 52

FIGURE 4. 25 TEMPORARY CONSTRUCTION ALONG HigUERA STREET............................... 53

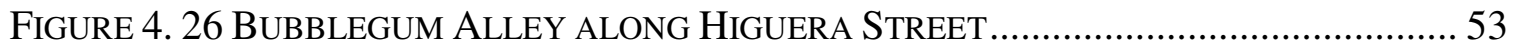

FIGURE 4. 27 WELL-MAINTAINED SIDEWALK ALONG HigUERA STREET ........................... 54

FiguRE 4. 28 SidEWALK IMPEDIMENTS AND OBSTRUCTIONS ALONG HigUERA STREET ..... 55

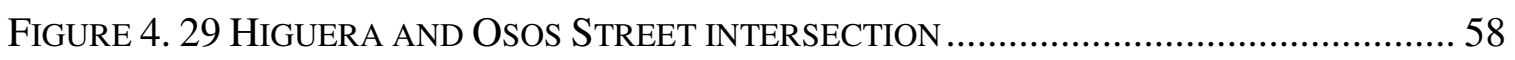

FigURE 4. 30 GAP AND RosS LADDER CROSSWALK ON HIGUERA STREET.......................... 59

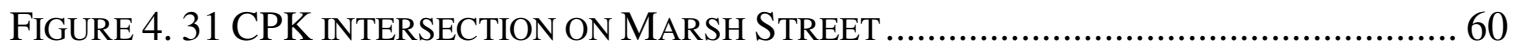

FIGURE 4. 32 SANTA RoSA AND HigUERA STREET INTERSECTION .................................. 61

Figure 4. 33 PANORAMiC VIEW OF Higuera StreEt BetweEn MORRo AND CHORRO

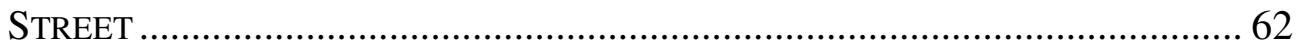

Figure 4. 34 View of Higuera Street WALKing From Morro to CHORRo StReET .... 62

Figure 4. 35 Panoramic View of Santa Rosa Street Between Pacific and

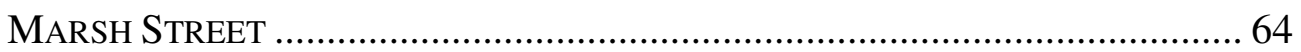

Figure 4. 36 View of SANTA Rosa StreEt WALKING From PACIFIC TO MARSH

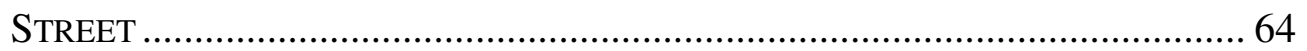

Figure 4. 37 PANORAMIC VIEW OF SANTA Rosa StREET IN BETWEEN MARSH AND

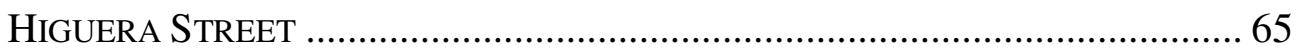

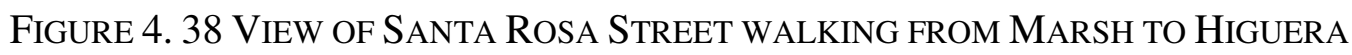
STREET 65

FIGURE 4. 39 PANORAMIC VIEW OF SOUTHWEST SIDE OF NIPOMO STREET BETWEEN

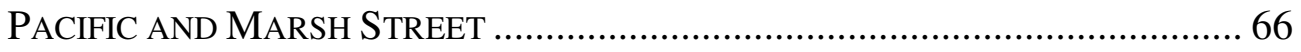

FigURE 4. 40 VIEW OF SOUTHWEST SIDE OF NIPOMO STREET WALKING FROM MARSH TO PACIFIC STREET. 66 
FIGURE 4. 41 PANORAMIC VIEW OF SOUTHEAST SIDE OF NIPOMO STREET BETWEEN PACIFIC AND MARSH STREET

FIGURE 4. 42 VIEW OF SOUTHEAST SIDE OF NIPOMO STREET WALKING FROM PACIFIC TO MARSH STREET

FIGURE 4. 43 CROSSWALK SCRAMBLE IN LOS ANGELES - PICTURE OBTAINED FROM HTTP://WWW.TREEHUGGER.COM/FILES/2008/11/DIAGONALCROSSWALKS-LOS-ANGELES-VIDEO-PEDESTRIANS.PHP 71

FIGURE 4. 44 TRAFFIC-CALMING FEATURES AND SIGNS FOUND IN THE STUDY AREA.......... 73

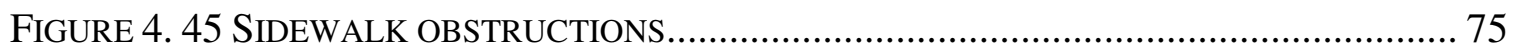

FIGURE 4. 46 NEWSPAPER STANDS BECOME AN OBSTRUCTION BY NARROWING THE

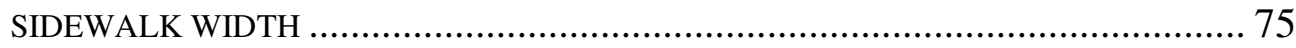

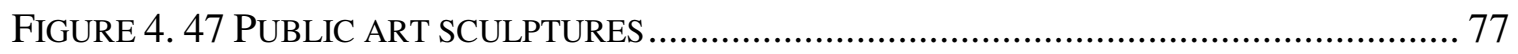

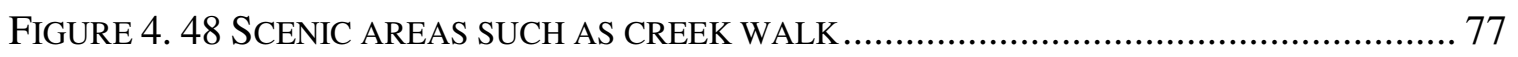

FIGURE 4. 49 DIFFERENCE OF PUBLIC SPACE WITH AND WITHOUT PEOPLE ........................ 78 


\section{CHAPTER 1}

\section{Introduction}

There are rising concerns over issues regarding the well-being of society from both the environmental and public health sectors (Kyle, Woodruff, \& Axelrad, 2006). During the $19^{\text {th }}$ century, the majority of health-related risks were caused by poor sanitation and excessive pollution; however, today's concerns are directly related to lack of physical activity (Emery, Crump, \& Bors, 2003; Southworth, 2005; Brown, Werner, Amburgey, \& Szalay, 2007; Forsyth, Hearst, Oakes, \& Schmitz, 2008). Research shows that physical activities done on a regular basis, even as simple and natural as walking, can provide better health results (Centers for Disease Control and Prevention, 2003; Brown, et al., 2007). Normalizing such physical activities can improve bodily health and quality of life, decreasing the chances of heart failure, mental illness, and other physical diseases such as obesity (Brownson, Baker, Housemann, Brennan, \& Bacak, 2001; Centers for Disease Control and Prevention, 2003; Emery, et al., 2003). And though "[w]alking 15 extra minutes a day would burn 100 calories and prevent the typical adult yearly gain of 1 to 2 pounds that can lead to obesity" (Brown, et al., 2007, p. 26), studies find that more than half of adults in the United States do not engage in any regular physical activity (Centers for Disease Control and Prevention, 2003). While " $60 \%$ of adults are still not sufficiently active to achieve health benefits, and close to $30 \%$ report no leisure-time physical activity" (Emery, et al., 2003, p. 38), the overall level of exercise activity in our society is disturbingly low (Forsyth, et al., 2008). 
Consequently, there is a push to transform our current pedestrian environment ${ }^{1}$ with efforts encouraging people to adopt a more active lifestyle by going outdoors and driving less, while battling the increasing rate of obesity (Sallis \& Glanz, 2006). In addition, modern cities have developed patterns that are detrimental to both human and environmental health, primarily caused by high resource consumption levels (Macera, et al., 2005; Centers for Disease Control and Prevention, 2003; Southworth, 2005; Alfonzo, Boarnet, Day, McMillan, \& Anderson, 2008). These trends actualized due to a shift from pedestrian-oriented communities to auto-centric planning and policy (Koplan, Lliverman, \& Kraak, 2005; Southworth, 2005), a paradigm shift that has led to a decrease in accessibility and connectivity throughout cities, especially with neighboring communities and its institutions. More than ever, people have grown accustomed to auto-dependent lifestyles, evident in their short driving trips to nearby amenities such as grocery stores or schools simply for speed, convenience, and comfort, though walking or biking are very feasible option.

Aware of these problems, the federal government as well as local jurisdictions have set forth initiatives aimed at promoting walkable communities ${ }^{2}$. According to Southworth (2005), walkability is “...the extent to which the built environment supports

\footnotetext{
${ }^{1}$ In this study, the pedestrian environment refers to the pedestrian walkways that provide accessibility and connectivity from one street, building, and park to another which includes intersections, overpasses, alleyways, and all modes of transport pedestrians utilize from one place to another that may or may not have barriers from vehicle, trees, bodies of water, and overbearing land.

${ }^{2}$ Walkable community is a term referring to a community with good pedestrian environment that encourage people to walk and engage in various modes of physical activity while providing safety, comfort, and easement for the users.
} 
and encourages walking by providing for pedestrian comfort and safety, connecting people with varied destinations within a reasonable amount of time and effort, and offering visual interest in journeys throughout the network" (p. 248). From a planning perspective, advocating walkabilty shows promise as a first step to tackling current public health issues (Koplan, et al., 2005), while also meeting the needs of city officials, environmentalists, designers and citizens by increasing the quality of life in their communities and decreasing environmental impact (Brown, et al., 2007). Local government policy makers, planners, and stakeholders have come to realize the importance of walkability and implementing pedestrian-friendly communities for a better quality of life and enhancing the health of the American population (Evans-Cowley, 2006; Agrawal, Schlossberg, \& Irvin, 2008).

Although several US cities have already developed pedestrian-oriented policies and refocused their overall planning approaches, this still does not guarantee that inhabitants of the community will embrace the new environments. What is important is how people view their environment, understanding how spaces are being used and the purpose of the surroundings, which will ultimately lead to a desire to take ownership of their habitats, becoming respectful stewards and adapting a sense of community. Therefore, it is equally important to understand and consider the needs of the area's end users when public officials are charged with the task of developing strategic plans for pedestrian neighborhoods. With efforts to cultivate walkable cities/communities, many assessment devices are being developed and administered to evaluate the quality of our existing surroundings, such as the Pedestrian Environmental Quality Index (PEQI). PEQI is an environmental assessment tool developed by San Francisco Department of Public 
Health (SFDPH) to assess and measure the quality of the pedestrian environment. In hopes of advancing walkability in communities, such tools are being used predominantly across the United States and other countries, the results of which provide policymakers and stakeholders with valuable and specific information regarding the existing physical conditions of the environment.

\section{Theoretical Background}

The ideal pedestrian environment provides walking routes, bike paths, gathering spaces, and other such amenities that ultimately allow a populace to engage in various physical activities. A city's livelihood is manifested in the quality of the pedestrian environment and by encouraging people to congregate, interact, and socialize amidst a safe and accessible space, it will permit people to engage in some form of physical activity.

Over the years, the character of pedestrian environments gradually transformed in American cities; streets and neighborhoods grew detached and walled in, while accessibility and connectivity to surrounding conveniences became limited and inefficient for pedestrians. Development patterns shifted from traditionally planned communities, designed to support convenient pedestrian travel for common activities, such as shopping and going to school (Sallis \& Glanz, 2006), to today's standards that are much more welcoming to automobiles, a change that has forced the US population into auto-dependent lifestyles. More Americans are choosing automobiles as their main mode of transportation due to the fast and easy access to freeways, stores, and other amenities. In surrendering the physical aspect of the current pedestrian environment, residents are also being deprived of the associated social and cultural benefits, considering the strong 
role walkability can play in bringing together people through sense of community and ownership of that community. Policymakers must focus on reinventing not only the physical advantages of increasing the quality in pedestrian environments but also maintaining the social and cultural aspects of a city/community.

\section{Importance of Topic}

Over the past decade, there has been an explosion of studies examining the relationship between the quality of the pedestrian environment and pedestrian activity as well as those that analyze the correlation between pedestrian activity and pedestrian perception. Yet, there is a lack of research conducted to specifically explore the connection between the pedestrian environment and people's perception of these environments. Studies found that community perceptions are largely dependent on and subjective to past experiences, personality, and cultural beliefs (Jervis, 2004; Brownson, Hoehner, Day, Forsyth, \& Sallis, 2009). There are also outside factors that contribute to people's perception such as recent changes and accidents, weather condition, lighting, and colors (Brown, Werner, Amburgey, \& Szalay, 2007). Identifying these outside factors can help us understand behaviors and attitudes toward the environment and how to incorporate them through design.

Environmental assessment tools have been developed and administered throughout US cities to analyze current conditions of the built environment in order for planners and decision makers to develop guidelines that address public health issues and increase walkability. Cities adopted pedestrian plans specifically geared toward increasing activity and safety of pedestrians. Yet, as Evans-Cowley (2006) asserts, "adequate pedestrian access requires comprehensive long-range planning, as well as the 
implementation of sidewalk policies" (p. 71). Because of this, many cities have started to use these studies and results to advise public officials on better options and strategies in developing pedestrian-friendly plans and programs (Santana, Santos, \& Nogueira, 2009). The evaluations provide information and ratings based on the present physical condition of the study area but fail to take into consideration the end users' needs, motives, and uses of the environment.

Currently, these tools are primarily geared toward and being implemented in big urbanized metropolitan hubs such as Los Angeles, San Francisco, Chicago, and New York, among others. However, areas that lack connectivity in pedestrian environments that make amenities and various resources accessible are predominantly around suburban areas where automobiles become the only reasonable mode of transportation because basic services are not in close proximity to peoples' homes. If initiatives are being administered to increase walkability in all built environments, then assessment tools must include variables that encompass the needs of suburban communities as well. Acknowledging this, the following study examines whether currently available assessment tools are appropriate in analyzing suburban settings and whether changes are necessary for said tools to be effective and applicable in different environments.

\section{Purpose of Study}

The purpose of this study is to expand the understanding of the relationship between pedestrian perception and existing physical environments, specifically in how people perceive these environments and the contributing factors to how those notions are formulated. This study specifically examined to what extent end users' perceptions paralleled findings from the evaluation of an urban environment, using one of the 
assessment tools previously discussed: the Pedestrian Environmental Quality Index (PEQI). The primary objectives are as follows: (1) to examine how end users' perception of the pedestrian environment relates to the quality of that environment, as determined by the PEQI method, (2) to identify the factors that contribute to end users' perception in order to understand their behaviors and attitudes towards an environment, and (3) to test the applicability of the PEQI assessment tool in a smaller urban setting.

The downtown area in the City of San Luis Obispo has been specifically selected for this case study to assess the quality of the pedestrian environment and to examine how people perceive said environments. Two methods of data collection were implemented: 1) PEQI observation survey tool, and 2) pedestrian perception survey.

\section{Chapter Contents}

Chapter Two is a review of existing literature related to pedestrian environment and pedestrian perception. Empirical studies can be separated into five domains: environment, health, pedestrian activity, pedestrian environment, and pedestrian perception. Chapter Three presents the research method employed for this particular study. This chapter discusses site selection, subjects, data collection method and explanation of instruments used. Chapter Four presents the results and further discuss the implications of the findings. Chapter Five provides conclusion, recommendation for planners, and direction for future studies. 


\section{CHAPTER 2}

\section{Literature Review}

Environments affect the health and lives of its inhabitants as conveyed through various sociological impact studies. Based on past empirical data, researchers have accepted five dominant themes that connect people with their surroundings: (1)

Environment, (2) Health, (3) Pedestrian Activity, (4) Pedestrian Environment, and (5) Pedestrian Perception.

\section{The Environment ${ }^{\underline{3}}$}

In studies showing how human health is dependent upon environmental health, current trends of human activity and growth patterns are leading to degradation of environmental quality and depletion of resources across the globe (Rainham \& McDowell, 2005). The natural environment provides essential needs for sustaining human life, including air, water, and food sources. Despite the fact that environmental resources are finite and diminishing, population growth and consumption rates are increasing demand and putting a strain on those resources (Jackson, et al., 2001). The alarming fact is that these trends are recurring worldwide and only lead to further erosion and pollution of the environment and its resources on a global scale. Bhatia and Wernham (2008) assert that "[e]nvironmental changes - including issues as diverse as global warming, deforestation, fisheries loss, and suburban sprawl - is now seen as a

\footnotetext{
${ }^{3}$ Refers to both the natural and built environments
} 
priority challenge to public health" (991). Rainham and McDowell's (2005) study on sustainability of the environment discovered that wealthier countries relying mostly on external resources maintained healthier populations because they consumed the most; however, sustaining such lifestyles in these developed countries cause extensive environmental damage around the world. Meanwhile, the less developed countries continue to advance and soon exhibit the same traits and bad habits of the developed countries, further leading to deterioration of environmental quality. Unfortunately, when governments and their people make decisions, they tend to prioritize economic goals over environmental benefits, failing to acknowledge that the "[d]eterioration of earth's global life-support system is a paramount health issue" (Rainham \& McDowell, 2005, p. 319).

The built environment refers to the places for people to live, walk, gather, people watch, and ultimately engage in different physical, social, and cultural activities. Therefore, the design of these settings is crucial in meeting the needs of its end users and in encouraging them to engage in various activities. Recent studies reveal the inadequacy of the built environment to sustain human health and lifestyle. The main causal factor for current health issues can be pinpointed to development practices that often discourage people from engaging in various activities. More studies relating to the built environment will be further discussed under pedestrian environment.

\section{Health}

Increasing rates of obesity and other health-related risks concern both environmental and health experts because of the environmental factors that affect human health (Kyle, et al., 2006; Hoehner, Ivy, Ramirez, Handy, \& Brownson, 2007; Forsyth, et 
al., 2008). Rainham and McDowell (2005) discovered that at least 23\% of global health issues are attributed to environmental factors and are preventable; therefore, addressing environmental factors that affect human health is a top priority for current and future populations in the United States (Hoehner, et al., 2007). Koplan et al. (2005), in their

study, lobby for a nationwide protocol to address this issue by examining and exploring causalities. If we, as a society, continue to neglect the environmental factors that affect our physical health, it will ultimately affect our economical, social, and cultural wellbeing.

\section{Lack of Physical Activity}

Beginning in the early $19^{\text {th }}$ century, health issues arose due to environmental factors such as poor sanitation and dense pollution (Southworth, 2005). These days, health concerns are directly related to the built environment that encourages use of automobiles as the primary mode of transportation. The Center for Disease Control and Prevention (2003) reveals that more than half of the current population in the United States is inactive and that the overall level of activity is low (Forsyth, et al., 2008). A similar study shows that nearly 60 percent of the American population does not achieve enough physical activity to receive the associated health benefits, while 30 percent have settled for living continuously sedentary lifestyles (Emery, et al., 2003).

Past studies suggest that engaging in daily physical activities increase health benefits while decreasing the likelihood of developing chronic diseases (Ball, Bauman, Leslie, \& Owen, 2001; Giles-Corti \& Donovan, 2002; Emery, et al., 2003). Brown et al. (2007) found that physical activities such as walking an extra ten to fifteen minutes a day will burn enough calories to prevent extra weight gain that would otherwise lead to 
obesity while achieving the recommended levels of daily physical activity. Regrettably, an increasing number of people are choosing to drive short distances, rather than to walk or bike. This dependence on automobiles not only prevents people from attaining healthier lifestyles but is also damaging to the natural environment by increasing air pollution, water contamination, and resource consumption. Clearly, natural and built environments and human health are inextricably linked; the main concern is a lack of incentives in providing comfortable and convenient alternatives to driving. In the interest of cultivating a healthy quality of life, the key is to provide an environment that supports physical activity, human interaction, and other incentives for people to minimize the use of their cars, and instead, choose to walk.

\section{Obesity}

Obesity and a number of other health problems are induced in part by a lack of physical activity (King, Brach, Belle, Killingsworth, Fenton, \& Kriska, 2003; Koplan, et al., 2005; Kyle, et al., 2006; Sallis \& Glanz, 2006). Not only are these ailments detrimental to one's physical well-being, they also affect social and mental health, and, oftentimes, financial difficulties accrue due to the high cost of healthcare (Santana, et al., 2009). Alarmingly, the number of childhood obesity cases has tripled over the past three decades, evoking an explosion of studies in obesity prevention and initiating interest in such preventative protocols (Koplan, et al., 2005).

A number of studies make compelling arguments that a strong relationship exists between children's activity level and their surrounding environment (Koplan, et al., 2005; Sallis \& Glanz, 2006; King, et al., 2003). Frank et al. (2007) compared a pedestrianfriendly environment to one that was auto-oriented with limited walkability. He 
discovered that obesity levels were twice as high in an automobile-dependent area compared to pedestrian-friendly environments. Unsurprisingly, people are less inclined to engage in physical activities as frequently when living in auto-oriented environments, resulting in substantially higher obesity rates. Some advocates argue that changing the built environment to provide better access to recreation and transportation will increase activity levels (Sallis \& Glanz, 2006) while others lobby to implement such strategies as organizing community events to educate the public on childhood obesity prevention (King, et al., 2003). In the end, it will be individual and societal behavioral change that will tip the scales in the American public's battle with obesity (Trasande, et al., 2009).

Reviews of past literature provide substantial evidence and causal inferences to current human health issues, finding that there is a strong correlation with both the natural and built environment. In order to address these issues, habitual changes are necessary, as they relate to human activity, behavior and lifestyle, in conjunction with revolutionizing community growth patterns that lead to improved human health and environmental quality.

\section{Pedestrian Activity}

In response to the rising concerns over human health, experts suggest a need to increase the level of pedestrian activity across the United States (Centers for Disease Control and Prevention, 2003; Alfonzo, et al., 2008). More than half of Americans fail to achieve the minimum level of activity to be considered healthy (Macera, et al., 2005), and fewer than $15 \%$ engage in vigorous activities such as running (Centers for Disease Control and Prevention, 2003). Studies assert that even simple exercises, as natural as walking, can help achieve the recommended levels of physical activity (Southworth, 
2005; Brown, et al., 2007). Yet, approximately $75 \%$ of American adults do not engage in enough daily physical activity and $25 \%$ are entirely inactive during their leisure moments (Southworth, 2005; Brown, et al., 2007).

The many studies connecting the relationship between pedestrian activities and pedestrian environment reveal that there are different spatial factors that influence physical activity (Humpel, Owen, Leslie, Marshall, Bauman, \& Sallis, 2004; Southworth, 2005; Sallis \& Glanz, 2006; Brown, et al., 2007; Frank, Saelens, Powell, \& Chapman, 2007; Brownson, et al., 2009). One group of studies suggests that the level of pedestrian activity varies across gender, age, socioeconomic and race demographics and is dependent upon environmental settings (Booth, Owen, Bauman, Clavisi, \& Leslie, 2000; King, et al., 2003; Foster, Hillsdon, \& Thorogood, 2004; Humpel, et al., 2004). Another group of research determined that work, neighborhood, and household environments influence the level of pedestrian activity (Giles-Corti \& Donovan, 2002; Humpel, et al., 2004; Southworth, 2005; Sallis \& Glanz, 2006; Brown, et al., 2007; Alfonzo, et al., 2008; Santana, et al., 2009; Wen \& Zhang, 2009).

\section{Gender}

Generally, the male population is more likely to be active than that of females (Booth, et al., 2000; King, et al., 2003; Brown, et al., 2007). Booth et al. (2000), in their study, found that $55 \%$ of men were physically active while only $38 \%$ of women reported regular exercise. Brown et al. (2007) argues that gender differences account for variations in the levels of physical activity because each sex has its own requirements and purposes, and thus have different travel patterns/destinations. Furthermore, men are more likely to have jobs that require physical labor and are generally more active in making use of 
nearby recreational facilities (Booth, et al., 2000; Macera, et al., 2005). Observing patterns of activities between the sexes amongst children, Carver et al. (2005) found that girls view walking as a means of exercise while boys see it as a mode of transportation. Her findings revealed that boys are more inclined to engage in vigorous activities such as biking while girls tend to partake in leisure walks and less strenuous exercises.

In contrast to their counterparts, women are more likely to walk for utilitarian purposes (King, et al., 2003), as Humpel et al.'s (2004) study of adult walking patterns reveal that women walk for convenience. Older women are generally found to be less active than men (King, et al., 2003), and when comparing walking patterns, women tend to walk at a slower pace (Finnis \& Walton, 2008). Females are inclined to engage in greater levels of activity with the presence of social support, i.e., when receiving encouragement from friends and family (Booth, et al., 2000; Ball, et al., 2001). Therefore, studies suggest placing a greater focus on increasing activity levels for older females, since they are portrayed as the group that requires the most drastic motivational and behavioral change.

Age

Regardless of gender differences, adults ages 18 to 29 were most active, and with each increasing year, the activity level decreases (Macera, et al., 2005). However, Booth et al. (2000) notes that the level of physical activity varies among different age groups, especially in the older population. Adults age 55 and over often report being incapable of exercising due to prior injuries and disabilities. In addition, they discovered that the level of activity varies significantly between the ages of 60 to 64,65 to 69 , and 70 and above; adults ages 65 to 69 displayed a higher level of physical activity than those reported in 
both the 60 to 64 and 70 and above groups. One reason for this disparity may be the fact that people retire around the age of 65 and tend to have more time to engage in active lifestyles, while those ages 60 to 64 are still assumed to be working, and the age group of 70 and above simply lack the physical capacity to endure such movements.

\section{Socioeconomic Status}

Levels of physical activity were greater among individuals that come from higher socioeconomic backgrounds. Whether male or female, people who have attained higher levels of education (Macera, et al., 2005), take in higher incomes (Brownson, et al., 2009) and live in areas that reflect higher socioeconomic status (Giles-Corti \& Donovan, 2002) engaged in higher levels of activity overall. Conversely, Giles-Corti and Donovan (2002) found that despite having more accessibility to parks and recreational facilities, those residing in lower socioeconomic communities were less likely to engage in leisurely physical activities than inhabitants of higher socioeconomic areas. The study also disclosed that walking patterns in the "poorer" neighborhoods were necessitated as means of transport rather than leisure - instead of engaging in vigorous activities, people walked extensively in deprived areas because they lacked alternative modes of transportation (Giles-Corti \& Donovan, 2002; Santana, et al., 2009).

\section{Race}

There are significant variations in the level of physical activity among different racial backgrounds (Forsyth, et al., 2008). Studies show that whites are more likely to live in higher socioeconomic communities, attend higher education institutions, receive greater annual incomes, and oftentimes own cars and homes in their auto-dependent suburban neighborhoods. One particular study determined that across all age groups, 
whites tend to engage in higher levels of physical activity more frequently, making use of recreational facilities and engaging in rigorous exercises (Centers for Disease Control and Prevention, 2003).

\section{Social Capital \& Support}

Social capital and social support have strong correlations to pedestrian activity (Booth, et al., 2000; Ball, et al., 2001; Santana, et al., 2009). Both Booth et al. (2000) and Santana et al. (2009), in their studies, found that people with strong social capital and social support engage in physical activities more regularly. In contrast, people without any form of social support are less inclined to engage in any form of exercise (Ball, et al., 2001). Both Booth et al. (2000) and Ball et al. (2001) conveyed that social support is especially crucial for women. People who are active often report that family members, friends and spouses constantly encourage and remind the individuals of the benefits of engaging in regular activity (Booth, et al., 2000). In addition, having an active spouse or friend who is equally active also helps to stimulate an increase in pedestrian activity (Brownson, et al., 2009). Other studies found among young adults who live near friends, have close relationships with neighbors and interact with similar social groups, are more active within their pedestrian environments. These factors were significant contributors to the level of physical activity especially among girls (Carver, Salmon, Campbell, Baur, Garnett, \& Crawford, 2005).

Similar studies reveal that the presence of other people can increase the level of pedestrian activity (Isaacs, 2000; Brown, et al., 2007). Brown et al. (2007), in their study, surveyed pedestrians to identify what destinations they considered desirable and found that people were more attracted to areas where other people were present. On the other 
hand, a lack of people often discouraged pedestrian activity and induced negative feelings toward the environment. Isaacs (2000), in his study, found that the presence of people greatly influenced where people chose to go, as many test subjects often preferred less aesthetically-pleasing environments because more people were present. Therefore, findings suggest that increasing pedestrian activity requires a focus on developing neighborhood environments that provide social opportunities (Giles-Corti \& Donovan, 2002) as well as create programs that encourage social activity (Foster, et al., 2004).

\section{Pedestrian Environment}

Many studies determined that the quality of the built environment greatly influences the level of pedestrian activity (Humpel, et al., 2004; Brown, et al., 2007; Wen \& Zhang, 2009; Giles-Corti \& Donovan, 2002). There is great interest and demand to understand what and how environmental factors affect pedestrian activity. Past literature has identified walkability (Emery, et al., 2003; Southworth, 2005; Sallis \& Glanz, 2006; Brown, et al., 2007; Finnis \& Walton, 2008; Santana, et al., 2009), safety (Koplan, et al., 2005; Agrawal, et al., 2008), and aesthetics (Alfonzo, et al., 2008; Brownson, et al., 2009) as strong correlates to increasing pedestrian activity.

\section{Walkability $^{4}$}

Highly walkable pedestrian environments encourage pedestrian activities that result in lower body mass indexes, lower rates of obesity, and reduction of other health-

${ }^{4}$ According to Southworth (2005), walkability is "the extent to which the built environment supports and encourages walking by providing for pedestrian comfort and safety, connecting people with varied destinations within a reasonable amount of time and effort, and offering visual interest in journeys throughout the network" (p. 248). 
related issues (Santana, et al., 2009). Southworth (2005), Sallis and Glanz (2006), and Santana et al. (2009), in their studies, explained the shift in design strategies of city planning and community development over the past several decades. These historical changes resulted in the current condition and state of the today's built environment. Prior to the 1920s, planning focused on implementing traditional designs to create more walkable and pedestrian-oriented communities (Southworth, 2005; Sallis \& Glanz, 2006; Santana, et al., 2009). These communities displayed high walkability that provided convenient pedestrian access to amenities, schools, and surrounding neighborhoods (Sallis \& Glanz, 2006). Because walking was the main mode of transport, development patterns required dense and well-connected neighborhoods to ease pedestrian travels (Southworth, 2005). However, as the automobile became the new symbol of America in the 1920 s, road constructions and street patterns rapidly adapted to motor access, forcing development capacity to expand and land use to change. The planning and design of cities and communities dismissed the antiquated pedestrian-oriented environments in place of the growing popularity of auto-oriented developments.

Today, there are numerous national efforts to reintroduce walkable communities and environments for the betterment of human life and health. Results show that the level of pedestrian activity was significantly higher in walkable environments, which was attributed to the area's high levels of accessibility, connectivity, density, and land use (Brown, et al., 2007; Santana, et al., 2009). Similar studies also identified these environmental factors as positive influences to pedestrian activity (Graham \& Glaister, 2003; Frank, et al., 2007; Lin \& Yang, 2009; Wen \& Zhang, 2009). 
Accessibility

Accessibility in pedestrian environments is important in promoting physical activities, such as walking (Ball, et al., 2001; Wilson, Kirtland, Ainsworth, \& Addy, 2004; Southworth, 2005; Brown, et al., 2007; Alfonzo, et al., 2008; Brownson, et al., 2009; Wen \& Zhang, 2009). Studies found that access to parks, trails, and recreational facilities are strong indicators that promote pedestrian activity (Ball, Bauman, Leslie, \& Owen, 2001; Wilson, et al., 2004; Brown, et al., 2007; Brownson, et al., 2009). Findings also suggest that restaurants, bars, and stores increase walkability and pedestrian activity (Sallis \& Glanz, 2006; Brown, at al., 2007; Wen \& Zhang, 2009). Southworth (2005), in his study, determined the importance of accessibility in places and spaces that serve daily needs, including grocery stores, laundromats, banks, shops, cafes, schools and parks. He further raises the issue that "most postindustrial development in the United States has lost walkability and the necessary fine-grained pattern of uses so that it is impossible in many areas to reach even one everyday activity on foot within 1/2 mi" (Southworth, 2005, p. 250). Not only does the current pedestrian environment lack accessibility, it is also deficient in connectivity, quality, and suitability. Additionally, poor planning has been responsible for other design features that function as safety elements, such as street lamps, newspaper stands, and utility poles, but such features are also deterrents to walking and limit accessibility to and from places.

\section{Connectivity}

Despite having greater accessibility in pedestrian environments, studies determined that local and regional connectivity from neighborhoods to amenities is still a crucial contributor to promoting pedestrian activity (Southworth, 2005). Accordingly, 
both Baran et al. (2008) and Finnis et al (2008), in their study, suggest that streets with high permeability increase pedestrian activity due to higher levels of accessibility to global and regional continuity. In his study, Southworth (2005) determined that path network continuity from neighborhoods to amenities and alternative modes of transportation without any breaks encourage pedestrian activity due to feasible access. He further recommends pedestrian bridges and other such design features as solutions for increasing connectivity. Brown et al. (2007), in their study, found that people are more likely to walk in certain areas that allow them to complete multiple errands and daily tasks efficiently. It is crucial that the pedestrian environment is well connected and accessible to desired locations and amenities. However, studies found that travel distances and direct path connections are taken into account when it comes to promoting pedestrian activity (Southworth, 2005; Agrawal, et al., 2008; Alfonzo, et al., 2008). People preferred direct paths to and from their desired destinations to be efficient with their time and cost of travel. Therefore, the following factors are important when trying to promote pedestrian activities: providing paths for both direct trips and leisure walks, limiting block lengths, and focusing on directly connecting alternative modes of transportation.

\section{Density}

Many studies have explored the benefits of density with respect to pedestrian activity. The word "density" is often misunderstood, as some might relate it to increased traffic congestion and higher cost of living, while others may think of restricting land and private property rights, among other preconceived notions. However, these are the same factors that forcefully bolster pedestrian activity (Forsyth, et al., 2008). For example, 
increases in density, traffic, and parking costs make driving progressively more difficult and inconvenient, so walking becomes easier and preferable due to time efficiency and cost-effectiveness (Lin \& Yang, 2009). Additionally, density factors require developments and other amenities to be closer in proximity, which decreases travel distances and attracts a wide range of businesses that appeal to the increased pedestrian traffic, including various commercial, retail, restaurants and stores(Southworth, 2005; Lin \& Yang, 2009).

\section{Land Use}

Over the course of planning history, land use changed as denser areas became commercial districts and residential communities dispersed into suburban neighborhoods (Southworth, 2005). This pattern of urban sprawl forced people to commute to work in the city while living in the suburb, often taking time away from social and active lifestyles. Southworth (2005), in his study, found that people who lived in suburban neighborhoods and communities "weighed $6.3 \mathrm{lbs}$. more on average than people in the most compact areas ... [and] [r] esidents of more compact areas were more likely to walk for leisure than residents of sprawl areas" (Southworth, 2005, p. 249). Because amenities and services are not within close proximity, people are required to drive and spend more time sitting in their cars. Hoehner et al. (2007) highly recommends mixed land use by providing commercial and retail conveniences near residential neighborhoods, as it promotes pedestrian activity and is beneficial to human health and life. Without providing mixed land use elements, even properly integrated and well-designed places fail to promote pedestrian activity. Ironically, creating dense residential communities does nothing to counteract the effects of urban sprawl. Similar to sprawled environments, 
people will still choose to drive in order to accomplish their tasks. These feeble efforts to reduce driving will still exist unless mixed land use is a core integral to communities.

Safety

Safety is an important aspect in any environment because it serves to protect pedestrians from casualties and other risks (Trasande, et al., 2009). Graham and Glaister (2003), in their study, found that the quality of the pedestrian environment is a strong determinant in pedestrian casualty rates, which are much higher in the United States than in some European countries (Southworth, 2005; Sallis \& Glanz, 2006). Southworth (2005), in his study, found that 6,000 pedestrians and bicyclists were killed each year due to accidents across the United States. Comparatively, Germany, the Netherlands, and other European nations have made extensive improvements on pedestrian and bicycle network systems that increased safety while dramatically decreasing related casualties (Southworth, 2005; Sallis \& Glanz, 2006). These countries adopted laws maintaining that drivers be held liable in any pedestrian or bicycle related accident (Sallis \& Glanz, 2006). With superior and highly walkable pedestrian network systems, the environments included multiple pedestrian safety elements such as traffic-calming features, crosswalks, and landscape components. Corresponding studies found these safety features as strong correlates of pedestrian activity (Brown, at al., 2007; Alfonzo, et al., 2008).

Pedestrian safety tends to be higher in areas with larger populations and higher densities, though this opposes common misperceptions that deem otherwise. Graham and Glaister (2003), in their study, explored the rate of pedestrian casualties from various populated environments and found that accidents occurred more often in sprawled residential areas due to a lack of safety features that can be found in commercial and 
more densely populated areas. Interestingly enough, the rate of pedestrian casualties increased with growing city populations, and decreased with higher population densities. Populated environments tend to have better control over traffic management involving speed rates, sidewalk features, and other elements that divide pedestrians and automobiles. These elements, such as plant buffers and other architectural features, significantly decrease pedestrian accidents while increasing driver awareness.

\section{Aesthetical Quality}

Studies found that the aesthetical quality of an environment influences pedestrian activities (Isaacs, 2000; Brown, et al., 2007). Brown et al. (2007), in their study, found that pedestrians prefer walkable environments because of its attractive elements, vibrancy, and well-maintained spaces. Corresponding studies show that people who enjoy such environments are more likely to return (Southworth, 2005).

Pedestrians respond to different characteristics and qualities of an environment (Forsyth, et al., 2008). Greenery along sidewalks tend to set positive moods for people (Brown, et al., 2007) and street transitions from narrow to wide scales maintain people's interest and curiosity (Isaacs, 2000). Isaacs (2000), in his study, determined that the physical design influences the type and duration of pedestrian activities. For instance, walking speed is decreased when there are more amenities and outdoor elements available nearby (Finnis \& Walton, 2008; Forsyth, et al., 2008). People spent more time in areas that were well designed with good seating, shading, gathering spaces, and other elements that encouraged social interaction (Brown, et al., 2007). Overall, it is important that architectural features engage pedestrian's attention as it underlines people's preference for pleasing and attractive environment. 


\section{Pedestrian Perception}

A number of studies have explored the thought process behind human's perception of environments and how such perceptions originated. Past research has found that perception is derived from subjective values, which are based on an individual's past experiences, lifestyles, cultural beliefs, and personalities (Kirtland, et al., 2003;

Brownson, et al., 2009). Similarly, Jervis (2004), in his study examining prospect theory, determined that "people evaluate their conditions and the state of their lives more by the recent changes they have experienced than by their total value positions" (p. 169). Also, environmental factors such as weather, noise, and light can also inflict varying perceptions (Brown, et al., 2007). Regardless of one's background, the level of activity differed depending on an individual's positive or negative views of the environment positive views were associated with increased physical activity while negative views discouraged people from engaging in any form of activity - with neither gender nor age having any impact.

Furthermore, some studies have examined the factors that specifically induce positive perceptions of the environment (Booth, et al., 2000; Giles-Corti \& Donovan, 2002; Humpel, et al., 2004; Wilson, et al., 2004; Brown, et al., 2007). Positive views are associated with people who engage in moderate to high levels of pedestrian activity and reside in high socioeconomic, walkable environments (Humpel, et al., 2004). People who engage in higher levels of pedestrian activities are more likely to acknowledge having easy access to sidewalks and other amenities, and view the environment as safe (Booth, et al., 2000; Addy, Wilson, Kirtland, Ainsworth, Sharpe, \& Kimsey, 2004). People with higher socioeconomic backgrounds have a more positive view of the environment, 
contrasting with both Giles-Corti and Donovan (2002) and Wilson et al. (2004), who, in their studies, found that people living in low socioeconomic status areas tend to view their environments as inadequate and unpleasant, which discourages them from using open areas for leisure walks and social gatherings. Lastly, people perceive walkable environments as attractive, safe, interesting, and suitable. This suggests that positive perception can be increased by including considerations for these elements.

\section{Accessibility}

Studies found that people who perceived their environments as having access to sidewalks and other amenities were more likely to walk and engage in pedestrian activity (Giles-Corti \& Donovan, 2002; Humpel, et al., 2004; Hoehner, et al., 2007). In fact, Giles-Corti and Donovan (2002), in their study, found that 65 percent of such people walked more because of easy access to sidewalks and other amenities. Other complementary studies found that such environments encouraged people to walk more because people perceived walking to be convenient (Humpel, et al., 2004).

\section{Aesthetics}

Past research determined that perception of aesthetically-pleasing environments is strongly related to levels of pedestrian activity (Giles-Corti \& Donovan, 2002; Ball, et al., 2001). Studies showed that people who reported their environment to be less aesthetically-pleasing are less likely to engage in pedestrian activities (Ball, et al., 2001). Ball et al. (2001), in their study, found that of those who negatively viewed their surroundings, $40 \%$ were less likely to engage in pedestrian activities compared to those who perceived their environments positively. People enjoy aesthetically-pleasing environments as it sustains their interest (Brown, et al., 2007). These are the same 
individuals who, oftentimes, take pride and ownership in their communities, establishing deep roots and connections.

Safety

Many studies suggest that perception of safety is another significant factor that contributes to pedestrian activity. The level of inactivity is higher in areas where people perceive the environment as unsafe (Ball, et al., 2001). Nevertheless, the ways people perceive safety in an environment is not only determined by physical features but also by cultural and social factors. Such factors include car traffic, crime, neighborhood trust, stray animals, and lack of pedestrians (Isaacs, 2000; Addy, et al., 2004; Brown, et al., 2007; Brownson, et al., 2009). In addition, parents' perception of safety within an environment affects the level of pedestrian activity among adolescents and children (Carver, et al., 2005; Sallis \& Glanz, 2006). Children tend to be more active when their parents vie an environment favorably. Overall, it is difficult to increase the level of pedestrian activity in environments that are perceived unsafe (Foster, et al., 2004; Humpel, et al., 2004).

Empirical research suggests that how people perceive an environment dictates how they intend to use the space. In order to increase the level of pedestrian activity in an environment, it is important to change how people view that specific area. People's engagement in pedestrian activity reflects their views or feelings of safety of an environment. Therefore, it is important to understand how people view their environments before any strategic pedestrian planning is implemented. 


\section{CHAPTER 3}

\section{Research Method}

The proposed study cross-examines an urban area to draw conclusions about the quality of a pedestrian environment and how it relates to and affects the human perception of those surroundings. This research employs a concurrent triangulation strategy, the most commonly used research method due to its flexibility, to gather two data sources under one design phase (Creswell, 2009); in this case, both quantitative and qualitative data are gathered simultaneously. Both sets of data will be analyzed collectively to determine the relationship between quality of the pedestrian environment and people's perception.

\section{Subjects and Subject Selection Procedures}

The intent of this study is to examine how people's perception of the pedestrian environment relates to the quality of that environment, as determined by the Pedestrian Environmental Quality Index (PEQI). Through past research, it has been determined that how people view the environment dictates the level of activity, livelihood, vitality, and quality of life of those surroundings (Booth, et al., 2000; Giles-Corti \& Donovan, 2002; Humpel, et al., 2004; Wilson, et al., 2004; Brown, et al., 2007). Therefore, this study attempts to analyze how people see the built environment, the factors that contribute to changes in their opinions, and the extent to which their perceptions correlate with the quality of these environments as determined by PEQI.

As measured by PEQI, this comparison contains two variables: (1) the independent variable is the pedestrian environment based on the PEQI ratings, and (2) the 
dependent variable is human perception evaluated through a pedestrian perception survey. The study assumes that the variables are relative, and presumes that an area assessed to have high pedestrian environmental quality will also have positive perceptions of those environments. Human perception of an environment undoubtedly differs based on personality, preference, and past experience (Kirtland, et al., 2003; Brownson, et al., 2009; Forsyth, et al., 2008). Therefore, this study will consider the factors that contribute to why people view the pedestrian environment the way they do through administering a pedestrian perception survey.

\section{Independent Variable}

Pedestrian environment refers to an area's physical surroundings and is usually characterized by “walkability” (San Francisco Department of Public Health, 2008), the term associated with how pedestrian-friendly a space is, including the extent to which it encourages walking by providing connectivity and safe access to various amenities (Southworth, 2005). In this study, the pedestrian environment is specifically associated with the pedestrian walkways that provide accessibility and connectivity from one street, building, and/or park to another within an urban area, which includes intersections, overpasses, alleyways, and all modes of passage for people to travel from one place to another that may or may not have barriers from vehicles, trees, bodies of water, and overbearing lands. For further clarification, the section on "Site Selection" will define the pedestrian environment boundaries that this study will assess and examine.

\section{Dependent Variable}

People's perception refers to how people view or perceive an environment. In this study, people's perception refers to the level of satisfaction one feels toward the test 
environment, in which data will be obtained utilizing self-administered surveys.

Everyone will formulate opinions about their surroundings, feelings that can be interpreted as positive or negative, and the full spectrum in between. Positive attitudes are generally associated with safe and open environments whereas negative impressions are associated with dangerous and dark spaces.

\section{Site Selection}

This study assesses the quality of the pedestrian environment for the downtown area in the city of San Luis Obispo, an area known for its unique character and has been ranked among the best places to live by Fortune Magazine, Sperling's Best Places List, Outside Magazine, and Sunset Magazine (San Luis Obispo Chamber of Commerce, 2010). Among the city's many great attributes, the spotlight shines on the downtown area, as it is considered a class of its own, being a proud recipient of The Great American Main Street Award in 1999 by the National Trust for Historic Preservation (San Luis Obispo Downtown Association, 2010). The downtown core is an irregularly-shaped rectangle and contains over 600 businesses (Figure 3.1 on p. 29).

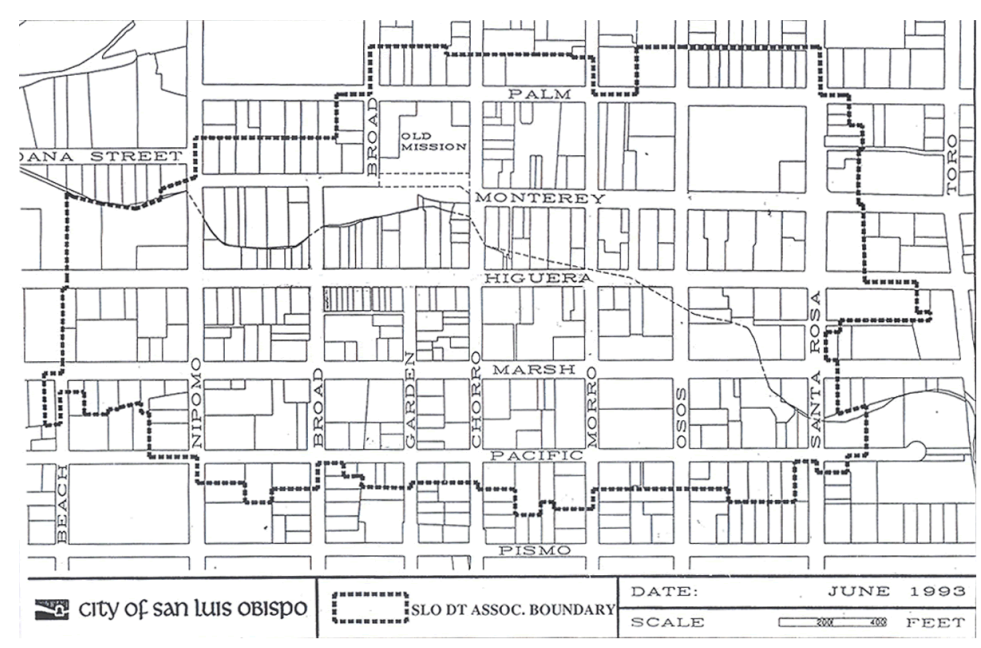

Figure 3. 1 Downtown San Luis Obispo Boundary Map 
The physical layout of the area has one dominant linear street - Higuera Street with the adjacent neighborhoods consisting of mostly single-family homes, multi-family dwellings, local government buildings, and light commercial buildings. The downtown area is well connected with neighboring streets and is located close to a major highway/freeway which allows for regional connectivity. The physical characteristics of downtown San Luis Obispo contains many great street components as defined by Jacob's (1995) The Great Streets, including an abundance of rich, historical, cultural and eclectic architectural styles that give the town a quaint, unique character, while providing a wide range of conveniences ranging from the commercial, retail, and service industries to planned elements such as trees, benches, and small pocket parks. Additionally, Higuera Street hosts major weekly local events such as Farmers' Market, which attracts people from neighboring cities to gather, people watch, and shop. The downtown area also provides ample parking with a number of parking structures and plenty of street parking that includes free, metered, and time-limited spaces for both visitors and residents. The many accommodating features make downtown San Luis Obispo an attraction in and of itself, which draws many people to come and enjoy.

The area of study will focus on the main downtown core of San Luis Obispo (Figure 3.2 on p. 31) which contains a total of 63 blocks, stretching from Palm Street to Pacific Street and Santa Rosa Street to Nipomo Street. For clarity, this study will examine the pedestrian quality of the major downtown streets and intersections, taking a holistic approach to understand the quality of the environment. 


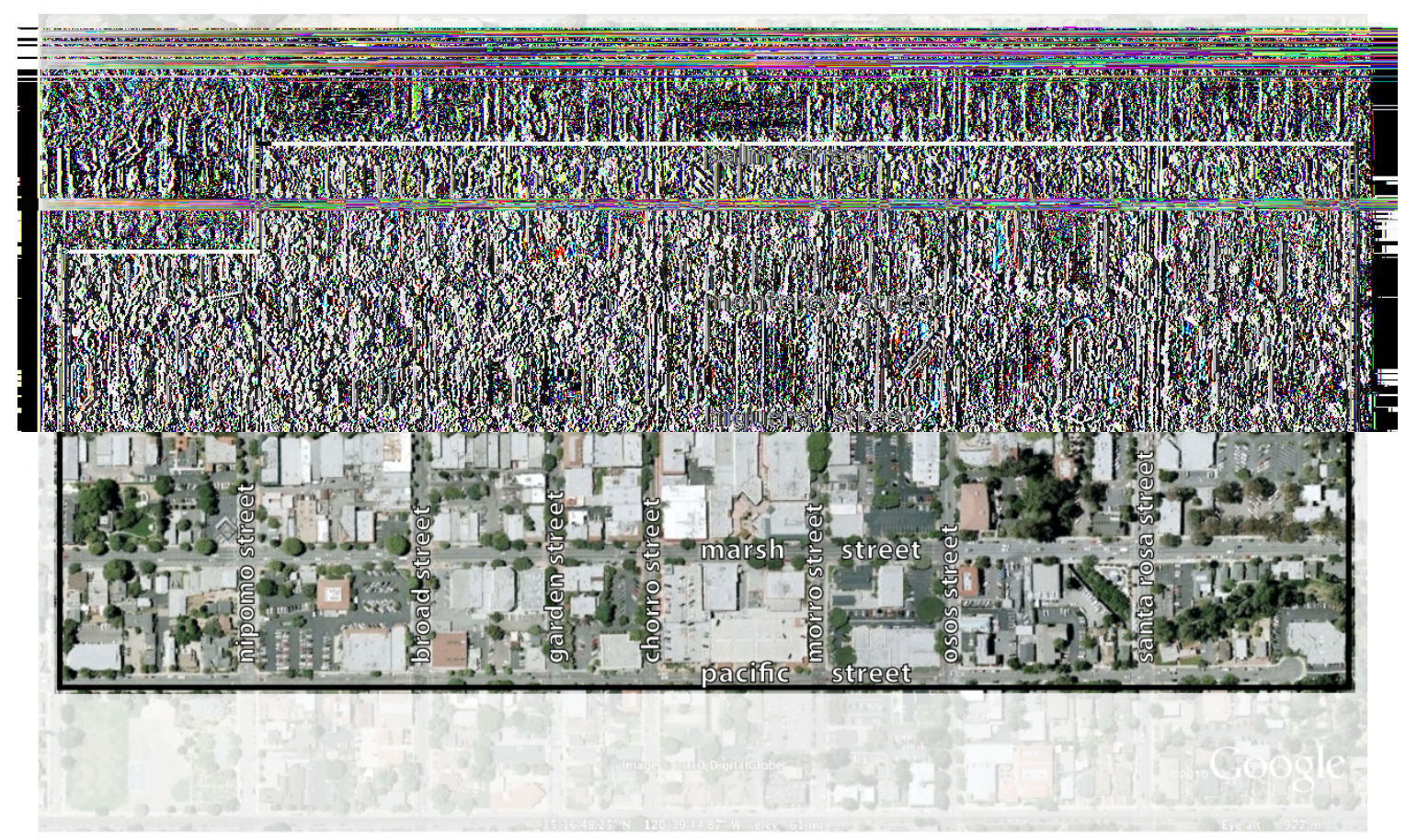

Figure 3. 2 The Study Area

\section{Participants}

The subjects of this study are surveyed students from California Polytechnic State University in San Luis Obispo (hereafter referred to as Cal Poly), primarily from the College of Architecture and Environmental Design. Participants of the survey are limited to residents who have lived in the city for at least two years and are self-identified as being knowledgeable and experienced with the streets and intersections of the study area. The students reported to have traveled these streets on a daily to weekly basis and were visually exposed to the surrounding areas while driving, walking, and/or biking through to reach their destinations. It is crucial to understand how this demographic of residents perceives the environment because they are extensive users of this study area. Mapping the students' walking paths and recognizing why they take certain routes will provide necessary information about their travel patterns and behaviors, how they perceive their 
environment, and the factors that contribute to their opinions. Consequently, the participants of the survey provide three critical pieces of information - perception, preferred routes, and travel patterns/behaviors.

\section{Procedure \& Methods}

This study employs two primary methods of data collection: (1) the Pedestrian Environmental Quality Index (PEQI) tool, which measures and assesses the quality of the pedestrian environment and (2) Pedestrian Satisfaction/Perception surveys, which examines pedestrian views of the selected environments.

\section{Pedestrian Environmental Quality Index (PEQI)}

The Pedestrian Environmental Quality Index (PEQI) is an observation-based survey tool developed by the San Francisco Department of Public Health (SFDPH) (See Appendix A for PEQI Assessment Tool on p. 91 \& 92). This assessment tool gauges the physical quality of a pedestrian environment and walking barriers of an urban environment. The PEQI is divided into two main categories - Intersection and Street Segments - with a total of five domains. Under the Intersection category, there is one domain - Intersection Safety - that measures 9 indicators. Within Street Segments, there are four domains - Traffic, Street Design, Land Use, and Perceived Safety - that measures a total of 21 indicators. Identified as factors that affect pedestrian activity by the SFDPH, these 30 indicators are measured and quantified using the survey form to determine the quality of the pedestrian environment. The tool requires that primary data is gathered through visual assessment of the intersection and street segments by directing a surveyor to fill out a 2-page checklist consisting of closed-ended questions. The PEQI can be downloaded with an accompanying manual for free via the SFDPH website. 
The PEQI tool is flexible and can be administered at any time as long as all factors can be measured without interference. Albeit, in the case of construction or other such occurrences, the assessment of that particular area will be re-evaluated after termination of the obstruction. The survey examines each street segment and intersection through a point-based system that ranges from 0 to 100 , indicating poor to high quality pedestrian conditions, respectively. The range is defined as follows (San Francisco Department of Public Health, 2008):

$$
\begin{aligned}
& 100-81=\text { highest quality, many important pedestrian conditions present } \\
& 80-61=\text { high quality, some important pedestrian conditions present } \\
& 60-41=\text { average quality, pedestrian conditions has room for improvement } \\
& 40-21=\text { low quality, minimal pedestrian conditions } \\
& 20-0=\text { poor quality, pedestrian conditions absent }
\end{aligned}
$$

The pedestrian environmental quality of the study area is identified using this rating system and is used to further determine the best and worst qualities of the environment.

\section{Pedestrian Perception Survey}

The second method of data collection was to develop and administer a pedestrian perception survey (See Appendix B for Pedestrian Perception Survey on p. 93), a map survey separated into seven categories - leisure, comfort, intersection safety, street safety, perceived street usage, visual quality and maintenance - that were selected using Great Streets by Jacobs (1995) and Measuring Urban Design Qualities by Active Living Research Program (2005). According to Jacobs (1995), streets must have certain elements to be classified as 'great'. He stresses that these streets must allow people to walk with some leisure and physical comfort, and have clear definition, transparency, 
proper maintenance, and aesthetical value. Jacobs also claims that great streets are not all the same in its physical form, as they cannot be engineered exactly alike in width or alignment, but instead, great streets can be designed for social, cultural, and physical aspects to all work cohesively in what he terms "the magic of design" (Jacob, 1995, p. 271). Similarly, the Active Living Research Program (2005) suggests that imageability (uniqueness), enclosure, human scale, transparency, and complexity are key attributes to measuring urban design qualities.

With consent from several Cal Poly professors, a 30-minute survey was administered during four separate class sessions from March 2010 to June 2010. Each student received a survey consisting of 7 maps along with three pens - blue, green, and red. For each category, the survey instructed students to map out the routes from most (blue) to moderate (green) to least (red) chosen/selected for travel and to explain why. This mapping provides critical information in understanding different travel patterns and obtaining information regarding each individual's travel behavior to, from, and through downtown. Past research examining pedestrian travel patterns found that it is important to record the distances and routes people take to substantiate validity and reliability of the data (Agrawal, et al., 2008). The map will be used to identify areas where students tend to walk/bike the most, which will help in comparing street segments and intersections to determine whether there are preferred routes of travel.

This survey was purposely conducted off site because this study is interested in identifying factors that are unique to its users. This might have produced misleading information had the survey been conducted on site, as participants may not necessarily notice specific elements until they were pointed out. In acknowledging this, the survey 
was intentionally designed to engage the respondents to think about and visualize the streets they travel through to avoid such circumstances. 


\section{CHAPTER 4}

\section{Results and Discussion}

This chapter introduces data analysis findings from the survey, which is structured to meet the goals and objectives of this study and will be discussed in four parts. Part one examined the results of the PEQI assessment tool. Part two analyzes the responses for each category to determine how people perceive the environment and the factors that contribute to street use. Part three compares the results of the analyses from parts one and two. Lastly, part four tests the applicability and usability of the PEQI tool in smaller urban settings.

\subsection{Results of Pedestrian Environmental Quality Index tool}

In total, 112 street segments and 35 intersections were assessed using the PEQI tool. The results determined that the street segments in downtown San Luis Obispo ranged from average to high quality while the intersections were of low quality standards, with some of poor and average quality (See Figure 4.1 for PEQI results of study site on p. 37). Within the past few years, downtown San Luis Obispo has undergone numerous renovations to retrofit current building infrastructures, which, in turn, necessitated the rebuilding and repaving of many street segments. As a result, current measures have increased the quality of the pedestrian environment in downtown San Luis Obispo. 


\section{PEQI RESULTS}

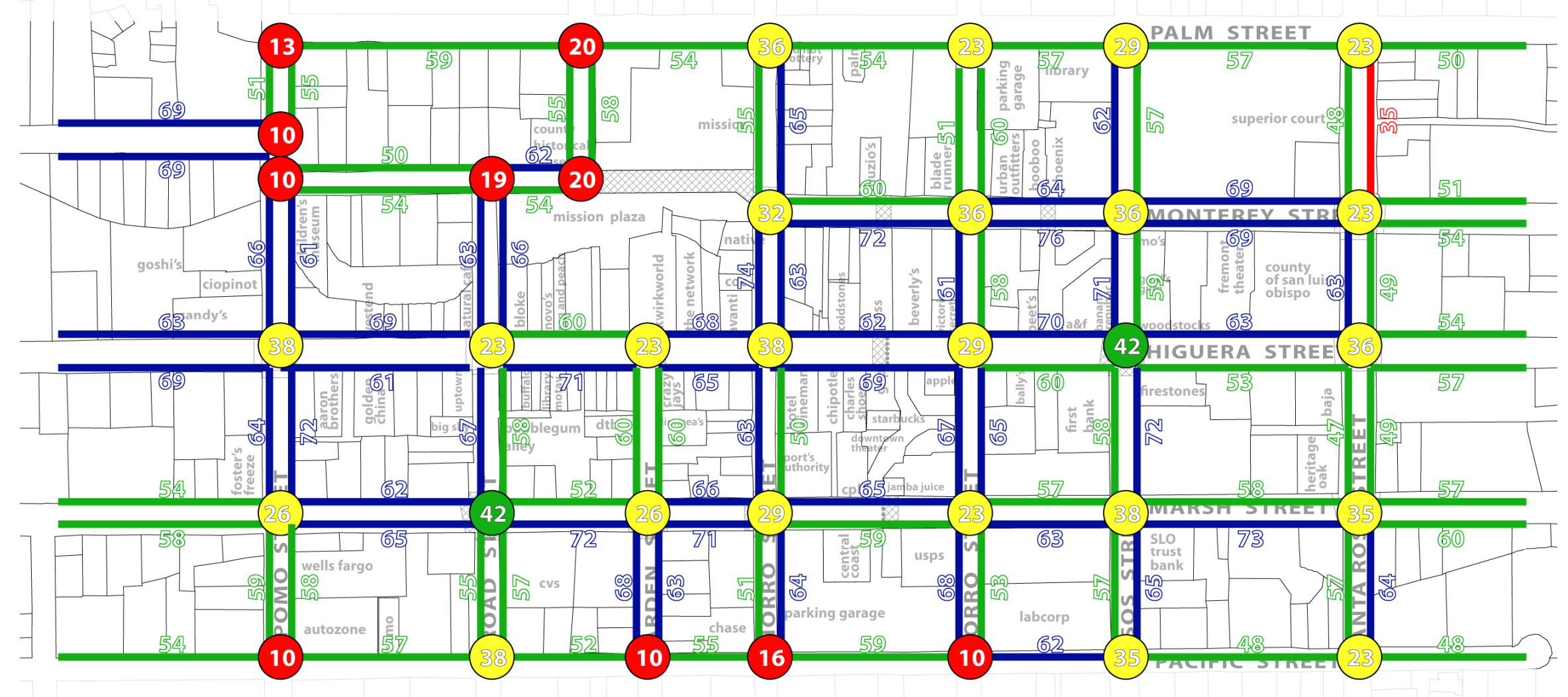

Figure 4. 1 PEQI Results 


\subsection{Results of Pedestrian Perception Survey}

Based on Great Streets by Jacob (1995) and Measuring Urban Design Qualities by Active Living Research Program (2005), seven categories were used to identify people's behaviors and attitudes toward the study site, which includes leisure, comfort, intersection safety, street safety, perceived street usage, visual quality, and maintenance. For each category, respondents were asked to identify areas they preferred the most, the least, or were indifferent to, and provide reasons why.

One hundred and thirty students from several different classes at Cal Poly were surveyed during the 2010 winter quarter on February 19 and March 8-10. Survey participants ranged from $2^{\text {nd }}$ year to $5^{\text {th }}$ year City and Regional Planning and Landscape Architecture students. Pedestrian perception surveys were distributed to each student, consisting of 7 separate categorical maps along with three different colored pens - blue, green, and red - to identify areas that were chosen the most, the least, or on occasion. Students were given instructions on how to respond to the survey prior to its distribution, and were encouraged to ask questions during the survey for further clarification. The survey was administered away from the area of study, requiring survey participants to visualize the preferred surroundings because this method places value on the details people remember since those are the elements that influence or impact him/her the most. Though on-site surveys have their advantages, people may not consider specific factors until they are verbally or visually reminded, and thus, the results may contain noticeable differences had the survey been conducted on site rather than remotely. In acknowledging both its limitations, the goal of this survey is to determine the intrinsic values that influence people's perception most significantly. 
Although survey participants were instructed to complete all parts of the exercise, some were left incomplete. The majority of survey participants did complete the survey by drawing in and identifying streets as well as providing reasons why. Some respondents left one or two categories blank due to possible lack of memory or knowledge of those particular areas on the map. Participants were more likely to identify and provide reasons for the most and least preferred routes/responses while ignoring the option of "moderate use"; therefore, this study will only analyze the responses for the most and least preferred areas for each category (See Appendix C for Pedestrian Perception Survey Map Results of most and least preferred areas for each category).

\subsubsection{Contributing Factors to Street/Intersection Use}

The following section presents the resulting survey responses. A table listing all indicators identified as contributing factors by PEQI and survey respondents for each category is available in the Appendix D - PEQI indicators versus Survey respondents' identified indicators for each category. Each category will present a summary of the responses followed by a breakdown of the most and least preferred areas for comparison (See Appendix E- Aggregated data from PEQI indicators versus Survey respondents' identified indicators for each category). The objective of this section is to identify the factors that contribute to people's perception to better understand their behavior and attitude towards an environment.

\section{Leisure Walk}

Respondents identified the following factors as reasons for choosing leisure walks: land use, street design, accessibility/connectivity, aesthetics, parking, public art/historic sites, traffic and people. 
$\underline{\text { Streets chosen most frequently for leisure walks - }}$

Respondents identified commercial (Figure 4.2 on p. 41), theaters, farmers' markets, window-shopping (Figure 4.3 on p. 41), bars, stores, food and other amenities such as banks and post offices (Figure 4.4 on pg. 41) as important land use elements. Out of 114 responses, 109 indicated that land use was the main factor in choosing a street for leisure walks, while 26 reported that connectivity, visibility, accessibility, and convenience were important factors in choosing a specific street for leisure walks. Respondents identified that they were more likely to walk in connected areas that directed them to certain destinations, often choosing specific routes for speed and convenience when traveling to and from home, school, parking, and other locations. Secondary factors include the following: street design (17) with pedestrian corridor, wide sidewalks, trees, lighting, and large gathering spaces (Figure 4.5 on p. 41); availability of and proximity to parking spaces/garages (16); public art/historic presence (14); and aesthetics (14) with visually appealing, scenic and attractive areas. Lastly, 7 students indicated that the presence of people was also important in choosing any street for leisure walks. 


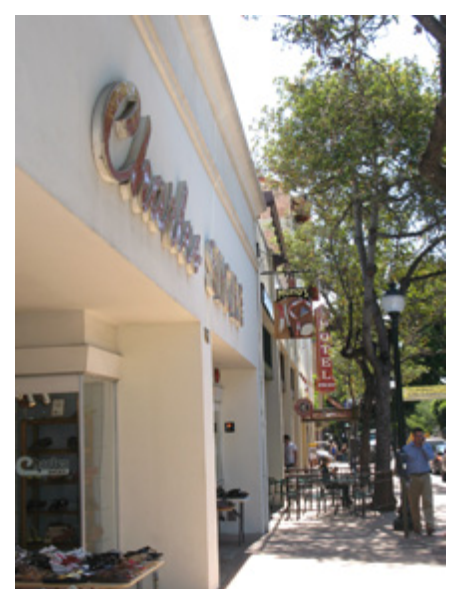

Figure 4. 2 Commercial area along Higuera Street

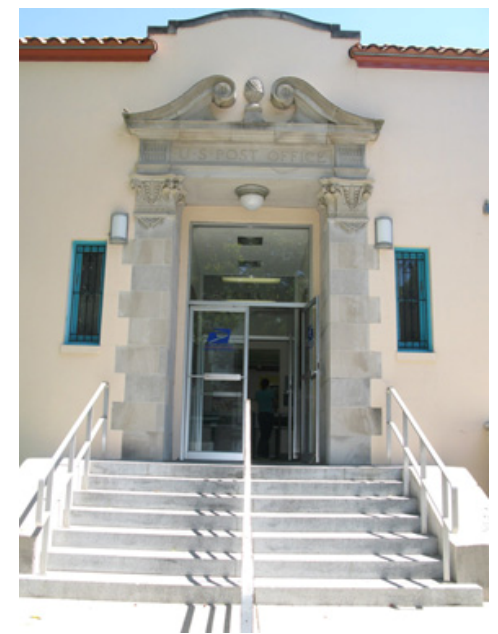

Figure 4. 4 Post office along Marsh Street

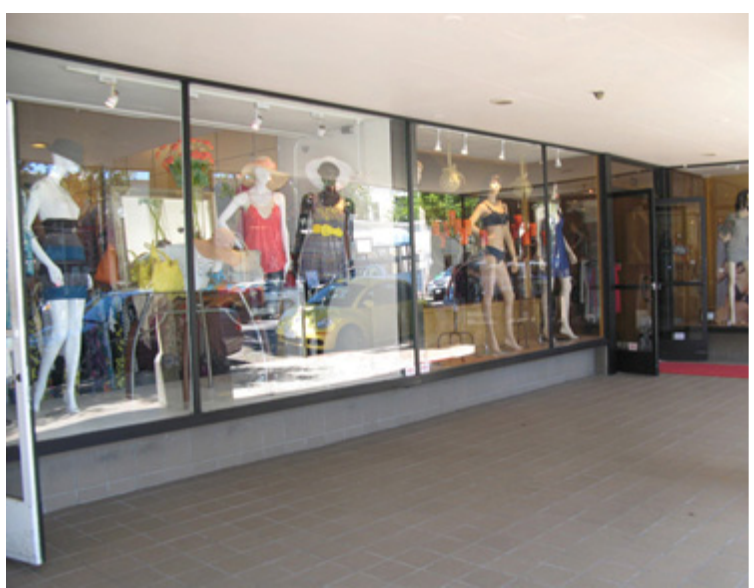

Figure 4. 3 Storefronts with windowshopping along Higuera Street

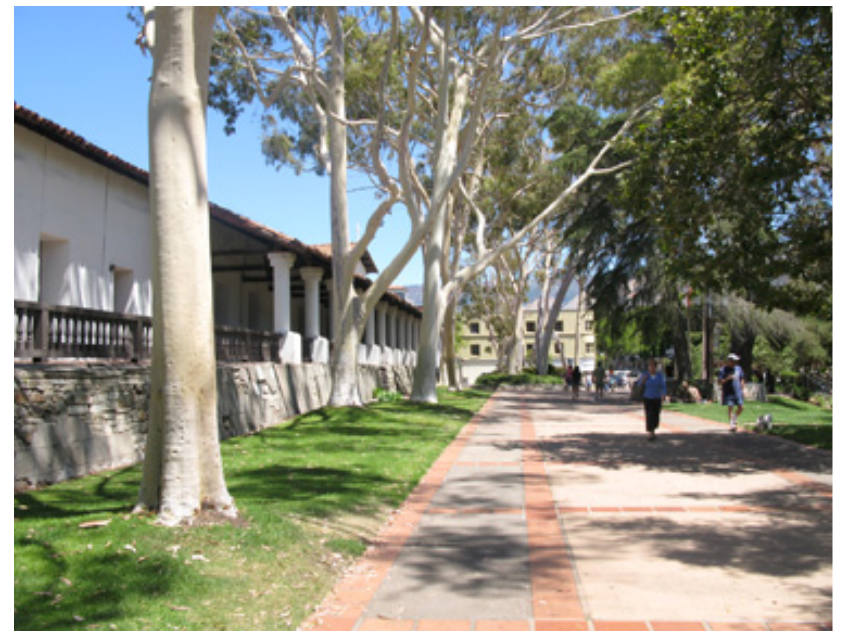

Figure 4. 5 Large gathering space with good street design elements

$\underline{\text { Streets chosen least frequently for leisure walks - }}$

Out of 98 responses, 64 students indicated that lack of activity was influential in not choosing a street for leisure walks. Respondents mentioned that they felt discouraged from going to areas with no land use elements, since they were lacking in activities (Figure 4.6 on p. 42) and were less appealing. Secondary factors include the following: street design (17) that lacks shade (Figure 4.7 on p. 42) and seating, has narrow 
sidewalks, is considered dark and crowded, along with the presence of trash cans factors in as discouragement for leisure walks; heavy and fast traffic (16); lack of appealing aesthetics (7) with ugly, less attractive scenery; lack of connectivity (7) to/from desired destination; lack of available parking and proximity to lots/spaces (4); dissatisfaction towards public arts/historical sites (2); and a general lack of public presence (1).

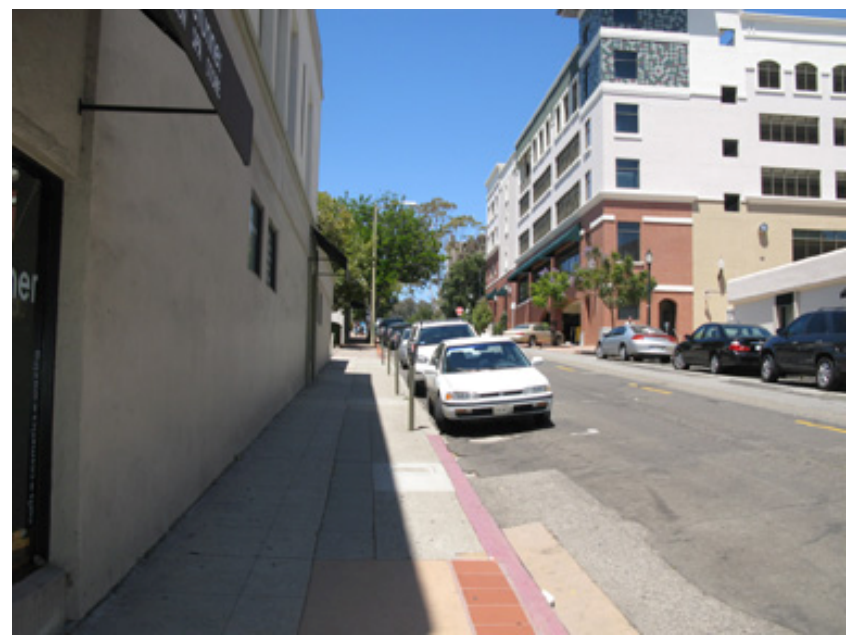

Figure 4. 6 Lack of activities along Morro Street

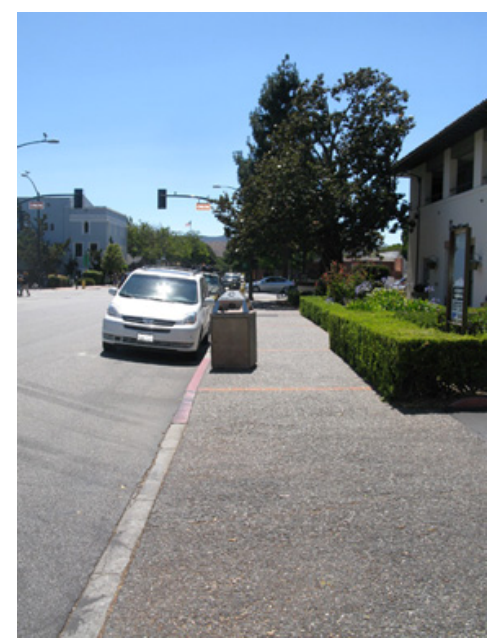

Figure 4. 7 Lack of shading along Marsh Street

\section{Comfort}

Respondents identified the following contributing factors when choosing areas based on comfort: presence of people, land use, traffic, street design, familiarity, aesthetics, safety, parking, and accessibility/connectivity/convenience/visibility.

\section{$\underline{\text { Streets chosen most for high comfort levels - }}$}

Out of 117 responses, 51 indicated that the presence of other people was high on their priority list, 47 reported street design elements such as lighting, wide sidewalks, trees, openness, pedestrian corridors (Figure $4.8 \& 4.9$ on p. 43), crosswalks, vegetations, seating, traffic signals, paving patterns and large open space affect their opinions, and 41 
decided land use with shops and welcoming/open/visible storefronts were the main factors that contributed to their level of comfort. Secondary factors are as follows: familiarity (18) with well-known and frequently used areas; low to no traffic areas (14); and aesthetically pleasing areas (12) with pleasant, nice, fresh surroundings. Respondents were most comfortable in familiar settings because they knew what to expect and where to go while aesthetically-pleasing environments evoke a calm, relaxed energy. Other contributing factors were parking (7), accessibility/convenience/visibility (4), and feeling safe (1).

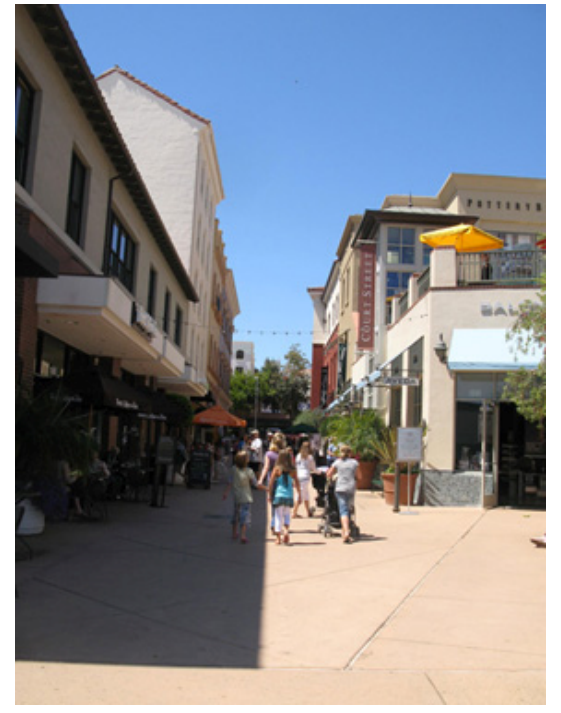

Figure 4. 8 Court Street pedestrian corridor

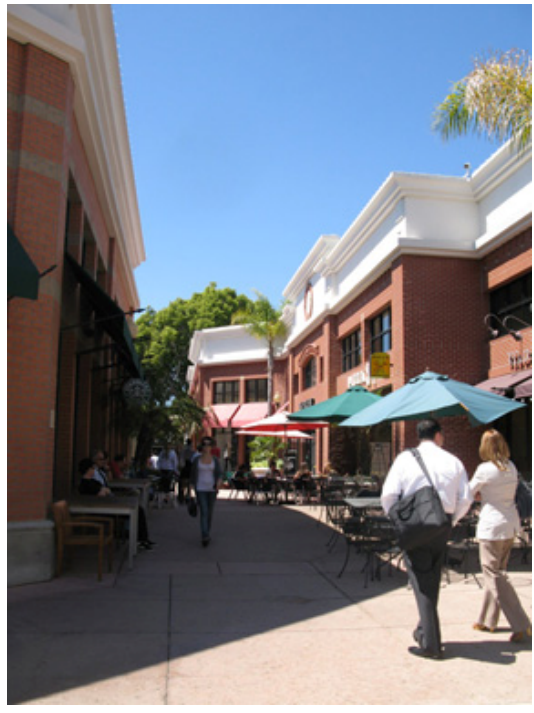

Figure 4. 9 Pedestrian Corridor in between Marsh and Higuera Street

\section{$\underline{\text { Streets chosen most for least comfort levels - }}$}

Out of 97 responses, 38 indicated that heavy traffic, fast cars, and auto-oriented streets made areas uncomfortable and 26 declared that a lack of people and/or presence of homeless/drunk people made for unattractive settings. Secondary factors include the following: land use (18) where there is the lack of buildings, stores, and amenities (Figure 
$4.10 \& 4.11$ on p. 44); and perception of safety (12), especially in dark areas where respondents felt endangered, unsafe and cautious. Other factors associated with comfort levels include lack of connectivity and accessibility (5), less familiar/frequented/known areas (5), ugly, unappealing, characterless and less aesthetically-pleasing areas (4), parking unavailability (4), and poor street design (3) with a lack of lighting, narrow sidewalks, wide streets, windy and poorly paved areas.

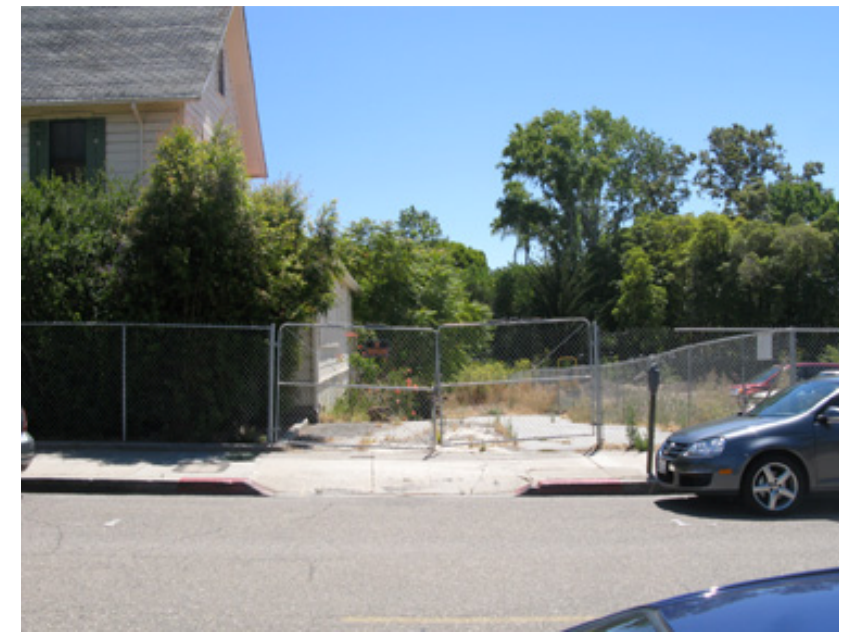

Figure 4. 10 Lack of building and abandoned area along Palm Street

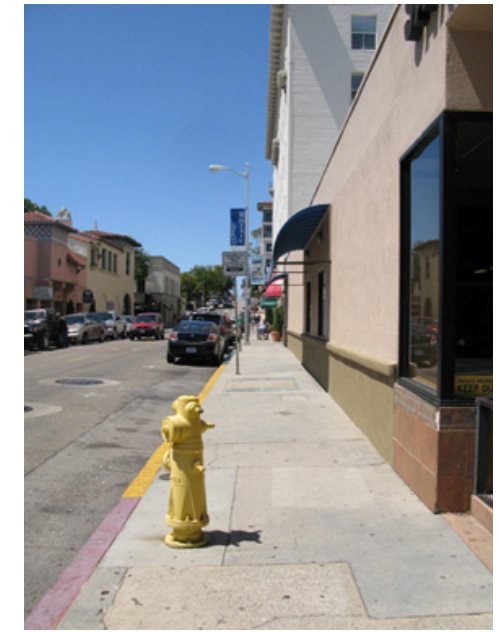

Figure 4. 11 Unattractive with lack of shading, people, amenities along Osos Street

\section{Intersection Safety}

Respondents identified the following factors as contributors to intersection safety: traffic, perceived safety, traffic lights (signals), crosswalks, presence of people, flashing lights, accessibility, signs, familiarity, and land use.

For intersections identified as the most safe -

Out of 97 responses, 29 indicated visible perception of safety, 28 reported traffic lights and signals (Figure 4.12 on p. 45), and 24 declared that traffic volume was a factor 
in identifying level of safety at an intersection. Respondents felt safest on the Higuera/Osos Street intersection and the Gap/Ross and California Pizza Kitchen (CPK) crosswalks because they believe that drivers are more cautious, pedestrians engage in fewer confrontations with drivers, and traffic is much slower in these pedestriandominant areas. In addition, signals for both pedestrian and vehicular traffic assures control of traffic to direct right-of-way. Secondary contributing factors including the presence of crosswalks (15) that are clearly marked, curb extensions (Figure 4.13 on p. 45) and the use of flashing lights (14). Most respondents preferred these elements because it notifies drivers of pedestrian crossings. Presence of people (9), visibility/connectivity (6), familiarity (3) and land use (1) are positive factors that contribute to levels of safety at an intersection.

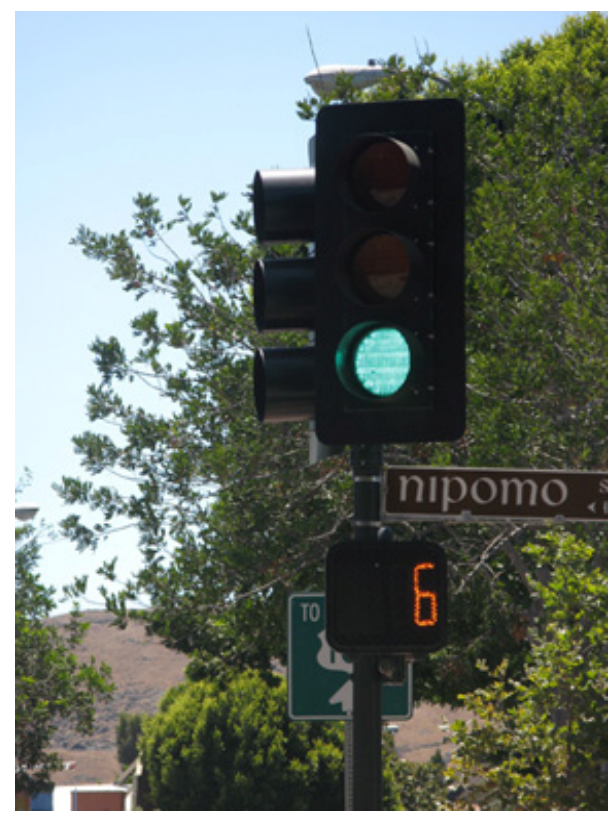

Figure 4. 12 Typical traffic and pedestrian signals around the study area intersections

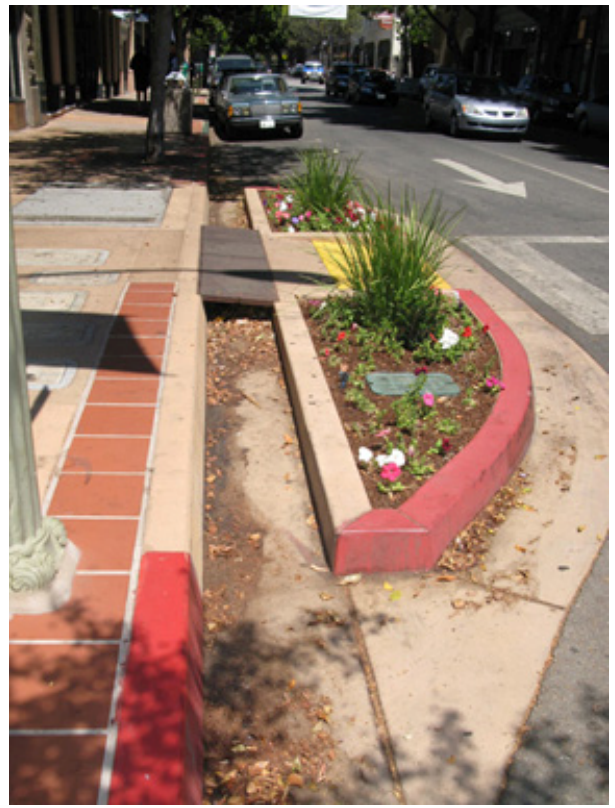

Figure 4. 13 Curb extension as traffic calming features on Garden Street Crosswalk 
For intersections identified as the least safe -

Out of 97 responses, 45 determined that heavy traffic, and 33 indicated that fast cars, traffic violators, general lack of awareness for pedestrians, and areas that have a history of accidents were factors that caused them to identify an intersection as unsafe. Respondents designated all intersections along Santa Rosa Street and the Higuera/Nipomo and Marsh/Nipomo crosswalks as the least safe intersections due to heavy traffic and a number of near accidents involving either the respondents or other pedestrians. People often feel uneasy about heavy traffic as it causes discomfort toward an environment because increased traffic volume correlates to an increase in speed and a decrease in pedestrians. Other factors related to intersection safety include a lack of lighting (9), a lack in presence of people (8), shortage of signage (6), difficult road, walkway, and car visibility (6), poorly marked crosswalks (Figure $4.14 \& 4.15$ on p. 46) (5), and a lack of commercial activities (1).

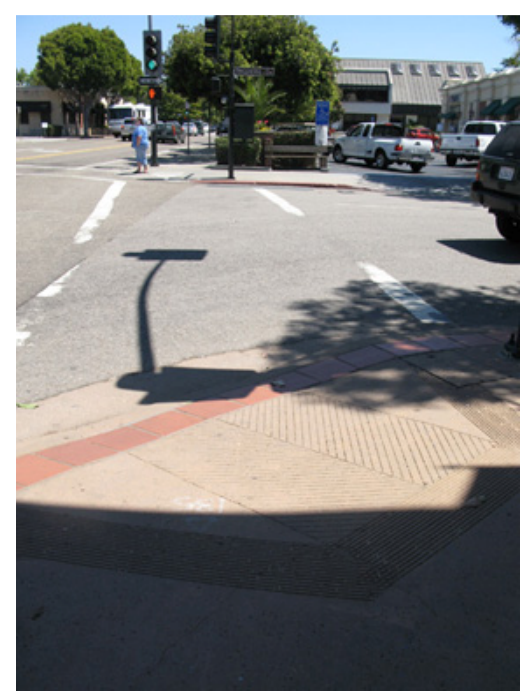

Figure 4. 14 Poorly marked pedestrian crosswalk on Santa Rosa and Higuera Street intersection

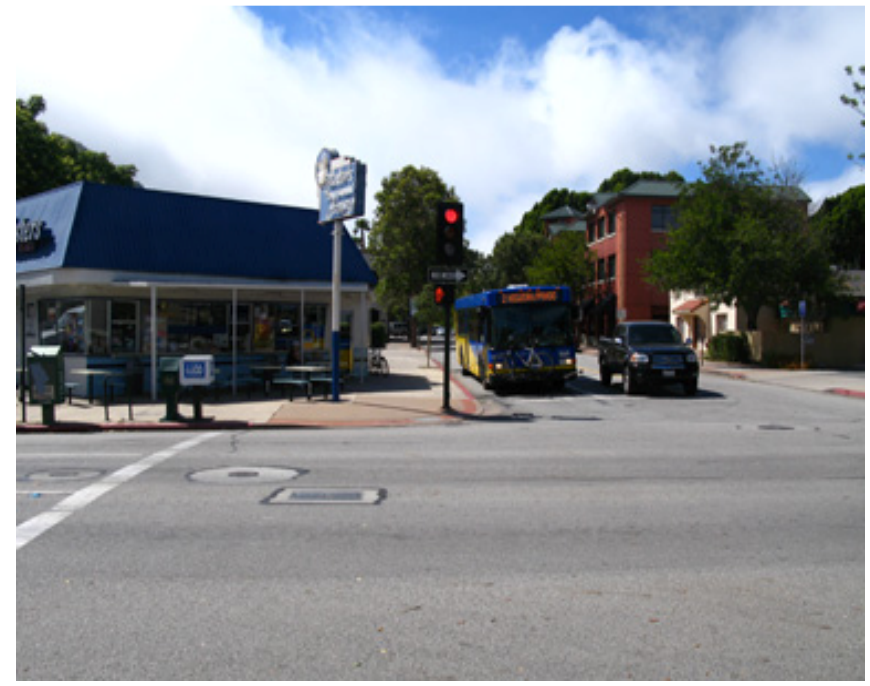

Figure 4. 15 No pedestrian crosswalk marking on Marsh and Nipomo Street intersection 


\section{Street Safety}

Respondents identified the following factors contributing to street safety: traffic volume, perception of safety, street design, presence of people, land use, visibility/connectivity/proximity, familiarity, and aesthetics.

\section{$\underline{\text { Streets chosen for highest street safety - }}$}

Out of 94 responses, 29 indicated traffic volume and 20 reported that perception of safety were factors in identifying the level of safety for streets. Students associated low traffic volume with perceived street safety because people felt that drivers were more aware of pedestrians and that cops were present patrolling traffic violations. Other contributing factors to street safety are visibility/connectivity/proximity (8), land use (8) consisting of more shops, stores, and government offices (Figure 4.16 on p. 47), aesthetics (3) with attractive facades and nice surroundings, street design (3) that includes trees, lighting, marked crosswalks, wide sidewalks, openness and signals, familiarity (3) of frequented areas, and the

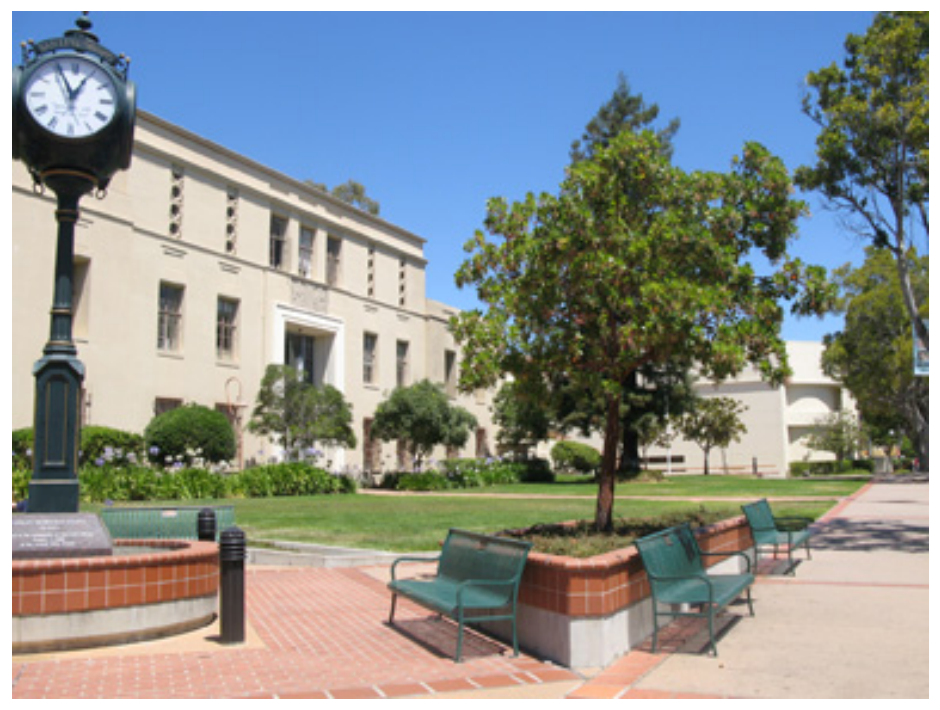

Figure 4. 16 Government buildings along Monterey Street presence of people (3). 


\section{$\underline{\text { Streets chosen for lowest street safety - }}$}

Out of 85 responses, 40 indicated heavy traffic, fast cars, and an auto-oriented environment and 31 indicated that lack of street design features were factors in identifying a street as unsafe. Respondents determined that lack of lighting/crosswalk markings/pavement patterns/signals/maintenance, narrow sidewalks (Figure 4.17 on p. 48), and litter are factors that make an environment unsafe. People indicated that there is a lack of pedestrian safety measures in areas with heavy traffic because less attention is given to those streets. Secondary factors related to street safety include lack of people and presence of homeless/drugs/bums (18) and because of this, 14 responses identified feeling unsafe. People associated the lack of people with forgotten and neglected areas, where drivers are unaware of pedestrians. Similarly, dark sidewalks and creepy atmospheres enhance feelings of an unsafe environment. Other contributing factors were land use (5) lacking in stores that attract different crowds, familiarity (3) in with less frequented areas, and lack of visibility (1) throughout the streets from

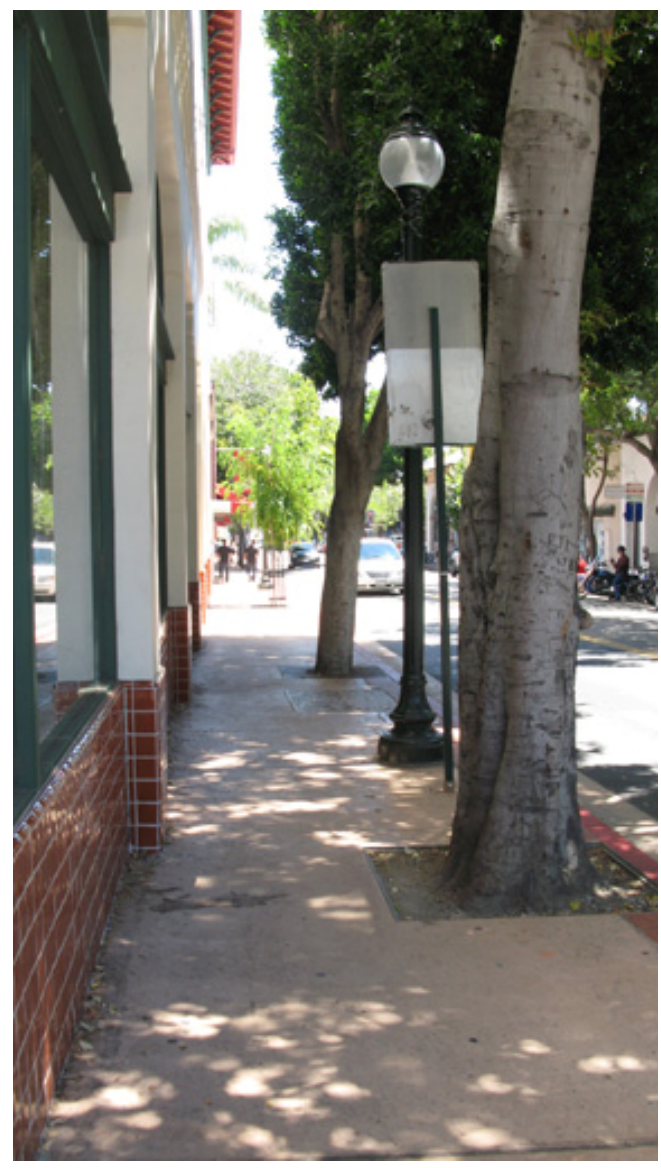

Figure 4. 17 Narrow sidewalk due to permanent sidewalk obstructions - trees, lighting, signage traffic and parked cars. 


\section{Perceived Street Usage}

Respondents identified the following factors as contributors to perceptions of street usage levels: land use, connectivity and accessibility, street design, traffic volume, presence of people, perception of safety, aesthetics, parking, public arts, and familiarity.

\section{$\underline{\text { Streets chosen for most perceived street usage - }}$}

Out of 92 responses, 83 participants indicated that land use was the main factor contributing to their perceptions of street usage levels, identifying restaurants, bars (Figure 4.18 on pg. 49), shops, stores and other related commercial activities as important land use elements that determine street usage levels. A secondary factor was connectivity and accessibility (Figure 4.19 on p. 49) (12) to other resources. Other contributing factors include street design (9) containing pedestrian-friendly environments, vegetation, large gathering spaces, lighting, trees and openness; the presence of people (6); availability of and close proximity to parking (5); aesthetical quality of new buildings and scenic routes (3); traffic volume (2); public arts/historical areas (2) such as the Mission (Figure 4.20 on p. 50) and adjacent creek; familiarity (1) with most used and frequented areas; and a general feeling of safety (1) due to increased usage.

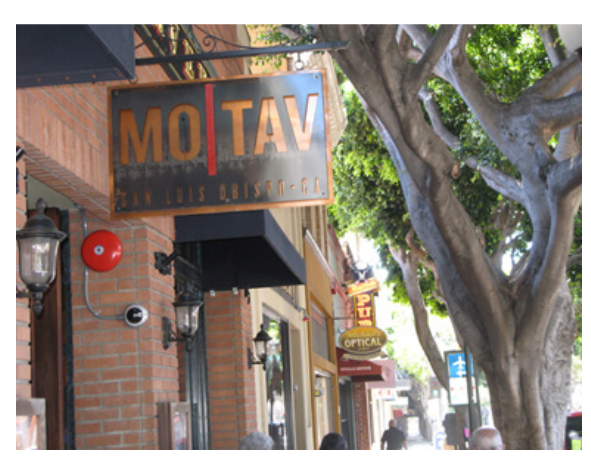

Figure 4. 18 Bars along Higuera Street

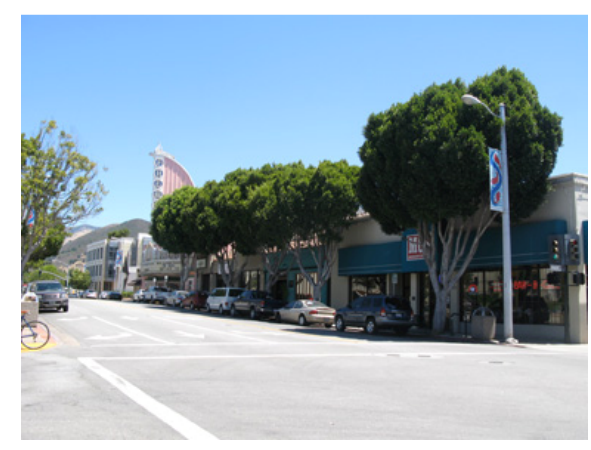

Figure 4. 19 Good accessibility to other amenities along Monterey Street 


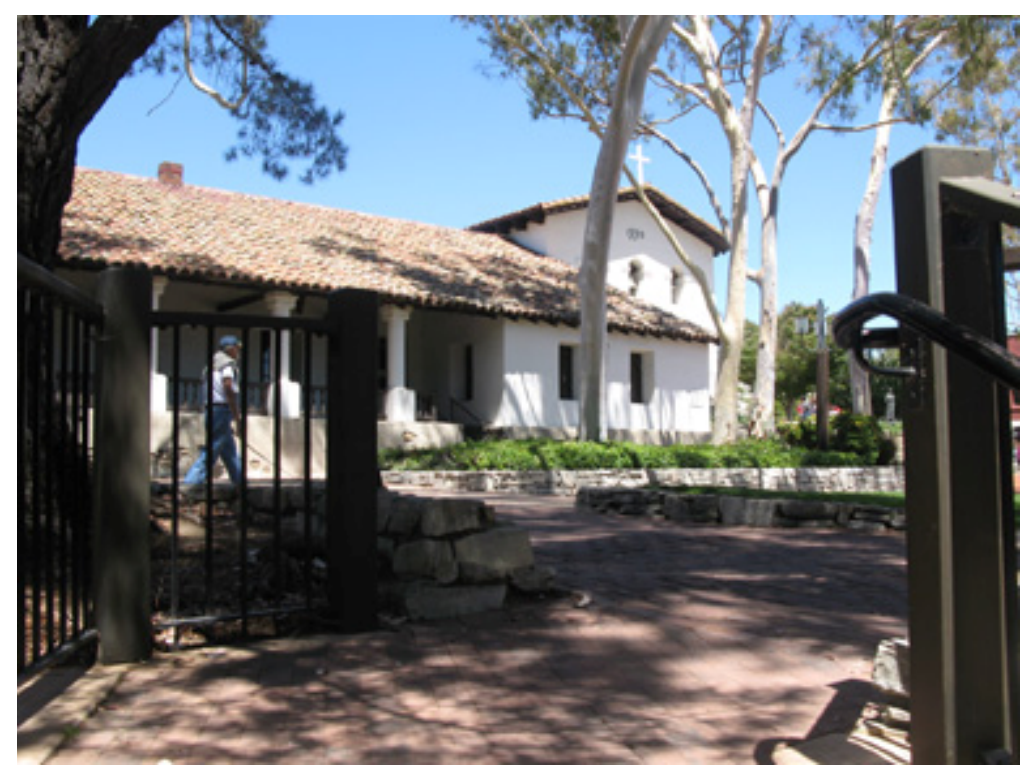

Figure 4. 20 San Luis Obispo Mission on Chorro Street

\section{$\underline{\text { Streets chosen for least perceived street usage - }}$}

Out of 77 responses, 51 indicated a lack of commercial activities having no stores, no destinations and no shopping areas as a factor contributing to their decision for perceiving lack of street usage. Respondents identified that the lack of different land use activities in certain areas do not provide reasons for pedestrians to hang out, walk, and linger around, especially in spaces outside the downtown core. A secondary factor is a lack of connectivity (14) to other amenities/activities, as respondents found that this discouraged pedestrians from venturing out into surrounding areas (Figure 4.21 on p. 51). Other contributing factors include traffic (9) in auto-oriented areas; safety (7) where high traffic and a lack of safety features lead people to perceive an environment as dangerous; street design (6) lacking pedestrian friendly elements; crosswalk/traffic lights/signals, and narrow sidewalks/spaces, minimal presence of people (Figure 4.22 on p. 51) (5); aesthetic quality (4) with unattractive and uninteresting facades/streets; and lack of parking availability and proximity (1). 


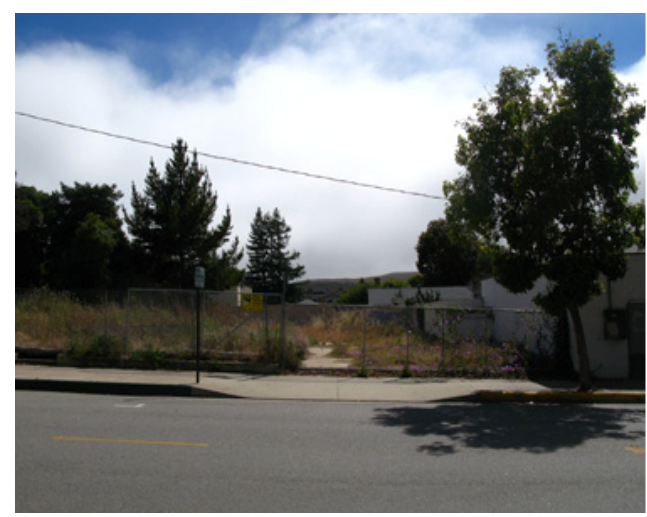

Figure 4. 21 Lack of amenities and activities and poor street design along Nipomo Street

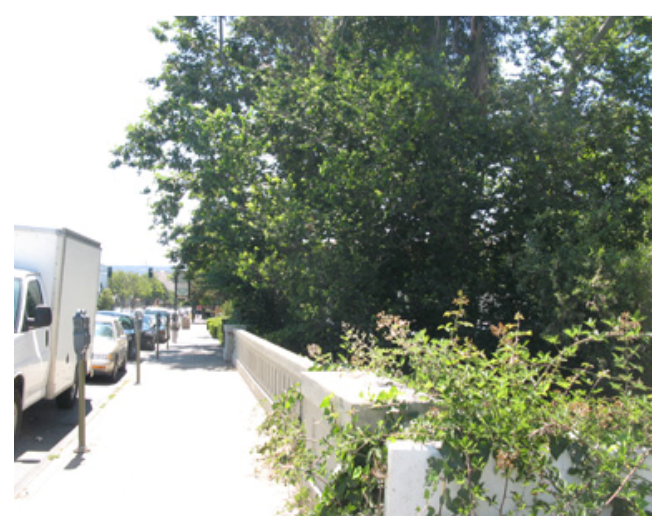

Figure 4. 22 Lack of pedestrian-friendly features such as lighting, seating, building

\section{Visual Quality}

Respondents identified the following factors as contributors to the visual quality of the pedestrian environment: aesthetics, street design, land use, public art/historic sites, traffic, presence of people, parking, and visibility.

\section{$\underline{\text { Streets chosen for highest visual quality - }}$}

Out of 104 responses, 66 indicated street design containing trees, signs (store), lighting (Figure 4.23 on p. 52), seating (Figure 4.24 on p. 52), sidewalk, maintenance, and paving patterns and 58 indicated aesthetics with diverse building facades, and nice, clean visuals at street level were factors for choosing a street based on visual quality. Secondary factors were public art/historical (23) areas with presence of the creek, sculptures, Bubblegum Alley, and the Mission, and land use (22) with storefronts, shops, restaurants, and window-shopping opportunities. Other contributing factors include the presence of people (7) making a place lively and vibrant, parking (1), and visibility (1). 


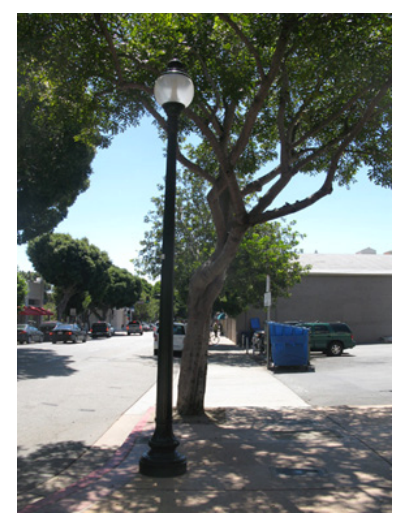

Figure 4. 23 Street lighting and trees along Higuera Street

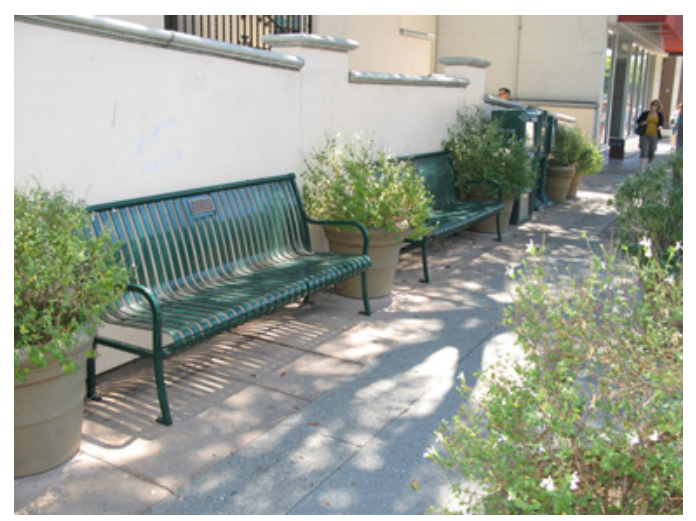

Figure 4. 24 Seating along Marsh Street

\section{$\underline{\text { Streets chosen for lowest visual quality - }}$}

Out of 86 responses, 47 indicated that run-down/neglected buildings, boring/ugly/old areas, and fake facades factored into their decision for not choosing a street based on visual quality. Respondents identified areas with low visual quality as undesirable to walk around and would discourage people from exploring. Secondary factors include street design (27) with lack of architectural elements (trees, lighting, vegetation, paving, maintenance, character, color), construction areas (Figure 4.25 on p. 53) and the presence of litter, land use (15) with no commercial elements, and heavy/busy traffic (12). Other contributing factors include parking (5) as large parking lots break up continuity of building facades, a lack of presence of people (3), and public art (1) displays such as Bubblegum Alley (Figure 4.26 on p. 53) which is considered unpleasant and unsanitary. Respondents have shown mixed feelings toward Bubblegum Alley where some embrace it as art while some associate it with litter and deem it environmentally hazardous. 


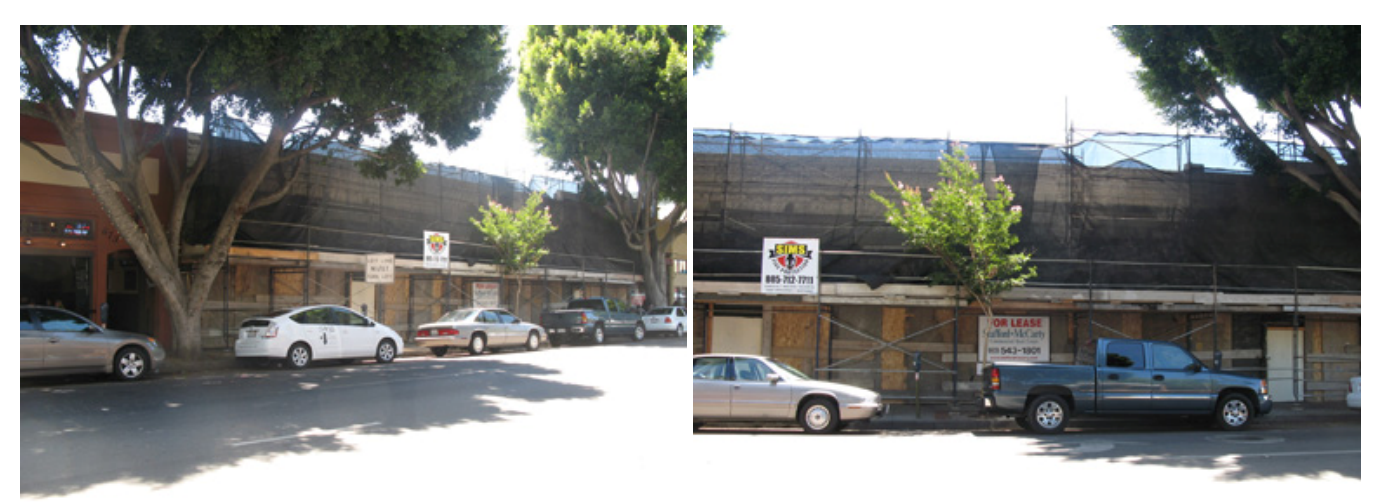

Figure 4. 25 Temporary construction along Higuera Street
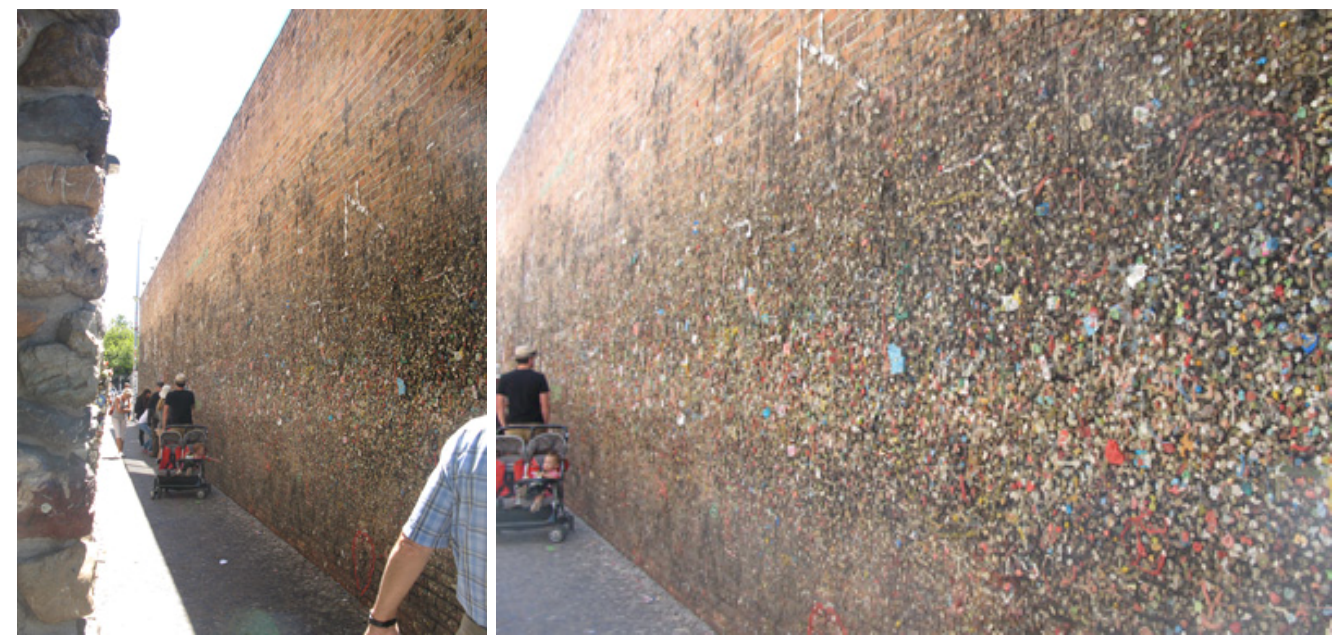

Figure 4. 26 Bubblegum Alley along Higuera Street

\section{Maintenance}

Respondents identified the following factors as contributors of maintenance: street design, land use, presence of people, aesthetics, historic sites (public art), and traffic.

$\underline{\text { Streets chosen for well-maintained areas - }}$

Out of 70 responses, 43 indicated that street design with good pavements, wellmaintained sidewalks/trees (Figure 4.27 on p. 54), no cracks/impediments, no litter, and 
graffiti was a factor in determining street maintenance quality. Secondary factors include presence of people (18), aesthetics (12), and land use (14), all of which assured a clean and safe environment, as local business owners have a vested interest in maintaining a positive perception of the area. One other contributing factor was historical elements (1) where the city or other interest groups dutifully keep the area clean and well maintained.
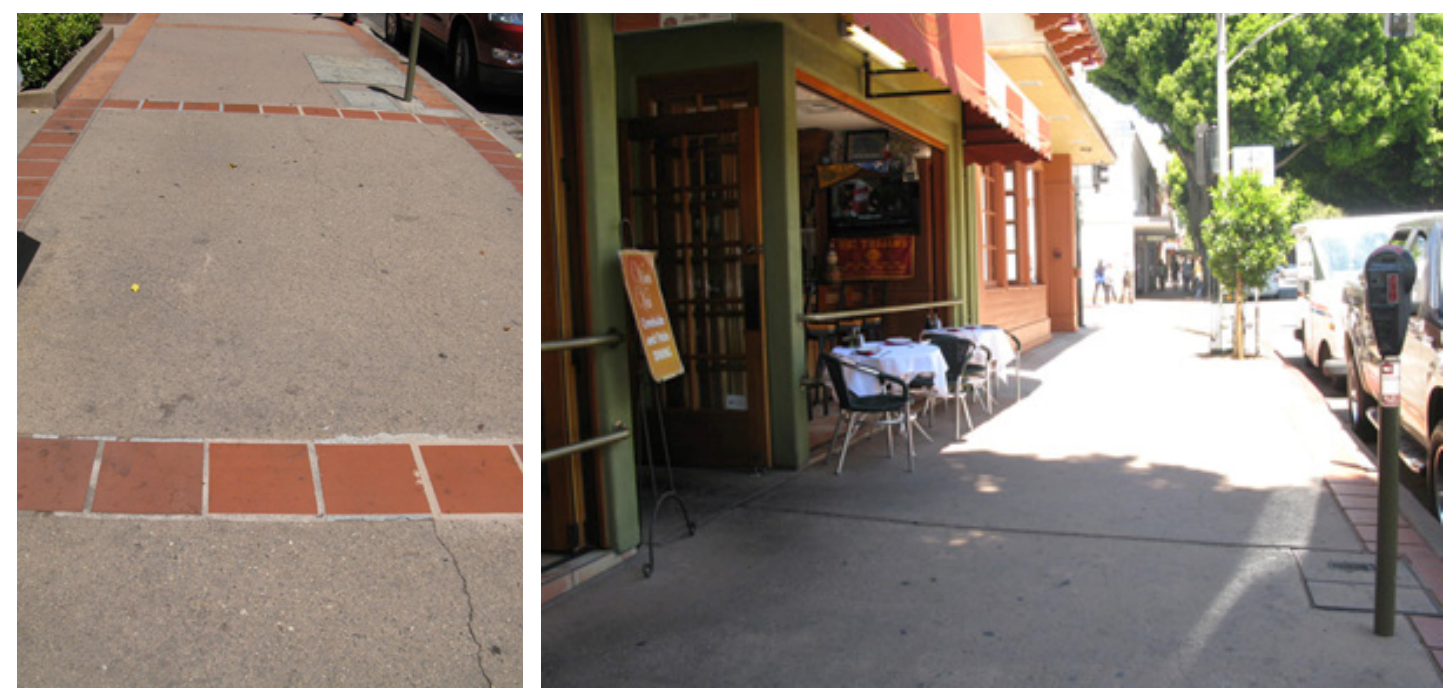

Figure 4. 27 Well-maintained sidewalk along Higuera Street

\section{$\underline{\text { Streets chosen for low-maintained areas - }}$}

Out of 53 responses, 27 indicated that bad/poor street design with presence of sidewalk cracks, pot holes, lack of vegetation, and disorganized streets that look messy/grungy was a factor in determining street maintenance quality (Figure 4.28 on p. 55). A secondary factor was the lack of land use (17) elements that allow for various diverse activities. There are assumptions that storeowners maintain areas surrounding their business and therefore, the lack of storefronts, shops, restaurants, and other related commercial activities mean that no one is keeping those environments clean. Other contributing factors include aesthetics (8) with ugly, dirty and old buildings/environment, 
lack in presence of people (8) since it is usually an indicator of safety, and traffic (1) with wide streets and auto-oriented environments signaling dense traffic with no pedestrian activity, and thus, less attention is given to it.
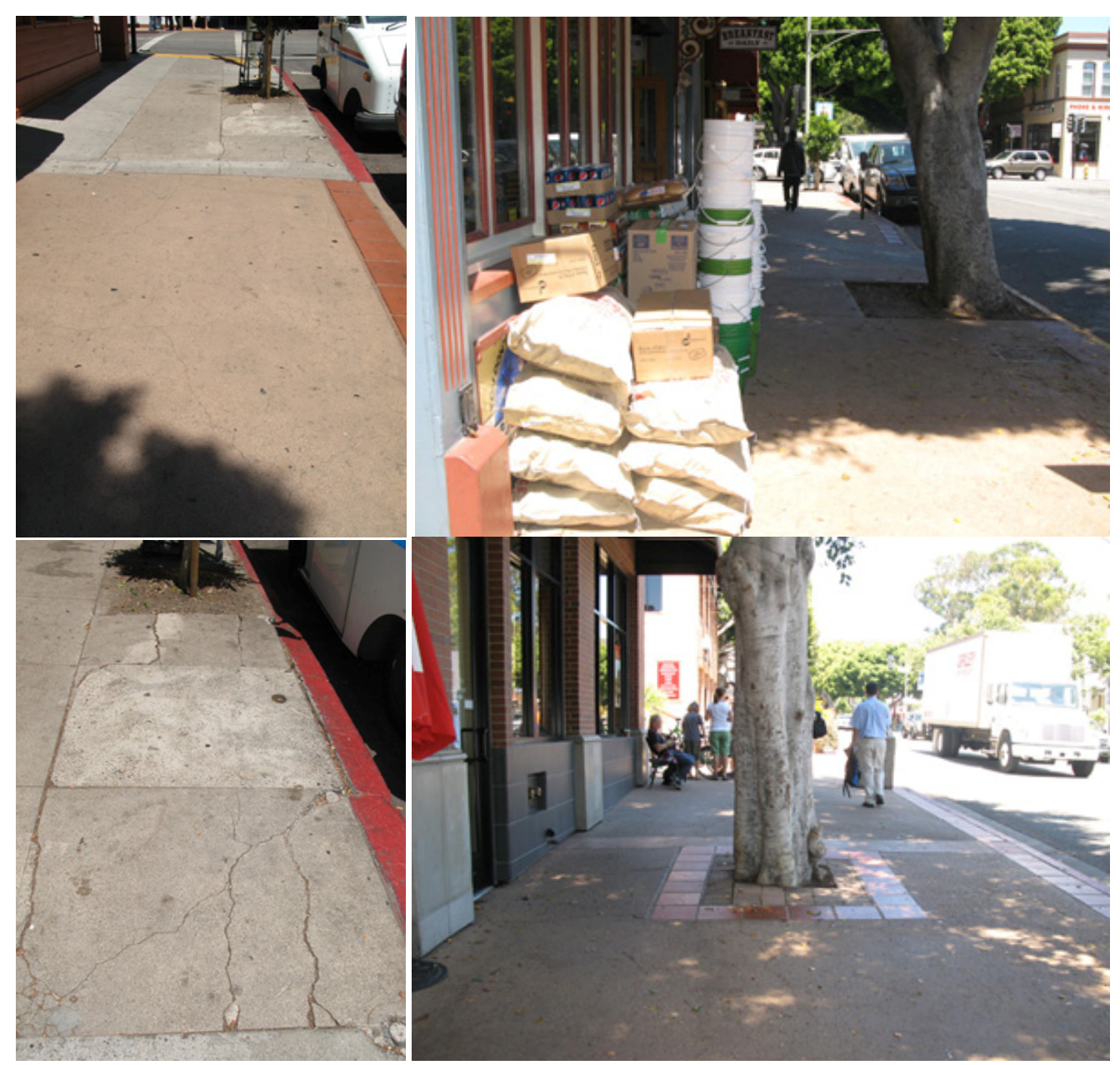

Figure 4. 28 Sidewalk impediments and obstructions along Higuera Street

\section{Summary}

Overall, results determined that land use, traffic, street design including aesthetics and presence of people were the primary contributing factors to people's perception of the pedestrian environment. For leisure walks and perceived street usage, land use is the single most dominant contributing factor. For comfort levels, the presence of people is 
the most important factor while secondary factors are land use, traffic and street design. For intersections and street safety, traffic is the most significant factor. In general, areas with less traffic are associated with the most pedestrian use, which is additionally associated with safety and increased levels of comfort. Lastly, visual quality and maintenance are determined mostly by street design including aesthetics where features including building facades, lighting, paving, seating, and trees all increase the aesthetical quality of the environment.

\subsection{Comparison between Results of PEQI and Pedestrian Perception Survey}

This part of the analysis examines how human perception of the pedestrian environment relates to environment quality, as determined by the PEQI tool. This will be addressed by juxtaposing how the PEQI results of the pedestrian environment compare and contrast to responses from the Pedestrian Perception Survey.

\section{Intersection}

$\underline{\text { Intersection most chosen for Intersection Safety - }}$

For intersections, respondents felt safest on the corners of Higuera/Osos Street (Figure 4.29 on p. 58) and the pedestrian crossings at Gap/Ross and near California Pizza Kitchen (CPK). PEQI rated the Higuera/Osos Street intersection with an average quality value of 42 (Table 4.1 on p. 58). This intersection was one of two intersections in the study site that received an average quality rating due to its traffic-calming features such as curb extensions and pavement treatments. The remaining intersections ranged from poor to low quality due to a lack of traffic-calming features. The crosswalks located between Gap/Ross and near CPK could not be measured using the PEQI tool because 
these did not qualify as intersections. Respondents chose the Higuera/Osos Street intersection as the safest intersection for several reasons: presence of traffic signals for both pedestrians and car; retail/commercial elements surrounding the intersection; pedestrian-friendly features such as clearly marked crosswalks with different pavement treatment; presence of people in all four corners; and heightened driver awareness of pedestrians. This intersection is one of only several in the city that has a separate pavement along the crosswalks. For this particular intersection, the way people perceived the environment parallels with how the PEQI rated the pedestrian environment quality. Similar to the criteria of the PEQI ratings, respondents identified traffic, presence of signals, crosswalks, pavements, adequate signage, and other traffic-calming features as important contributing factors for both the quality and human perception of the intersection. 


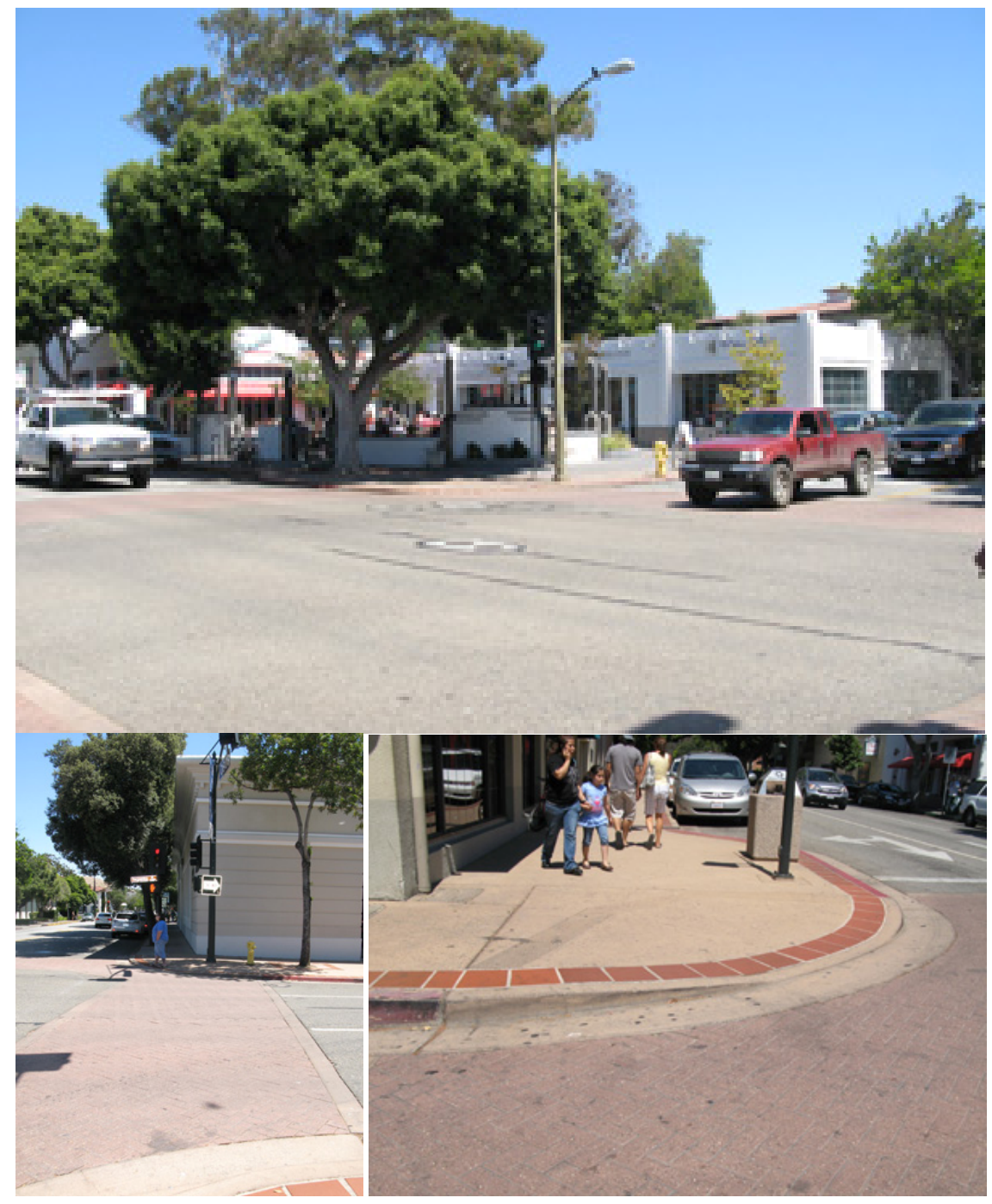

Figure 4. 29 Higuera and Osos Street intersection

\begin{tabular}{|l|r|r|}
\hline \multicolumn{1}{|c|}{ Variables } & Values & \multicolumn{2}{c|}{ Score } \\
\hline Crosswalk & 4 directions & 21 \\
\hline Ladder crosswalk & None & 8 \\
\hline Countdown in signal & 4 directions w/o countdown & 19 \\
\hline Crossing speed & Slower than 3.5 ft/sec & 20 \\
\hline Crosswalk scramble & None & 5 \\
\hline No turn on red & None & 5 \\
\hline Tcfs & 1 to 2 & 15 \\
\hline Additional signs for ped & None & 7 \\
\hline & Total & 100 \\
\hline & Minimum score possible & 56 \\
\hline & Weighted score & 1.05 \\
\hline Calculation = (total score - min. score possible)/weighted score \\
\hline & PEQI score \\
\hline
\end{tabular}

Table 4. 1 PEQI intersection scoring of Higuera and Osos Street Intersection 
Respondents identified the crosswalks between Gap/Ross (Figure 4.30 on p. 59) and at CPK (Figure 4.31 on p. 60) as safe compared to all intersections in the area of study. These pedestrian crossings were chosen primarily because of its traffic-calming features such as flashing lights that indicate when pedestrians are crossing and different pavement patterns. Even though there are no pedestrian signals and traffic lights to control traffic, respondents realized that there are alternative traffic-calming features that function for the safety of pedestrians. In addition, these crosswalks are shorter in length, enclosed by tree canopies, and surrounded by a number of retail/commercial stores, often evoking feelings of comfort and safety when using these crosswalks. People were less likely to choose similar crosswalks elsewhere due to distance, lack of enclosures, and fewer traffic-calming features such as the flashing lights.
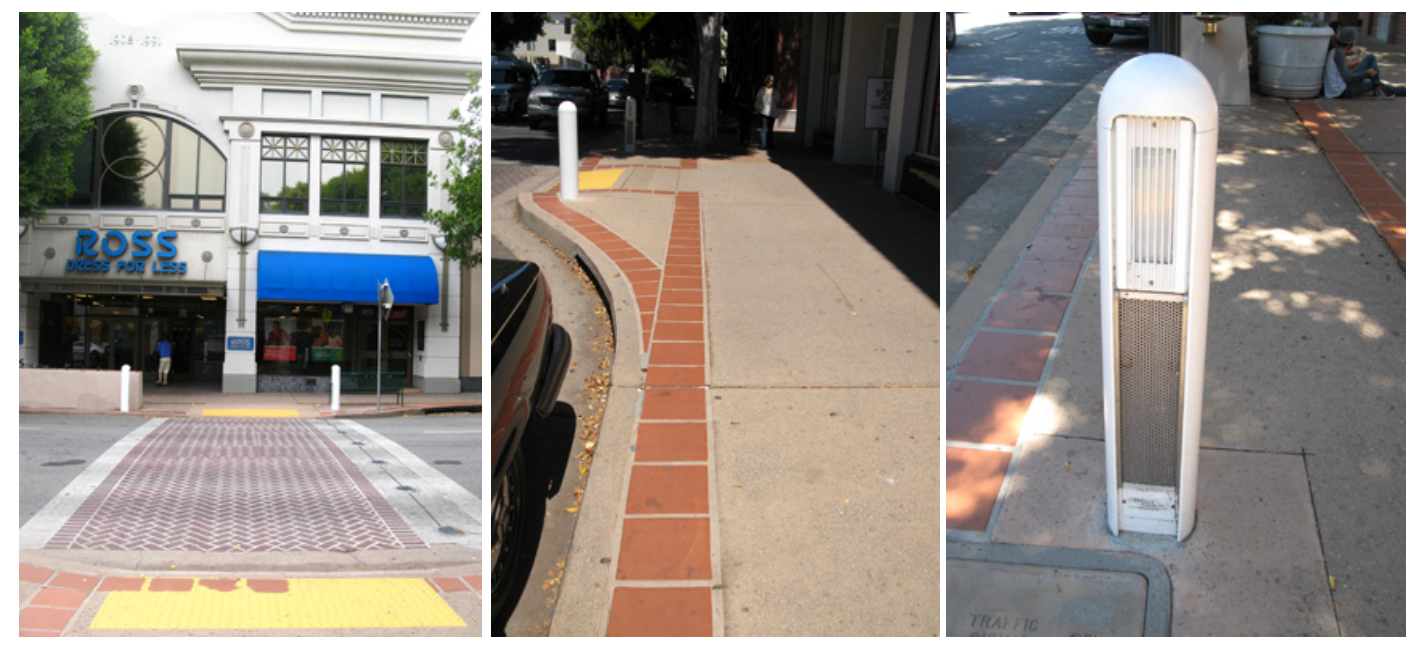

Figure 4. 30 Gap and Ross ladder crosswalk on Higuera Street 


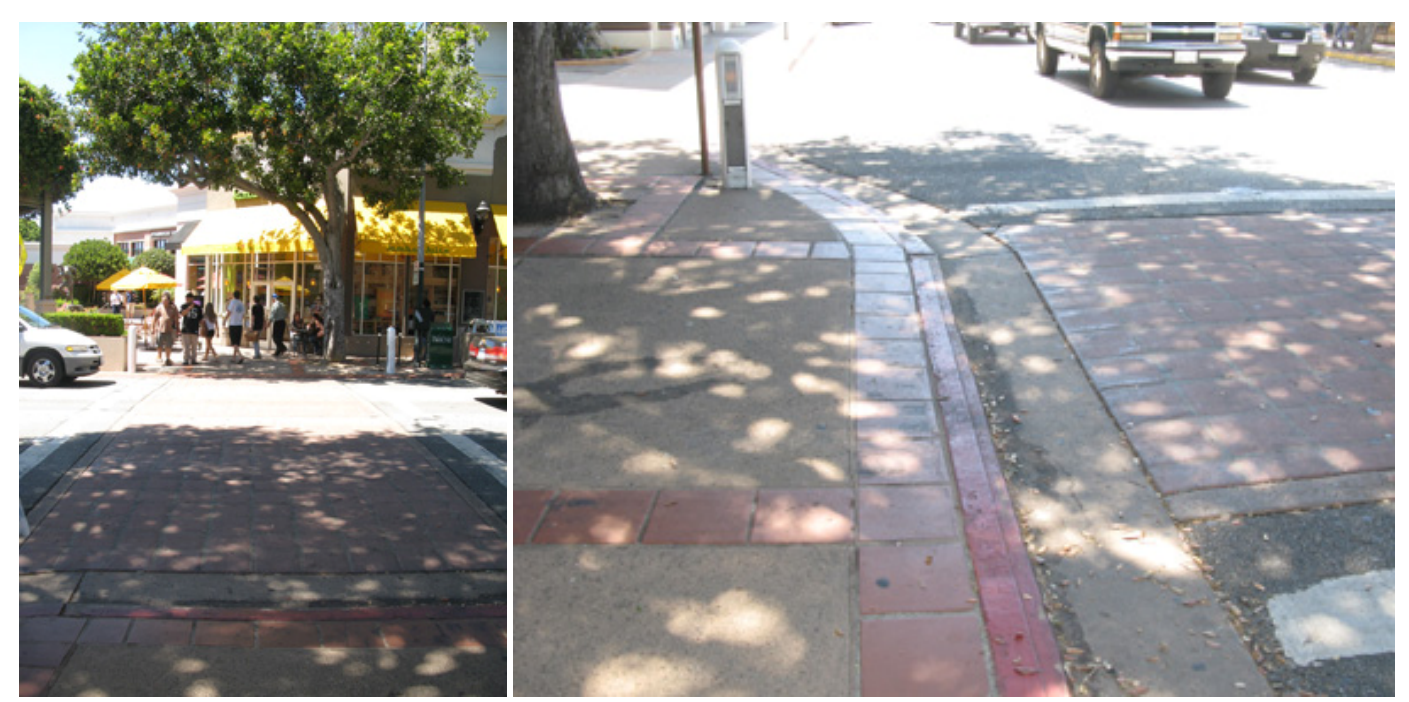

Figure 4. $31 \mathrm{CPK}$ intersection on Marsh Street

\section{Least chosen for Intersection Safety -}

Respondents felt the least safe at the Higuera/Santa Rosa Street intersection (Figure 4.32 on p. 61). PEQI rated this intersection with a low quality value of 36 (Table 4.2 on p. 61) attributed to its lack of traffic-calming features and signs. Participants of the survey indicated that this particular intersection felt unsafe due its heavy/fast flow of traffic and wide crossing distance. People complained that drivers are unaware of crossing pedestrians when making turns at this downtown intersection. Several other responses indicated that poor lighting and a minor presence of people also detract from the perceived level of safety. 

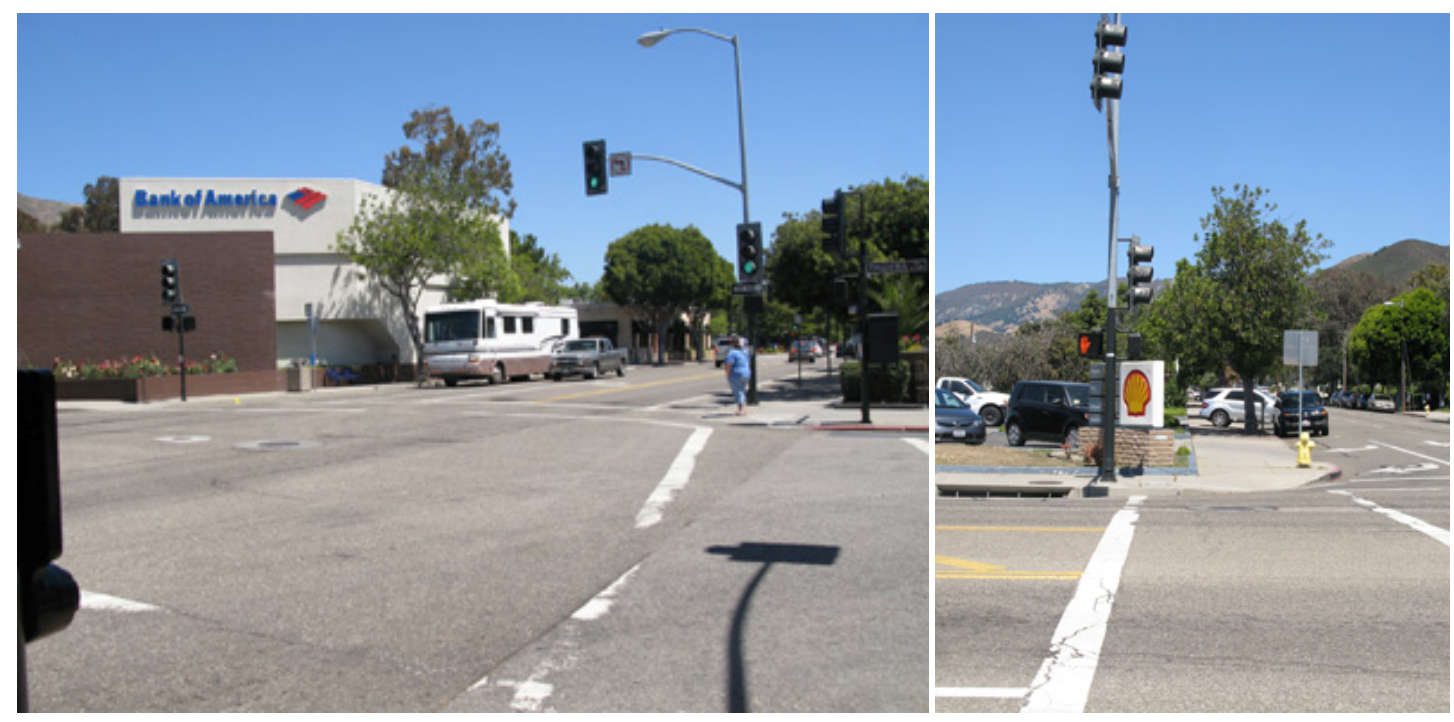

Figure 4. 32 Santa Rosa and Higuera Street intersection

\begin{tabular}{|l|r|r|}
\hline \multicolumn{1}{|c|}{ Variables } & Values & Score \\
\hline Crosswalk & 4 directions & 21 \\
\hline Ladder crosswalk & None & 8 \\
\hline Countdown in signal & 4 directions w/o countdown & 19 \\
\hline Crossing speed & Slower than 3.5 ft/sec & 20 \\
\hline Crosswalk scramble & None & 5 \\
\hline No turn on red & None & 5 \\
\hline Tcfs & None & 9 \\
\hline Additional signs for ped & None & 7 \\
\hline & Total & 94 \\
\hline & Minimum score possible & 56 \\
\hline & Weighted score & 1.05 \\
\hline Calculation = (total score - min. score possible)/weighted score \\
\hline \multicolumn{2}{|c|}{ PEQI score } \\
\hline
\end{tabular}

Table 4. 2 PEQI intersection scoring of Santa Rosa and Higuera Street intersection

\section{Street Segment}

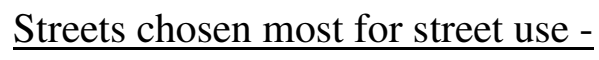

Respondents identified the south side of Higuera Street between Morro Street and Chorro Street (Figure 4.33 on p. 62) as the street segment most chosen for leisure walks, comfort, street safety, perceived street usage, visual quality and maintenance. PEQI rated this Street Segment with a high quality value of 69 (Table 4.3 on p. 63) attributed to its 
good street design qualities and availability of various amenities. This particular section of the street was identified as having good connectivity and accessibility from parking and other destinations, particularly as the pedestrian corridor provides easy access between Marsh and Higuera Street, and boasts an aesthetically-pleasing environment integrating planters, seating, retail, restaurants, and other amenities. Other responses indicated diversity, presence of people, well-maintained sidewalks and good lighting contributed to their opinions, as well.

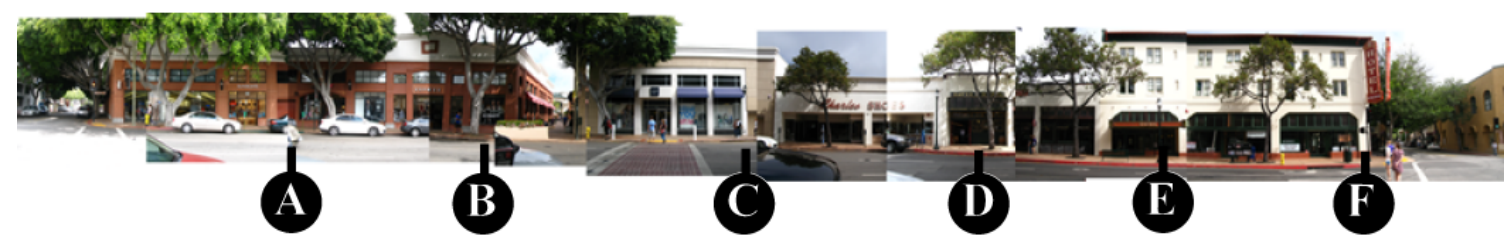

Figure 4. 33 Panoramic view of Higuera Street between Morro and Chorro Street

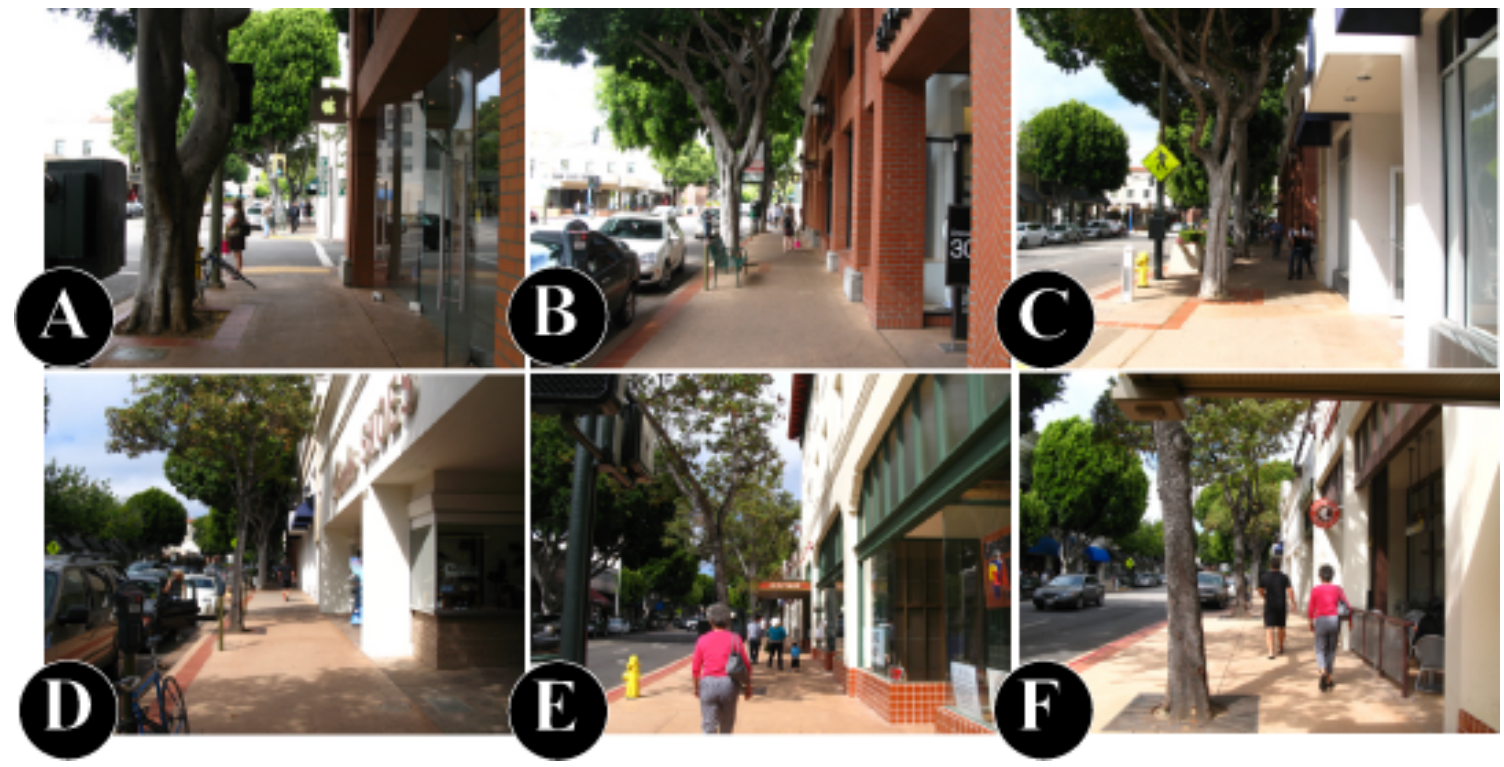

Figure 4. 34 View of Higuera Street walking from Morro to Chorro Street 


\begin{tabular}{|c|c|c|}
\hline Variables & Values & Score \\
\hline Number of lanes & 3 lanes & 9 \\
\hline Two way traffic & No & 7 \\
\hline Vehicle speed & Yes $-25 \mathrm{mph}$ & 22 \\
\hline Tcfs & No & 7 \\
\hline Width of sidewalk & 8 ' to $12^{\prime}$ & 19 \\
\hline Sidewalk impediments & None & 24 \\
\hline Large sw obstructions & Yes, temporary & 10 \\
\hline Presence of curb & Yes & 17 \\
\hline Driveway cuts & None & 15 \\
\hline Trees & Continuous line & 16 \\
\hline Planters/gardens & Yes & 9 \\
\hline Public seating & Yes & 13 \\
\hline Presence of buffer & Timed-parallel parking & 11 \\
\hline Public art/historical sites & $\begin{array}{r}\text { No } \\
\end{array}$ & 6 \\
\hline Restaurant/retail use & $3+$ & 19 \\
\hline Illegal graffiti & No & 9 \\
\hline Litter & No & 10 \\
\hline Lighting & Yes, public/private & 25 \\
\hline Constructions sites & No & 13 \\
\hline \multirow[t]{4}{*}{ Abandoned buildings } & Yes & 5 \\
\hline & $\begin{array}{r}\text { Total } \\
\end{array}$ & 266 \\
\hline & Minimum score possible & 106 \\
\hline & Weighted score & 2.3164 \\
\hline \multicolumn{3}{|c|}{ Calculation $=($ total score - min. score possible $) /$ weighted score } \\
\hline
\end{tabular}

Table 4. 3 PEQI street segment scoring for Higuera Street between Morro and Chorro Street

$\underline{\text { Streets chosen least for street use - }}$

Respondents identified the following two street segments as the least chosen for leisure walk, comfort and street safety: the southwest side of the street segment along Santa Rosa Street between Pacific and Marsh Street (Figure 4.35 on p. 64); and Santa Rosa Street in between Marsh and Higuera Street (Figure 4.37 on p. 65). PEQI rated these street segments with average quality values of 57 (Table 4.4 on p. 64) and 47 (Table 4.5 on p. 65), respectively, due to its lack of safety features such as road buffers and street lighting. Similarly, respondents to the survey indicated that these streets were the least chosen because of the heavy/fast flow of traffic, lack of activities, and poor lighting, which are all factors that decreased the perceived quality of the environment whereby people often felt unsafe and uncomfortable. 


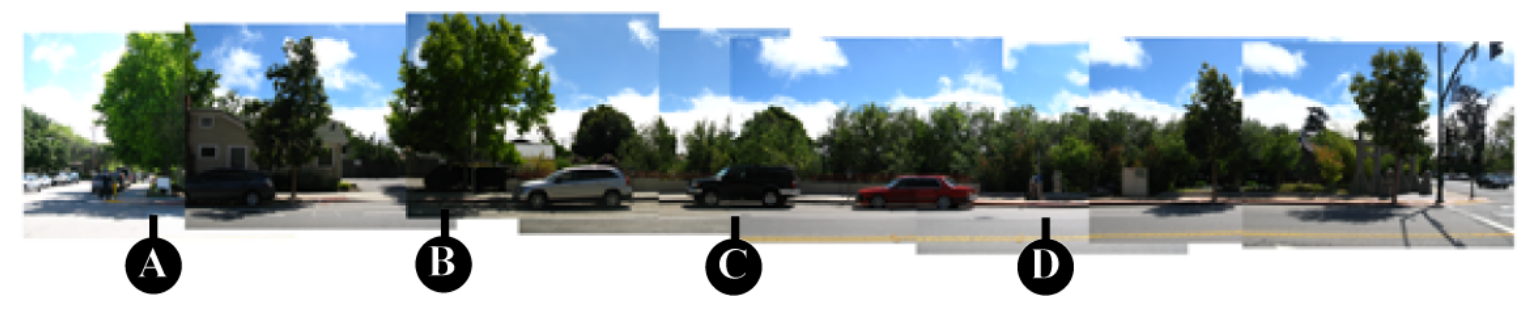

Figure 4. 35 Panoramic view of Santa Rosa Street between Pacific and Marsh Street

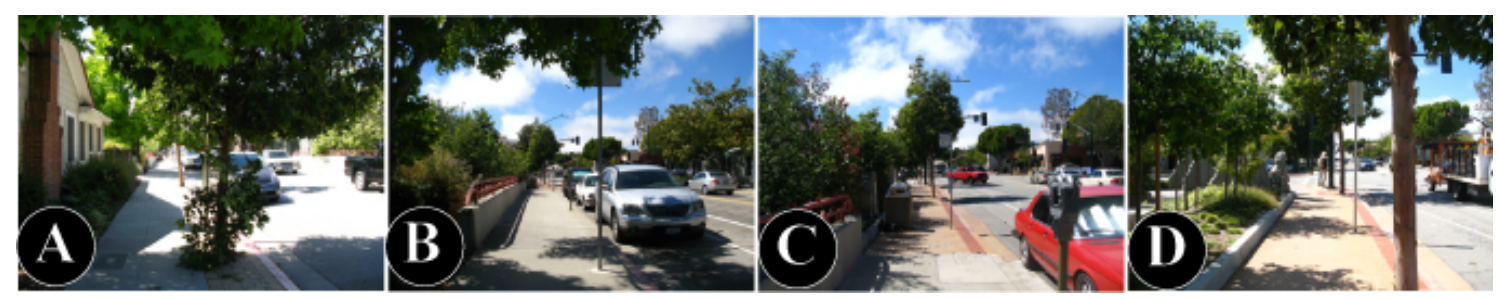

Figure 4. 36 View of Santa Rosa Street walking from Pacific to Marsh Street

\begin{tabular}{|l|r|r|}
\hline \multicolumn{1}{|c|}{ Variables } & Values & \multicolumn{1}{c|}{ Score } \\
\hline Number of lanes & 2 lanes & 19 \\
\hline Two way traffic & Yes & 10 \\
\hline Vehicle speed & Yes - 25 mph & 22 \\
\hline Tcfs & No & 7 \\
\hline Width of sidewalk & ' to 7' 11" & 13 \\
\hline Sidewalk impediments & None & 24 \\
\hline Large sw obstructions & Yes, permanent & 9 \\
\hline Presence of curb & Yes & 17 \\
\hline Driveway cuts & Few (<5) & 10 \\
\hline Trees & Yes & 11 \\
\hline Planters/gardens & No & 13 \\
\hline Public seating & None & 7 \\
\hline Presence of buffer & None & 4 \\
\hline Public art/historical sites & 1 to 2 & 6 \\
\hline Restaurant/retail use & No & 13 \\
\hline Illegal graffiti & No & 9 \\
\hline Litter & None & 10 \\
\hline Lighting & No & 7 \\
\hline Constructions sites & No & 13 \\
\hline Abandoned buildings & Total & 15 \\
\hline & Peally lined \\
\hline & PEQI score & 239 \\
\hline & & 106 \\
\hline Calculation = total score & min. score possible)/weighted score & 2.3164 \\
\hline & $\mathbf{5 7}$ \\
\hline
\end{tabular}

Table 4. 4 PEQI street segment scoring of Santa Rosa Street between Pacific and Marsh Street 


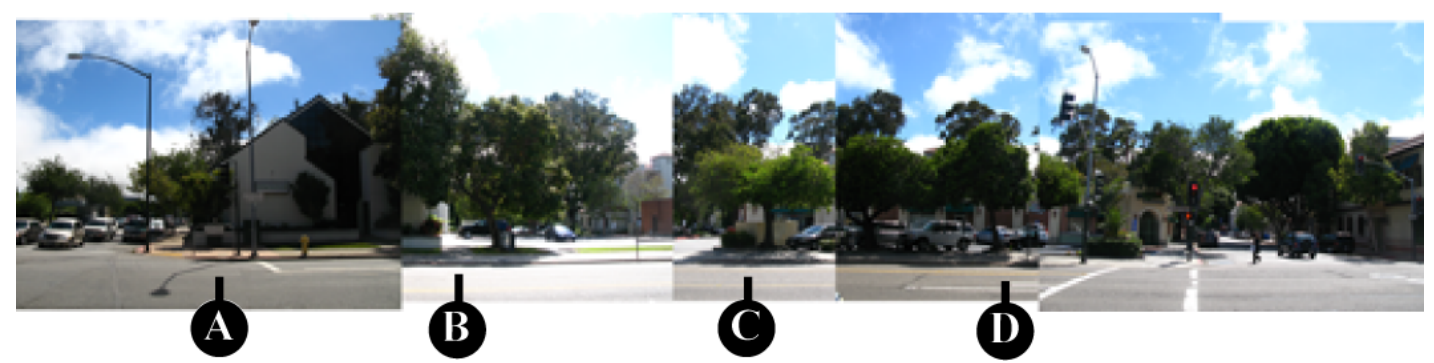

Figure 4. 37 Panoramic view of Santa Rosa Street in between Marsh and Higuera Street

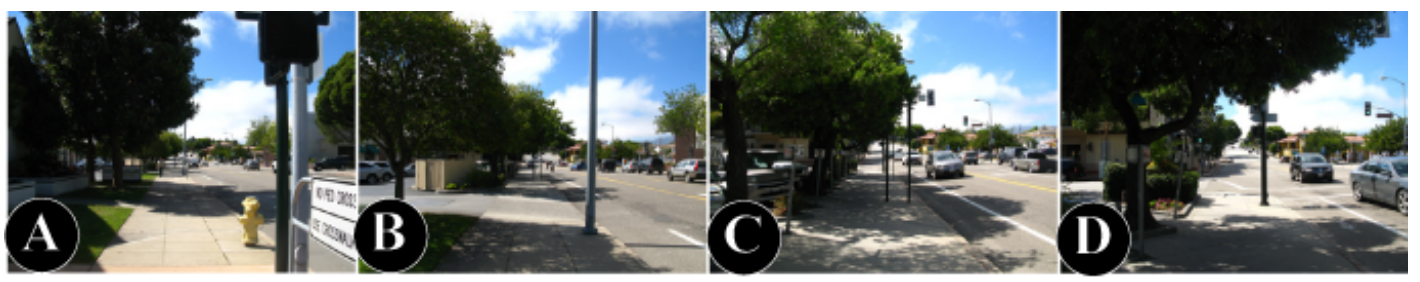

Figure 4. 38 View of Santa Rosa Street walking from Marsh to Higuera Street

\begin{tabular}{|c|c|c|}
\hline Variables & Values & Score \\
\hline Number of lanes & 3 lanes & 9 \\
\hline Two way traffic & Yes & 10 \\
\hline Vehicle speed & No & 22 \\
\hline Tcfs & No & 7 \\
\hline Width of sidewalk & 5' to 7' 11 "' & 13 \\
\hline Sidewalk impediments & Few & 13 \\
\hline Large sw obstructions & No & 15 \\
\hline Presence of curb & No & 17 \\
\hline Driveway cuts & Few $(<5)$ & 10 \\
\hline Trees & No & 7 \\
\hline Planters/gardens & No & 4 \\
\hline Public seating & No & 7 \\
\hline Presence of buffer & Parallel parking & 13 \\
\hline Public art/historical sites & None & 6 \\
\hline Restaurant/retail use & None & 9 \\
\hline Illegal graffiti & No & 9 \\
\hline Litter & No & 10 \\
\hline Lighting & None & 7 \\
\hline Constructions sites & No & 13 \\
\hline \multirow[t]{4}{*}{ Abandoned buildings } & No & 15 \\
\hline & $\begin{array}{r}\text { Total } \\
\end{array}$ & 216 \\
\hline & Minimum score possible & 106 \\
\hline & Weighted score & 2.3164 \\
\hline \multicolumn{3}{|c|}{ Calculation $=($ total score - min. score possible $) /$ weighted score } \\
\hline & PEQI score & 47 \\
\hline
\end{tabular}

Table 4. 5 PEQI street segment scoring of Santa Rosa Street between Marsh and Higuera Street 
Respondents identified the southwest (Figure 4.39 on p. 66) and southeast (Figure 4.41 on p. 67) side of the street segment along Nipomo Street between Pacific and Higuera Street as the street with the lowest perceived street usage, visual quality, and maintenance. PEQI rated both street segments as average with a score of 58 (Table 4.6 on p. 67) and 59 (Table 4.7 on p. 68). Both parts had similar qualities, lacking in trafficcalming features, maintenance, and amenities such as stores and seating areas.

Respondents indicated that fast traffic, lack of amenities/interest, and the bordering residential zone made the street segment unattractive and undesirable to travel through.

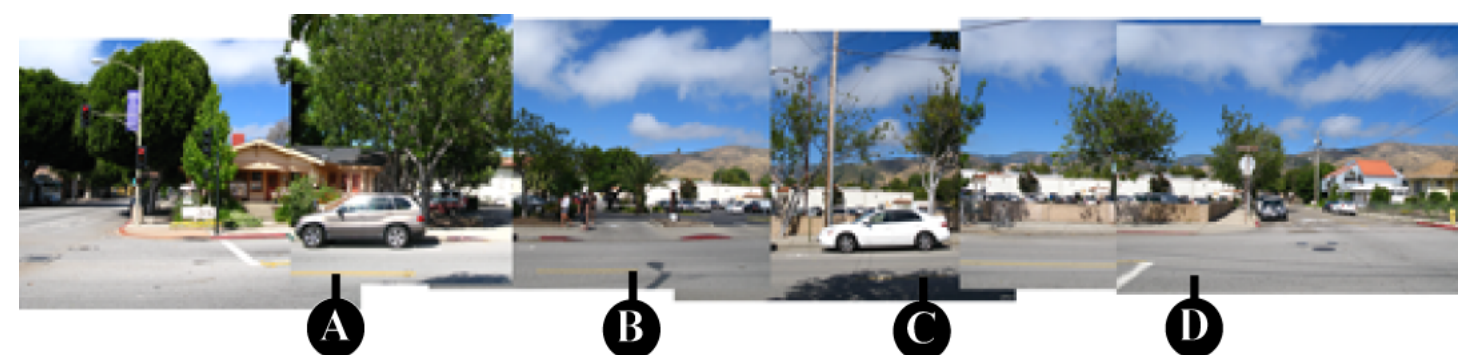

Figure 4. 39 Panoramic view of southwest side of Nipomo Street between Pacific and Marsh Street

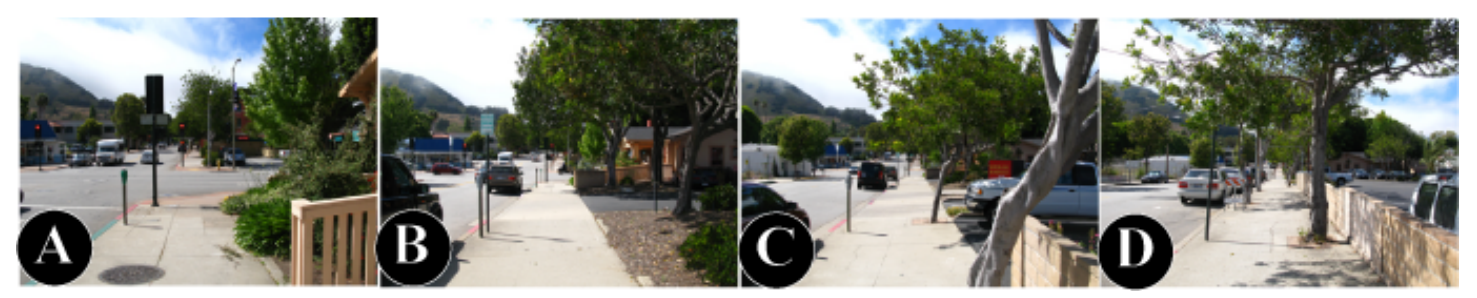

Figure 4. 40 View of southwest side of Nipomo Street walking from Marsh to Pacific Street 


\begin{tabular}{|c|c|c|}
\hline Variables & Values & Score \\
\hline Number of lanes & 2 lanes & 19 \\
\hline Two way traffic & Yes & 10 \\
\hline Vehicle speed & No & 22 \\
\hline Tcfs & No & 7 \\
\hline Width of sidewalk & 8 ' to 12 ' & 19 \\
\hline Sidewalk impediments & Significant & 2 \\
\hline Large sw obstructions & No & 15 \\
\hline Presence of curb & Yes & 17 \\
\hline Driveway cuts & Few $(<5)$ & 10 \\
\hline Trees & Sporadically lined & 11 \\
\hline Planters/gardens & Yes & 9 \\
\hline Public seating & No & 7 \\
\hline Presence of buffer & Timed-Parallel parking & 11 \\
\hline Public art/historical sites & None & 6 \\
\hline Restaurant/retail use & None & 9 \\
\hline Illegal graffiti & No & 9 \\
\hline Litter & No & 10 \\
\hline Lighting & Yes, public & 20 \\
\hline Constructions sites & No & 13 \\
\hline \multirow[t]{4}{*}{ Abandoned buildings } & No & 15 \\
\hline & Total & 241 \\
\hline & Minimum score possible & 106 \\
\hline & Weighted score & 2.3164 \\
\hline \multicolumn{3}{|c|}{ Calculation $=($ total score - min. score possible $) /$ weighted score } \\
\hline
\end{tabular}

Table 4. 6 PEQI street segment scoring of southwest side of Nipomo Street between Marsh and Pacific Street

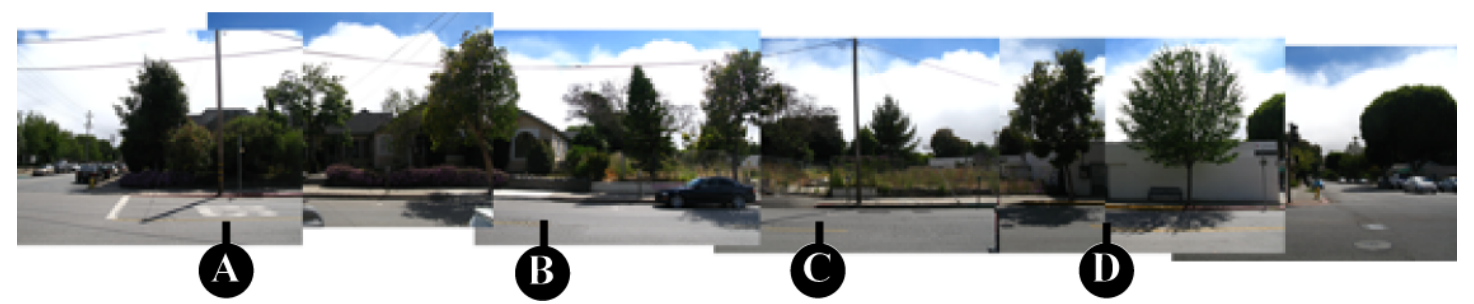

Figure 4. 41 Panoramic view of southeast side of Nipomo Street between Pacific and Marsh Street

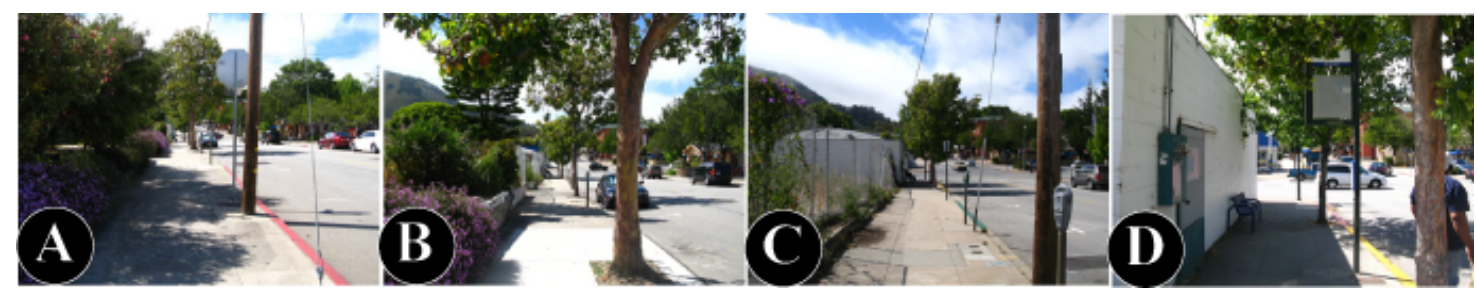

Figure 4. 42 View of southeast side of Nipomo Street walking from Pacific to Marsh Street 


\begin{tabular}{|l|r|r|}
\hline \multicolumn{1}{|c|}{ Variables } & \multicolumn{1}{c|}{ Values } & Score \\
\hline Number of lanes & 2 lanes & 19 \\
\hline Two way traffic & Yes & 10 \\
\hline Vehicle speed & No & 22 \\
\hline Tcfs & No & 7 \\
\hline Width of sidewalk & ' to 12 & 19 \\
\hline Sidewalk impediments & Few & 13 \\
\hline Large sw obstructions & No & 15 \\
\hline Presence of curb & Yes & 17 \\
\hline Driveway cuts & Few (<5) & 10 \\
\hline Trees & Yes & 11 \\
\hline Planters/gardens & No & 9 \\
\hline Public seating & Sporadically lined \\
\hline Presence of buffer & None & 11 \\
\hline Public art/historical sites & None & 6 \\
\hline Restaurant/retail use & No & 9 \\
\hline Illegal graffiti & No & 9 \\
\hline Litter & Timed-Parallel parking & 10 \\
\hline Lighting & Yes, public & 20 \\
\hline Constructions sites & No & 13 \\
\hline Abandoned buildings & Yes & 5 \\
\hline \multicolumn{2}{|c|}{ Total } \\
\hline
\end{tabular}

Table 4. 7 PEQI street segment scoring of southeast side of Nipomo Street between Pacific and Marsh Street

\section{Summary for Intersection \& Street Segment}

The PEQI criteria captured certain aspects of how people may perceive the environment but the rating factors were only secondary. The existing on-site features for both intersections and street segments were important but the primary factors that contributed to people's perception was dependent on how the environment was functioning.

For intersections, PEQI rated the quality of the environment based on “[p]edestrian accommodations at intersections includ[ing] signalization, pavement marking, various signage and features to slow traffic and increase visibility" (San Francisco Department of Public Health, 2008). General responses verified that people were acutely aware of PEQI indicators, especially with regard to traffic-calming features, as they tended to rely on these features for safety when crossing the intersections and/or 
crosswalks. Although people favored intersections with more traffic-calming features, they settled for using less preferred intersections with caution when necessary.

PEQI rated the quality of the pedestrian environment for street segments based on vehicle traffic, street design of sidewalks, land use, and perceived safety. For vehicles traffic domain, PEQI measured "factors that are predictive of exposure distance for pedestrian, conflict points, pedestrian injury severity and pedestrian mobility" (San Francisco Department of Public Health, 2008, p. 4). For street design, PEQI assessed the existing state of the sidewalk including its width, presence of barriers (impediments/obstructions), street buffers (curbs, planters/trees), and other design features such as seating. For land use domain, PEQI counted the number of storefronts/commercial activities and public arts/historical sites present for each street. Lastly, for perceived safety domain, PEQI counted presence of illegal graffiti, litter, lighting, construction sites, and abandoned buildings.

High quality street segments were determined as the most frequently used streets while average quality street segments were simply less preferred. In comparing all street segments, having a high quality street segment did not necessarily induce positive perceptions. Although the PEQI criteria used to rate the physical environment do instill certain positive/negative perceptions, based on the responses, there are other contributing factors such as presence of people, perceive safety, familiarity, and connectivity/accessibility/visibility. The first three domains - vehicle traffic, street design for sidewalks, and land use - affected how people perceived the quality of the environment. Streets with less vehicle traffic, more traffic-calming features, wide sidewalks with less impediments and obstructions, the presence of 
buffers/trees/planting/seating, and a number of commercial/retail elements all induced positive perceptions of the environment and paralleled the PEQI rating criteria.

According to the PEQI manual, the intents of perceived safety domain are to record "how physical features of an environment shape people's perception of safety, and, therefore their willingness or comfort with walking" (San Francisco Department of Public Health, 2008, p. 6). The identified indicators under perceived safety domain did not measure people's perception for this particular study area.

\subsection{Applicability and Usability of the PEQI tool for smaller urban setting}

Since the PEQI observation tool was specifically designed for use in big urbanized cities, some indicators are not appropriate for measuring factors within smaller cities $^{5}$. This study tested the applicability and usability of the PEQI assessment tool in a smaller urban setting, using the City of San Luis Obispo as a pilot in its first smaller urban setting case study.

Intersection

The intersection domain measures 9 indicators: crosswalk, ladder crosswalk, pedestrian signal, traffic signal, crossing speed, crosswalk scramble, No Turn on Red signs, traffic-calming features (TCFs), and additional signs for pedestrians (San Francisco Department of Public Health, 2008), the first five of which are the same for both environments. When comparing two environments, the physical layout of intersections

${ }^{5}$ For this study, smaller cities refer to city size with population ranging between 40,000 to 60,000. The City of San Luis Obispo is considered a small-urban environment. 
remains the same, as both contain traffic signals, with some having pedestrian signals and countdowns, and cross speed durations dependent on the width of the streets. The scores carry extra weight for intersections and crosswalks with pedestrian signals and countdowns.

On the other hand, the latter four indicators are either not applicable or should be modified in scoring smaller cities. For instance, crosswalk scramble (Figure 4.43 on p. 71) is not appropriate for smaller cities because the streets are not always populated, and therefore, measuring this indicator would decrease the quality of the intersection and fail to provide true qualitative assessment.

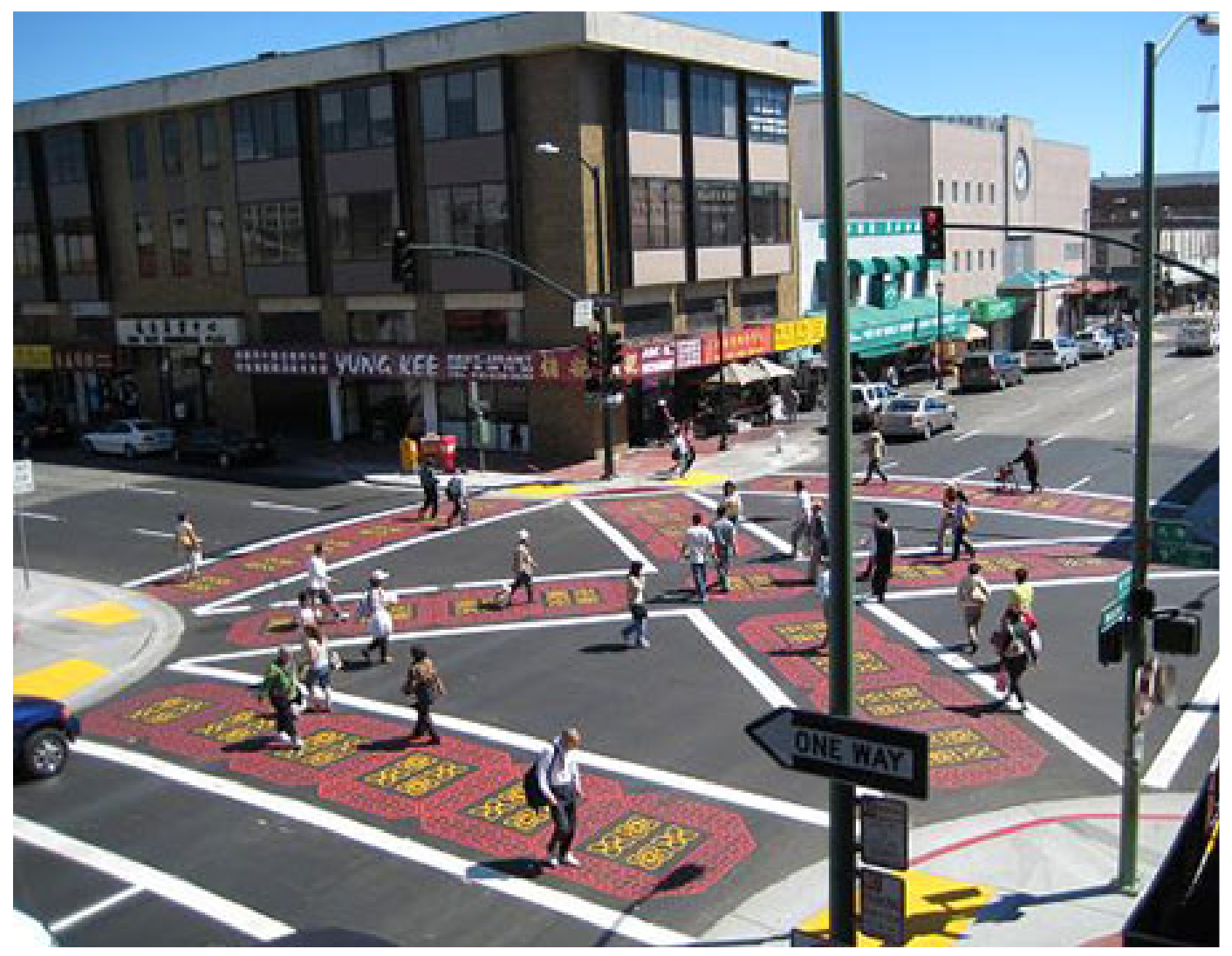

Figure 4. 43 Crosswalk scramble in Los Angeles - picture obtained from http://www.treehugger.com/files/2008/11/diagonal-crosswalks-los-angeles-videopedestrians.php 
According to SFDPH, "No Turn on Red" signs "eliminat[e] a possible conflict between vehicles and pedestrians...[i]ncreasing vehicle stopping before turning and reducing pedestrians yielding to cars " (San Francisco Department of Public Health, 2008, p. 20). The National Highway Traffic Safety Administration (NHTSA) Office of Traffic Safety Program conducted a study on the effectiveness of Right-Turn-On-Red (RTOR) laws, analyzing crashes in four states that implemented RTOR laws and findings concluded that RTOR crashes were relatively minimal compared to other casualties (http://www.nhtsa.gov/people/injury/research/pub/rtor.pdf). Since there are zero "No Turn on Red" signs within the study site, the research conducted does not include the number of traffic accidents related to RTOR, since testing the appropriateness and effectiveness of such signs in a smaller urban to rural environment ${ }^{6}$ is unnecessary; however, this investigation does recommend alternative case studies to test the effectiveness of such signs by comparing various streets with and without the feature.

The number of traffic-calming features and pedestrian signs needed for big and smaller cities may differ significantly. TCFs (Figure 4.44 on p. 73) such as pavement treatments, curb extensions, and bike lanes are appropriate for both environments, with 2 to 3 types of TCFs deemed as sufficient for smaller cities. Therefore, PEQI scoring should be modified to weighing " 0 to $3+$ TCFs" rather than " 0 to $5+$ TCFs". In addition, smaller cities take pride in openness and are much smaller in scale, so having too many signs can be distracting and encroaching, while taking away from the unique small town

${ }^{6}$ In this study, rural environment refers to city or community service district with population size below 40,000. 
character. TCFs are far more beneficial and appropriate for smaller cities than placing pedestrian warning signs. Respondents identified that while TCFs were pedestrian's safety elements, additional pedestrian signs were considered more as driver's safety elements.

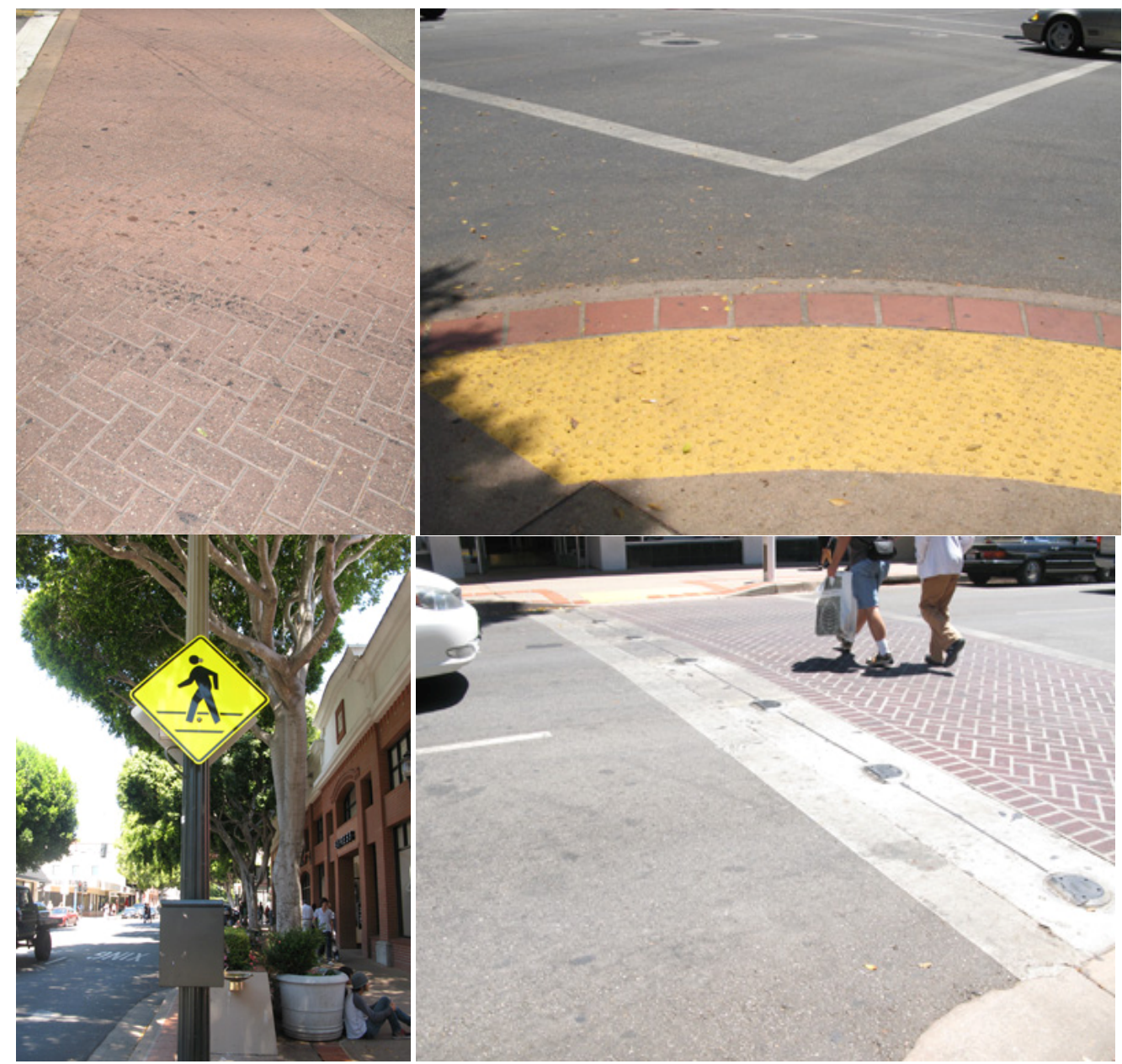

Figure 4. 44 Traffic-calming features and signs found in the study area

\section{Street Segments}

Street segment has four domains - traffic, street design for sidewalk, land use, and perceived safety - and measures a total of 21 indicators (San Francisco Department of Public Health, 2008). Within the traffic domain, 4 out of 5 indicators - number of lanes, 
two-way traffic, vehicle speed limit, and TCFs - are appropriate and similar for both environments, but traffic volume may vary significantly. PEQI accommodated two types of scoring: (1) with traffic count and (2) without traffic count. Due to insufficient data, this study utilized the latter option - without traffic count. Although smaller cities and rural environments tend to be more auto-dependent, population size is significantly less than urban areas, so modifying the traffic volume scoring system may be more appropriate for rural communities, though numbers should vary depending on the city's traffic count data.

Within the street design for sidewalk domain, 7 out of 9 indicators - sidewalk width, sidewalk impediments, presence of curb, driveway cuts, trees, planters/gardens, and public seating - were appropriate and similar for both environments. Measuring sidewalk obstructions should carry more weight because though sidewalks were wide, there were too many permanent obstructions including trash bins, newspaper stands, overgrown trees, and signage that became barriers encroaching into pedestrian space, sometimes forcing pedestrians to walk on the streets to avoid these impediments (Figure $4.45 \& 4.46$ on p. 75$)$. 


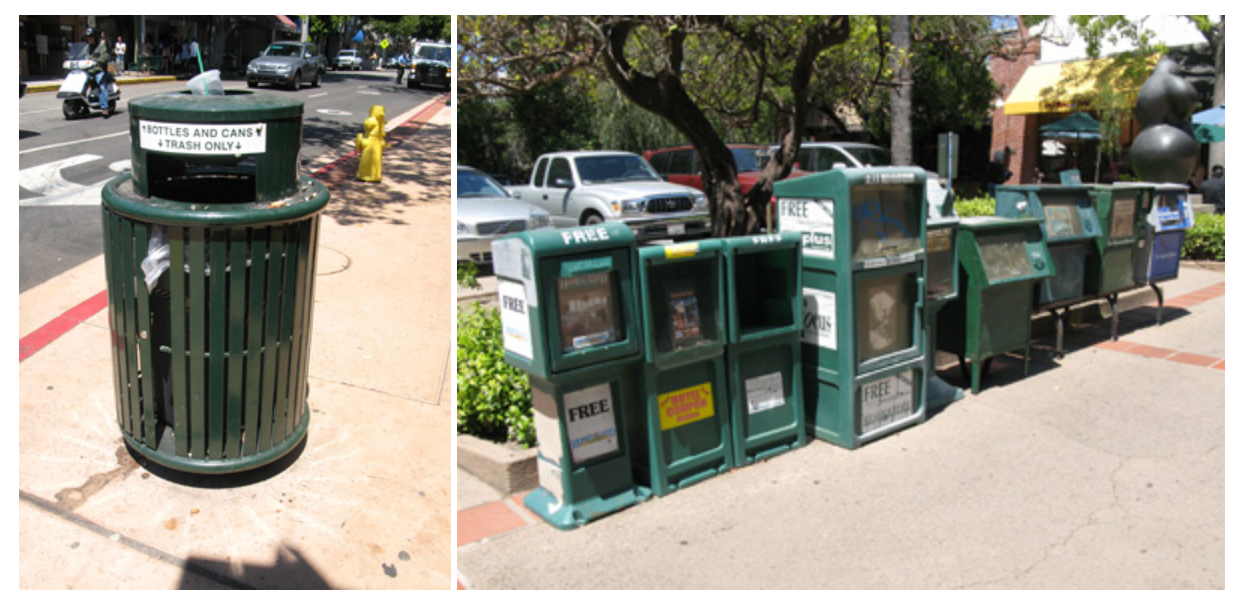

Figure 4. 45 Sidewalk obstructions

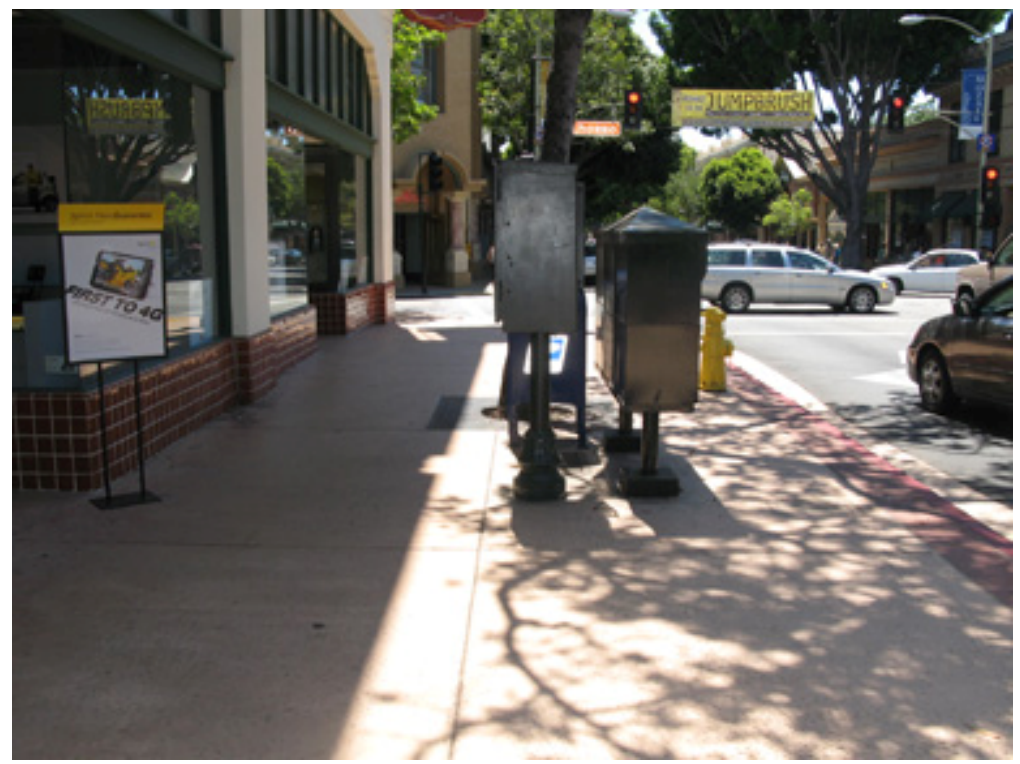

Figure 4. 46 Newspaper stands become an obstruction by narrowing the sidewalk width

The presence of buffers needs scoring modification when assessing smaller cities.

Parallel parking exists as a problem as it is so readily available throughout the streets of San Luis Obispo that it almost discourages people from walking more, as many respondents acknowledge that they can usually drive and park right in front of or near 
their desired destinations. The areas where available parking was located did not provide much incentive for people to walk around downtown upon finishing errands and/or activities in specific places. In creating walkable environments, it is important to reconsider valuing all forms of parallel parking (Time/No-Time Restricted Parallel Parking), especially when planters raised 2 to 4 feet on the sidewalk can result with increasing the aesthetical quality of the street segment. This study acknowledges the ongoing debate and concerns regarding the use, appropriateness, importance, and effectiveness of parallel and other form of parking near commercial zones. Yet, this study strongly suggests that for smaller cities and other rural environments, parking may be a limiting factor to increasing walkability. Although it may be safer for pedestrians, especially within smaller cities and other rural environments, there needs to be greater incentives for people to walk rather than drive.

For the land use domain, measurement for 2 indicators - public art/historic sites (Figure 4.47 on p. 77) and restaurant/retail use - were appropriate and similar for both environments. Adding natural and scenic areas (Figure 4.48 on p. 77) as other indicator would be suitable for rural environments, especially in this particular study site since portions of downtown are adjacent to a creek and serve as good public space. 


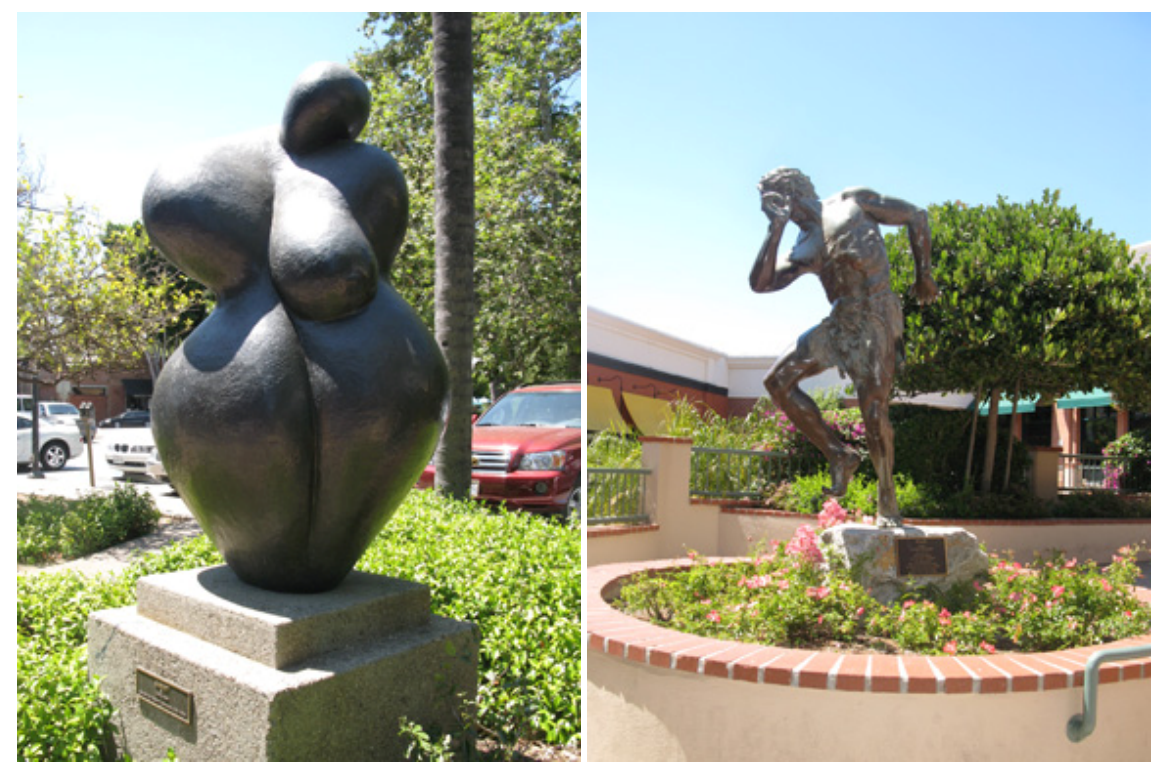

Figure 4. 47 Public art sculptures

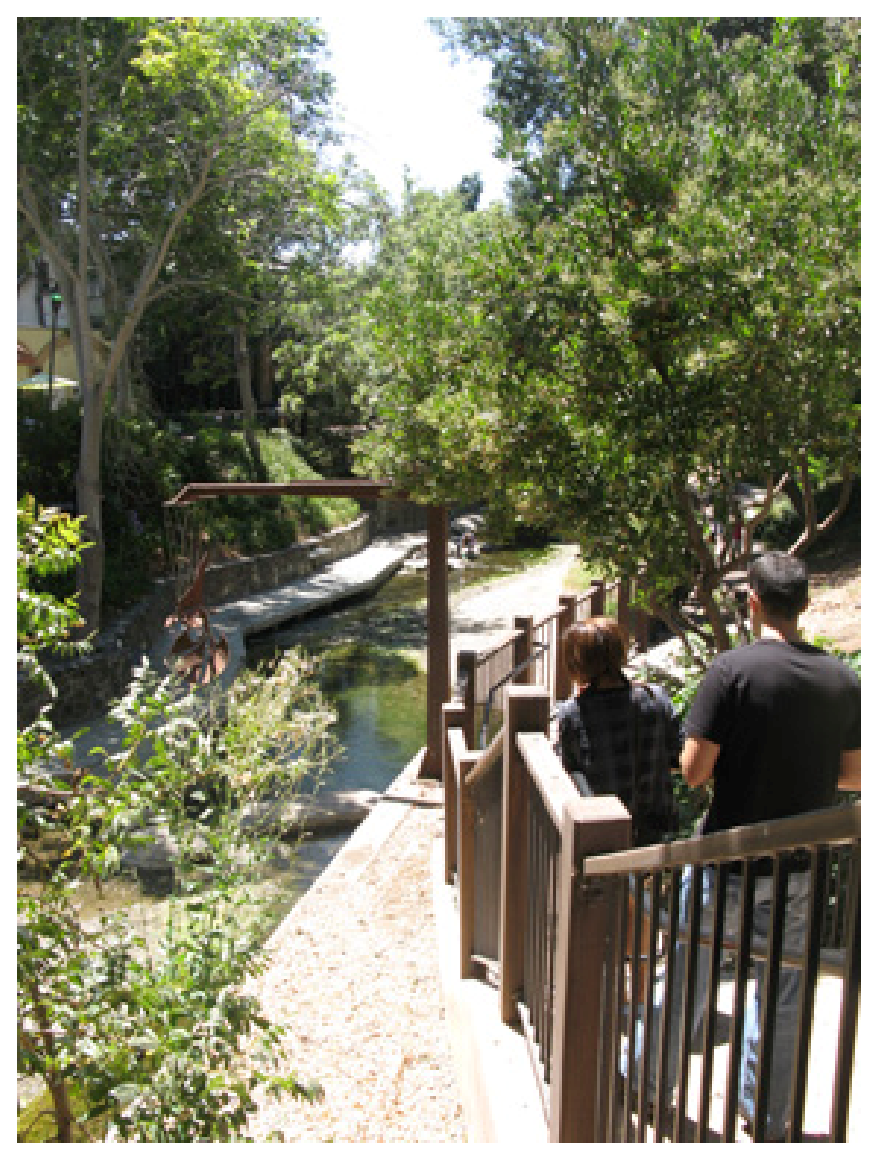

Figure 4. 48 Scenic areas such as creek walk 
Lastly, for perceived street safety domain, all indicators - illegal graffiti, litter, lighting, construction sites, and abandoned buildings - were appropriate and similar for both environments. As discussed in part three, the perceived street safety domain does not capture people's perception with respect to this study site. Results from survey responses in conjunction with empirical findings indicate that the presence of people is one of the primary factors that contribute to human perception. Adding a $6^{\text {th }}$ indicator measuring the presence of people (Figure 4.49 on p. 78) will help "shape people's perception of safety and therefore their willingness or comfort with walking" (San Francisco Department of Public Health, 2008, p. 6) as intended with PEQI.

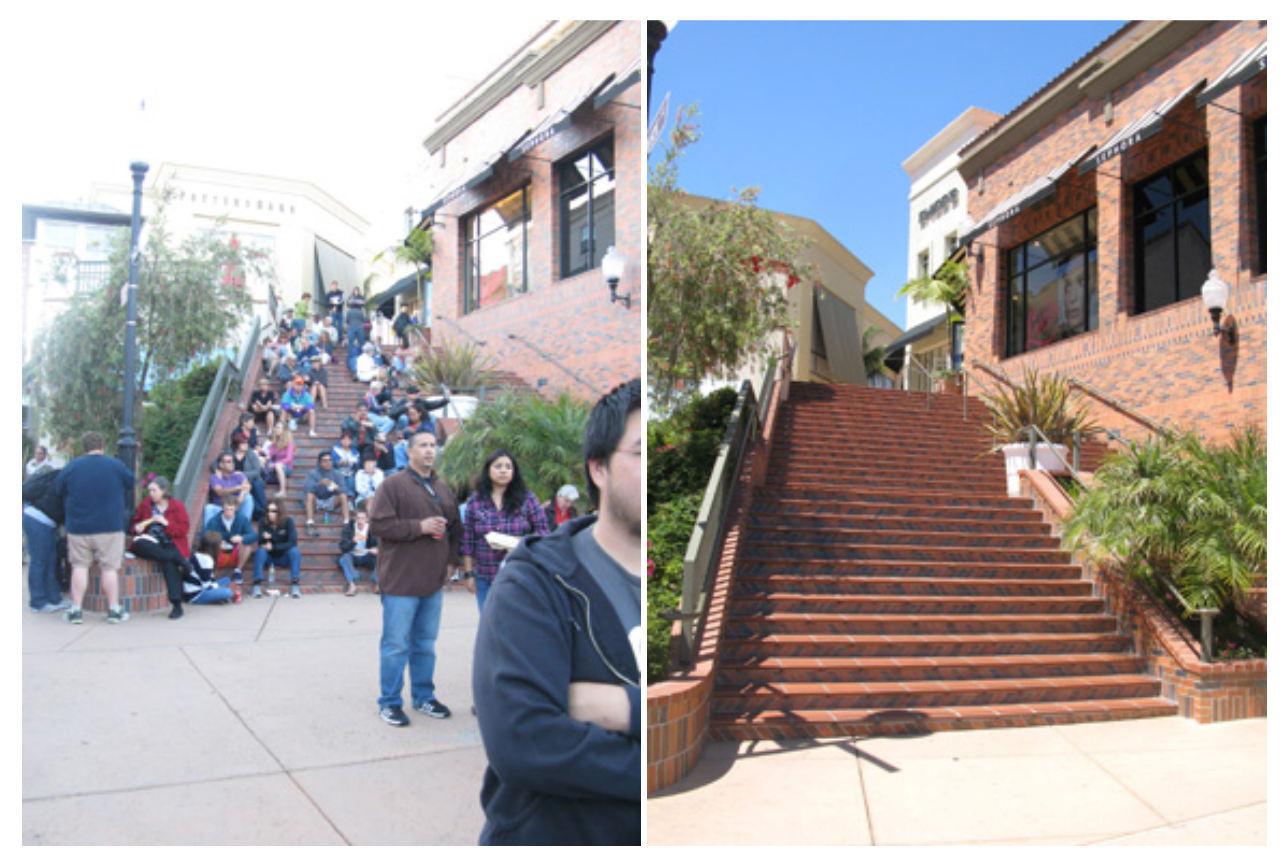

Figure 4. 49 Difference of public space with and without people

Another suggestion is to measure the number of trash receptacles and recycling bins along the streets. In the study site, there was hardly any litter spotted due to an 
abundance of trashcans, having 1 or 2 located along each street segment. After several national alarms for public safety, trashcans and other receptacles were banned from many streets and near widely populated areas such as airports and other buildings. This measure forced people to hold onto their trash until appropriate disposal bins were provided. 


\section{CHAPTER V}

\section{Conclusion, Recommendations, and Future Study}

The primary goal of this study is to expand the understanding of pedestrian perception and its relationship to the environment, more specifically in how people view their surroundings and the identifying contributing factors to which these notions are formulated. There are three primary objectives within this study: (1) examine how human perception of the pedestrian environment relates to the quality of that particular environment, as determined by the PEQI tool; (2) identify factors that contribute to human perception in order to better understand behaviors and attitudes towards an environment; and (3) test the applicability and usability of the PEQI assessment tool in a smaller urban setting.

Findings determined that the quality of a pedestrian environment, as rated by the PEQI tool, affects how people perceive that environment. Respondents preferred high quality street segments to those of average quality and chose average quality intersections over low/poor quality ones, demonstrating that people were able to identify between quality street elements versus those that lack appeal. Nevertheless, when taking into account the entire study site, certain high quality street segments and average quality intersections were not perceived positively. The criteria of the PEQI scoring system were secondary to the subjective variables of human perception. People generally preferred street segments/intersections with more traffic-calming features (TCFs), commercial activities, and charming street designs.

Results from the survey identified factors that contribute to people's perceptions, providing a better understanding of their behaviors and attitudes toward an environment. 
Using the seven categories identified by Great Streets by Jacob (1995), Measuring Urban Design Qualities by Active Living Research Program (2005), and indicators classified under PEQI domains, results determined that the following indicators are primary contributing factors to development of human perception: land use, traffic, street design including aesthetics and presence of people. Additional indicators that influence views are accessibility/connectivity/visibility, perceived safety, familiarity, and parking.

This study tested the applicability and usability of the PEQI assessment tool in a smaller urban setting, piloting its first case study in the City of San Luis Obispo. Despite the many similarities between urban and rural environments, subtle differences require that the PEQI assessment tool be revised and adapted to smaller urban settings to accurately measure such environments. Some indicators currently under the domain of the tool are not applicable to or appropriate for smaller cities and other rural environments such as crosswalk scramble. Signage such as 'No Turn on Red' (RTOR) requires context-based testing and must be adapted to smaller urban environments. The following indicators under the PEQI domains require scoring modification: TCFs for intersection, traffic count, sidewalk obstruction, and presence of buffer. Additional suggested indicators to be added under the PEQI domain are natural/scenic/public spaces under the land use domain, and number of trash/recycle cans, and number of people/users under the perceived safety domain. 


\section{Limitations of this Study}

There are several known limitations to this study.

First of all, I, the surveyor assessing the quality of the pedestrian environment, was self-trained using the PEQI User's Manual. Though SFDPH provides a training workshop, meeting or funding for the available training workshop was difficult, so lack of training may result in questionable surveying of the environment. To compensate for any inadequacies, the manual was thoroughly reviewed and questions for PEQI scoring were directed to the developer of the PEQI tool at SFDPH via email and phone.

Secondly, the subjects of the perception survey were primarily design students between ages from 19 to 25 from the College of Architecture and Environmental Design who tend to be more aware of design elements, street layouts and structures. The results provide a good understanding of the college demographic and how they use and perceive the current downtown area. Thus, responses may have been biased based on knowledge the subjects attained through architectural and planning courses. Responses may or may not have been different for students in other disciplines.

Lastly, this survey was specifically conducted off site to identify factors that are unique to its users. On-site surveys may have produced unreliable information, as participants may not necessarily have noticed specific elements until confronted either verbally or visually. To counterbalance such discrepancies, the survey specifications were designed to engage respondents to carefully visualize and consider the streets they travel through. In addition, the study area consists of a total of 63 blocks. Survey responses may differ if scope of the study was smaller and only looking at two to three blocks. Many 
comments provided may have been generalized to the entire study site and not specific streets/areas.

\section{Recommendation for Planners}

For future planning, this study strongly recommends the following factors and issues to increase walkability.

Evaluations using PEQI provide valuable information regarding the current condition of an environment; however, as acknowledged by SFDPH, PEQI "is only a partial measure of what is actually happening in the real world" (San Francisco Department of Public Health, 2008, p. 17). Available assessment tools should not be the only instruments used to determine the quality of pedestrian environments as they are not perfect. Sole dependence on such instruments will not provide a fully accurate assessment of pedestrian environments. Therefore, a multitude of analytical methods must be used in conjunction with source data to provide a full and accurate perspective to successfully increase the quality of environments. With a focus on creating walkable environments, one factor to consider is that merely providing a high quality environment does not guarantee the community's embrace and acceptance of the new surroundings. Studies detail the importance of an environment's social aspect with respect to how people use, engage, and perceive the environment through the use of surveys, interviews, and other modes of analysis (Booth, et al., 2000; Ball, et al., 2001; Foster, et al., 2004; Frank, et al., 2007). Increasing walkability in big and small urban environments requires the social and cultural needs of pedestrian environments to be met. Both facets are necessary, yet overlooked components in shaping user's perception. This can be achieved 
by understanding the motives of current users and how the environment is being used through various modes of analysis such as surveys or post-occupancy studies.

Because PEQI explicitly favors urban planning studies, it is necessary to modify assessment tools to appropriately measure indicators based on smaller urban and rural settings. One of SFDPH's intent was to develop a tool that provided "answers as to how pedestrian environmental quality and safety objectives can be achieved and represent local communities' needs and concerns" (San Francisco Department of Public Health, 2008, p. 17). The current PEQI tool is specifically developed for large urban environments, accurately measuring such cities as San Francisco, but streets in San Luis Obispo are vertically and horizontally different from those of larger metropolitan areas, so discrepancies arise in applying the original, unmodified PEQI tool to smaller urban settings. Such physical differences must be taken into account when revising PEQI's assessment tools, so that results will provide accurate information based on "local communities' needs and concerns". Thus, smaller urban city planners can generate a more generic environmental assessment tool by modifying some indicators.

For modifications regarding the PEQI tools, findings of this study strongly suggest the following changes for TCFs and presence of buffer:

\section{For TCFs specifically for intersections -}

To address the problems of pedestrian environment, a critical balance must be made between pedestrians and drivers to maximize safety. Pedestrians and drivers have distinguished user environments; intersections allow both to come together, increasing the likelihood of accidents for both parties. The inclusion of traffic-calming features is necessary in mitigating pedestrian casualties, functioning to increase safety and 
awareness for both pedestrians and drivers. Emphasis has largely been exclusively placed on drivers' awareness but pedestrians must be held equally accountable for traffic safety. Common occurrences within the pedestrian environment during the assessment of the study site included jaywalking and other violations of pedestrian traffic laws. Such violations put both pedestrians and drivers at risk and must be addressed accordingly. Lack of regulation and enforcement permits pedestrians to continue violating minor traffic rules, so implementing more features to increase the drivers' awareness only serves to only to promote bad tendencies pedestrians are accustomed to. Therefore, solutions require that pedestrian environments include an appropriate balance of TCFs and signage for both drivers and pedestrians to increase awareness of surroundings and minimize accidents for both parties.

$* * *$

Furthermore, some respondents who drove to the study area indicated that TCFs are more useful compared to additional pedestrian signage, indicating that signs were distracting and that features, such as flashing lights, increase the level of safety and comfort for pedestrians, as drivers become more aware of pedestrians crossing.

$* * *$

\section{For presence of buffer -}

Parallel parking with bike lanes receive the highest score under the street design domain using PEQI, since “[b]ike lanes and parallel parking are two significant streetscape elements that create a buffer for pedestrians" (San Francisco Department of Public Health, 2008, p. 6), with time-restricted parallel parking and bike lanes receiving the second highest score. Some responses valued the availability of parallel parking as 
buffers while others regarded it as disruptive to the aesthetical quality of downtown San Luis Obispo's unique character.

The presence of parallel parking discourages people from exploring the downtown environment as it eliminates the need for pedestrian travel since it places people in front of or near their destinations. Respondents agreed that parallel parking in the downtown core allow people to arrive at their desired locations without having to walk any further than necessary. Buffers such as planters raised 2 to 4 feet provide the same buffering purpose as parallel parking, while also increasing the aesthetical quality of a street segment, though it does lack the functional element of parking spaces. With current efforts to increase walkable environments and address public health issues, factors that promote automobile dependency must be minimized to improve societal health and quality of life. The unaltered PEQI scoring system identifies parallel parking as safety measures for pedestrians. Contrary to such assessments, the current PEQI scoring is unsuitable for smaller urban settings based on this study's findings. The abundance of parallel parking creates a lack of incentives for people to walk to their destinations, and thus discourages walkability, especially for those living in rural environments.

\section{Creating Walkable Environments and Problem with Connecting Streets}

Several high quality street segments were chosen as 'less likely to travel through' due to a lack of activity, interest and diversity. Respondents indicated that they had no reason to travel through such streets because downtown's unique character is lost when transitioning into residential zones. People were less inclined to travel through these street segments that border the study site, and preferred to congregate in and around areas 
with the most commercial and downtown activities. These neglected streets serve as connections to and from the downtown core, so it is necessary to address this alarming concern in order to revive the quality of the environment for future urban planning and development of cities.

Studies illuminate a strong correlation between high crimes rates and connecting streets of downtown areas. For example, the streets of Los Angeles' Skid Row are defined by large sidewalk widths, few sidewalk impediments/obstructions, appropriate lighting, and low traffic congestion, while also serving as connecting segments from neighboring communities and residential areas to the downtown core. This area, however, is predominantly populated with homeless people and contains many abandoned buildings. The physical quality of such environments mask the more important issues that must be addressed, as these areas reflect a disregard for social and cultural implications, which plays a larger role in having a successfully developed community. These areas cannot continue to be neglected and ignored if planners and city officials are to utilize such strategic opportunities in contributing to the development of American cities into successful, walkable environments.

Merely creating and building walkable environments will not change our autodependent lifestyles that is detrimental to both human and environmental health. People will continue to drive, park and walk through and around these, so-called, 'walkable environments'. Such practices further increase the social and cultural gap associated with the environment, while encouraging certain streets to be neglected and unused, notably decreasing the quality and perception of the environment. 
Therefore, a study on different types of land use is important to revive these neglected areas. Bringing the same amenities available in the downtown area will only increase competition and create another smaller downtown. Rather, providing small pocket parks and recreational facilities/areas may be an appropriate solution to increase incentives for walking to provide a stop to and from work for commuters.

\section{Future Directions for This Study}

This is the first study that explores the relationship between human perceptions and pedestrian environments within a smaller urban setting. Therefore, comparative studies of similar environments are necessary to employ the framework of this study and juxtapose its findings. Future research and case studies will provide substantial information help in understanding the tested relationship and provide recommendations for policy changes.

However, in order to measure an accurate walkability of downtown San Luis Obispo, a proximity analysis is recommended. Resident who live in close proximity to the study area can be the more ideal subjects examining walkability because they are the ones who have the most and quick access to downtown and are also likely to have the most knowledge and experience using the connecting streets compared to other residents living in the city. These residents will pass through or visually see the study area on a daily basis like running errands or other related activities while driving, walking, and/or biking through to and from home. Therefore, it is important to understand how these residents perceive the environment because they are the predominant users of the study area. A survey asking questions about their perceptions and preferred routes in accessing their downtown along with mapping where the residents prefer to walk and why they 
walk in that way will inform a great deal about the travel patterns/behavior, how they perceive those environment and why. Therefore, the participants will provide three crucial facts - perception, preferred routes, and in general, travel pattern/behavior.

Furthermore, continued research must explore the conditions of connecting streets to understand how environments will function as transitional components to the downtown core and provide solutions in creating more welcoming and attractive surroundings. The conditions of these areas require critical attention to rectify what has been socially, culturally, and economically neglected by society. The physical, social, and cultural context shapes its environment, as mechanisms applied to one area may not be adapted to another, thus factors for each environment must be considered independently. Minimizing social and cultural gaps within such environments and understanding the present quality of the existing area as it functions will generate future opportunities. A call to action must be made to highlight and promote walkability in every environment across cities in the United States. 


\section{APPENDICES}

Appendix A: Pedestrian Environmental Quality Index (PEQI) Assessment Tool 


\section{PEQI Assessment Tool, Page 1}

Pedestrian Environmental Quality Index (PEQI) Survey

San Francisco Department of Public Health, Program on Health, Equity and Sustainability: www.sfphes.org Last Revised: August 2008

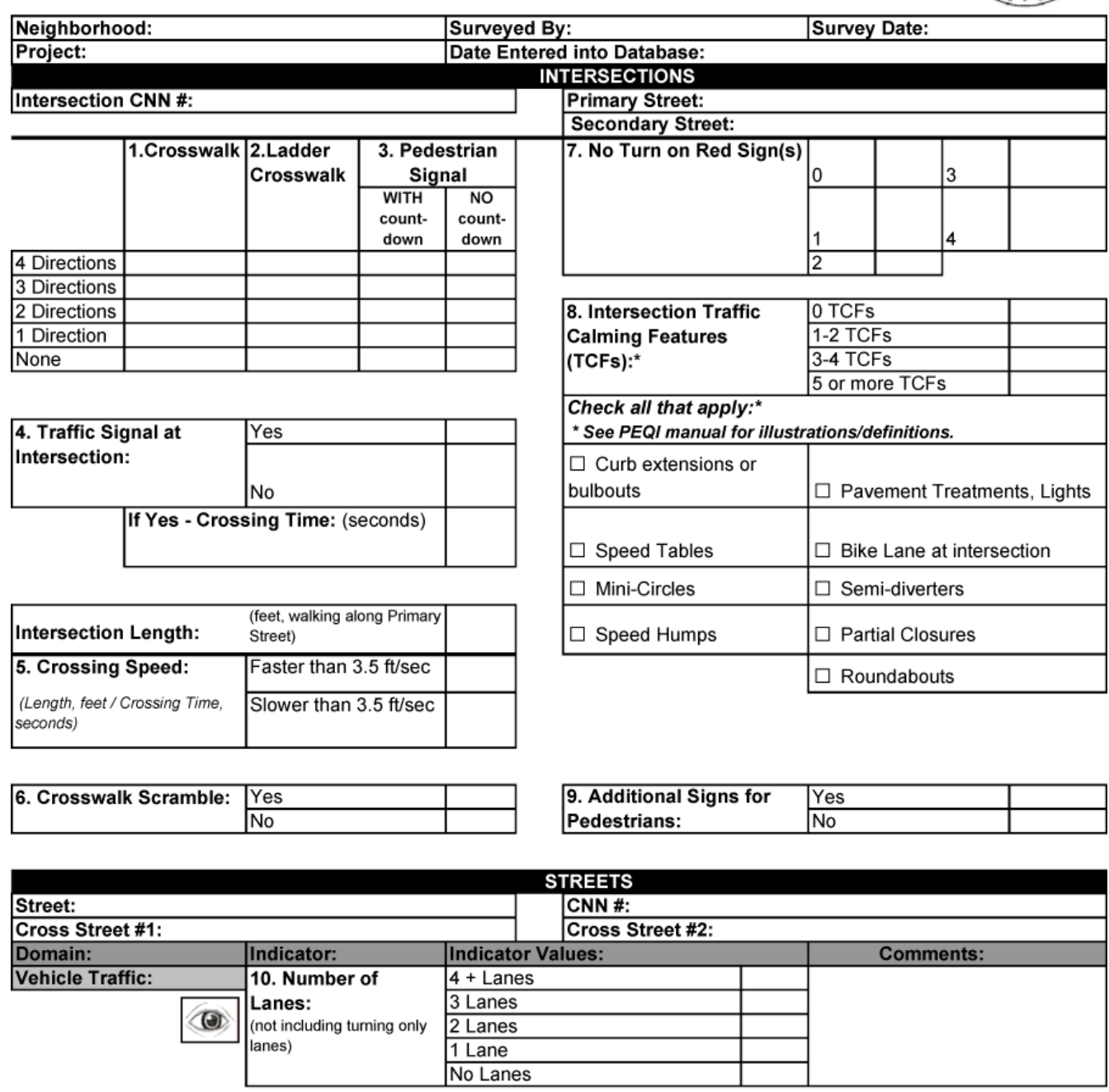

\begin{tabular}{|l|l|l|l|}
\hline (11. Two Way Traffic: & Yes & & \multirow{2}{*}{} \\
\cline { 2 - 3 } & No & & \\
\hline
\end{tabular}

\begin{tabular}{|c|c|c|c|}
\hline \multirow{2}{*}{$\begin{array}{l}\text { 12. Vehicle Speed - } \\
\text { Is there a posted } \\
\text { speed limit? }\end{array}$} & \multicolumn{2}{|l|}{ Yes } & \\
\hline & \multicolumn{2}{|l|}{ No } & \\
\hline \multirow[t]{6}{*}{ Speed Limit: } & $10 \mathrm{mph}$ & $35 \mathrm{mph}$ & \multirow{6}{*}{$\begin{array}{l}\text { Note: San Francisco default street speed } \\
\text { limit is } 25 \mathrm{mph} \text {. }\end{array}$} \\
\hline & $15 \mathrm{mph}$ & $40 \mathrm{mph}$ & \\
\hline & $20 \mathrm{mph}$ & $45 \mathrm{mph}$ & \\
\hline & $25 \mathrm{mph}$ & $50 \mathrm{mph}$ & \\
\hline & $30 \mathrm{mph}$ & $55 \mathrm{mph}$ & \\
\hline & & $>55 \mathrm{mph}$ & \\
\hline
\end{tabular}

\begin{tabular}{|l|l|l|l|}
\hline 13. Street Traffic & Yes & & Note: See PEQI manual for illustrations \\
\hline
\end{tabular}

\begin{tabular}{|l|l|l|}
\hline $\begin{array}{lll}\text { Calming Features: } \\
\text { Check all that apply: }\end{array}$ & & \\
\hline Co & Nond definitions. \\
\hline$\square$ Chicanes & $\square$ Street Medians & $\square$ Speed Tables \\
\hline$\square$ Speed Humps & $\square$ Rumble Strips & $\square$ Speed Limit Enforcements \\
\hline
\end{tabular}

(d) : should be able to observe while standing in one place

: best assessed while walking along the street 


\section{PEQI Assessment Tool, Page 2}

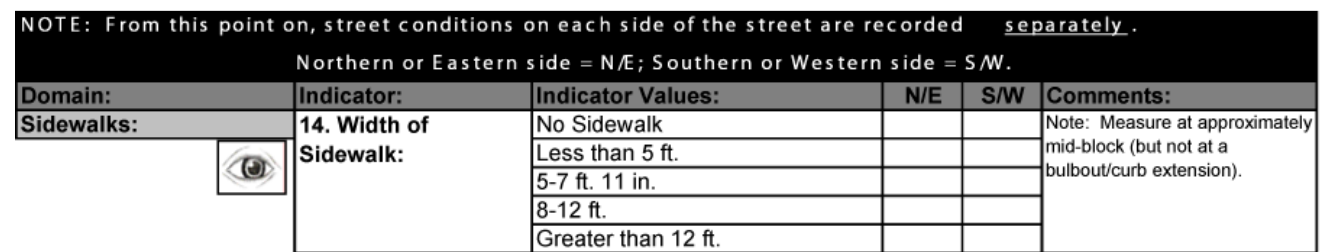

(6)

15. Impediments in Significant

Sidewalk Surface

\begin{tabular}{|l|l|l|l|}
\hline Significant & & & $\begin{array}{l}\text { Note: } 1 \text { large impediment on } \\
\text { segment is significant. Should } \\
\text { be able topush a stroller without } \\
\text { Few }\end{array}$ \\
\hline None & & & \\
\hline No Sidewlem.
\end{tabular}

16. Large Sidewalk Obstructions:

\begin{tabular}{|l|l|l|l|}
\hline Yes, Permanent & & & $\begin{array}{l}\text { Note: 2 people should be able to } \\
\text { walk side-by-wide along the } \\
\text { entire sidewalk. }\end{array}$ \\
\hline Yes, Temporary & & & \\
\hline No & &
\end{tabular}

(2)

\begin{tabular}{|l|l|l|l|l|}
\hline $\begin{array}{l}\text { 17. Presence of } \\
\text { Curb: }\end{array}$ & Curb & & & \\
\hline & No Curb & & & \\
\hline
\end{tabular}

is

18. Driveway Cuts: (Please enter count and check a category)

\begin{tabular}{|l|l|l|l|}
\hline Enter Count (\#): & & & $\begin{array}{l}\text { Note: Parking garages count as } \\
2 \text { (i.e., vehicle entry and exit in } \\
\text { 5 or more }\end{array}$ \\
\hline Few (less than 5) & & & \\
\hline None & & & \\
\hline
\end{tabular}

\begin{tabular}{|l|l|l|l|l|}
\hline 19. Trees: & Continuously Lined & & & \multirow{2}{*}{} \\
\cline { 2 - 4 } & Sporadically Lined & & \\
\hline & None & & & \\
\hline
\end{tabular}

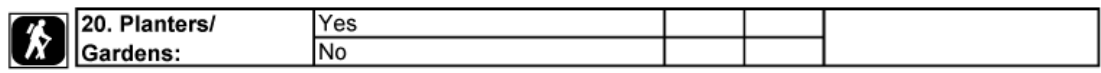

\begin{tabular}{|l|l|l|l|l|}
\hline 21. Public Seating: & Yes & & & \\
\cline { 2 - 3 } & No & & & \\
\hline
\end{tabular}

\begin{tabular}{|l|l|l|l|l|}
\hline 22. Presence of & Bike Lane (BL) & & & Note: Street cleaning \\
\cline { 1 - 3 }
\end{tabular}

\begin{tabular}{|l|l|l|}
\hline $\begin{array}{l}\text { Parallel Parking - not time } \\
\text { restricted (PP) }\end{array}$ & & \\
\hline $\begin{array}{l}\text { Time-restrictions do not count as time- } \\
\text { restricted parallel parking. } \\
(\mathrm{TPP})\end{array}$ & & \\
\hline BL and PP & & \\
\hline BL and TPP & & \\
\hline None & & \\
\hline
\end{tabular}
Buffer:

\begin{tabular}{|l|l|l|l|l|l|}
\hline Land Use: & 23. Storefront/ Retail 3 or more & & & $\begin{array}{l}\text { Note: This should reflect } \\
\text { businesses only. Include ground }\end{array}$ \\
\cline { 4 - 5 } & 1 Or 2 & & & $\begin{array}{l}\text { floor businesses with window } \\
\text { treatments, displays and open } \\
\text { shades. }\end{array}$ \\
\cline { 5 - 6 } & 0 & & & \\
\hline
\end{tabular}

\begin{tabular}{|l|l|l|l|l|}
\hline 24. Public Art $I$ & Yes & & & \\
\cline { 2 - 3 } & No & & & \\
\hline
\end{tabular}

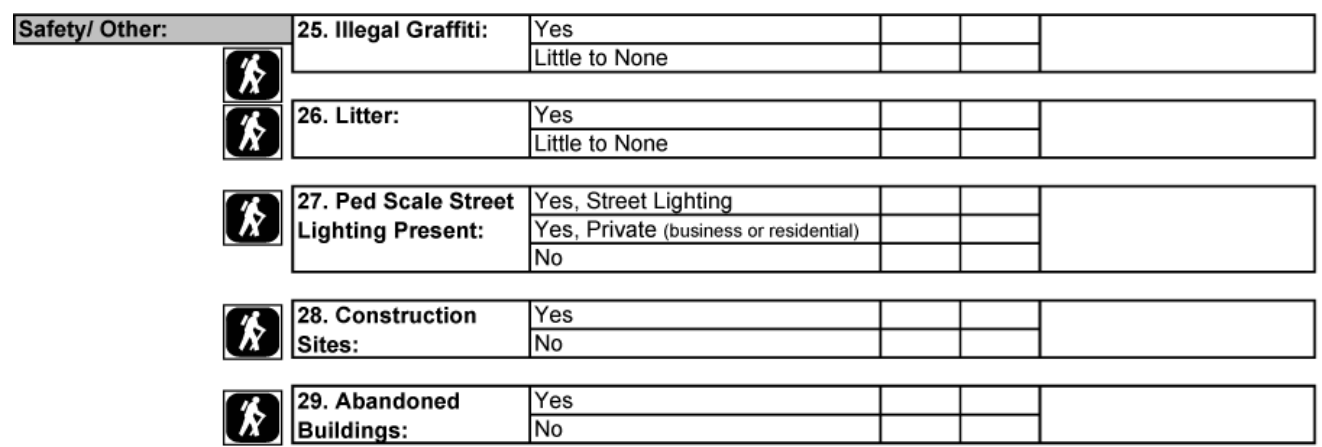

(a) : should be able to observe while standing in one place 
Appendix B: Pedestrian Perception Survey 


\section{Pedestrian Perception Survey - Page 1 to 2}

\section{LEISURE WALKS}

PLEASE IDENTIFY THE STREETS YOU PREFER FOR LEISURE WALKS AND INDICATE REASONS WHY BELOW
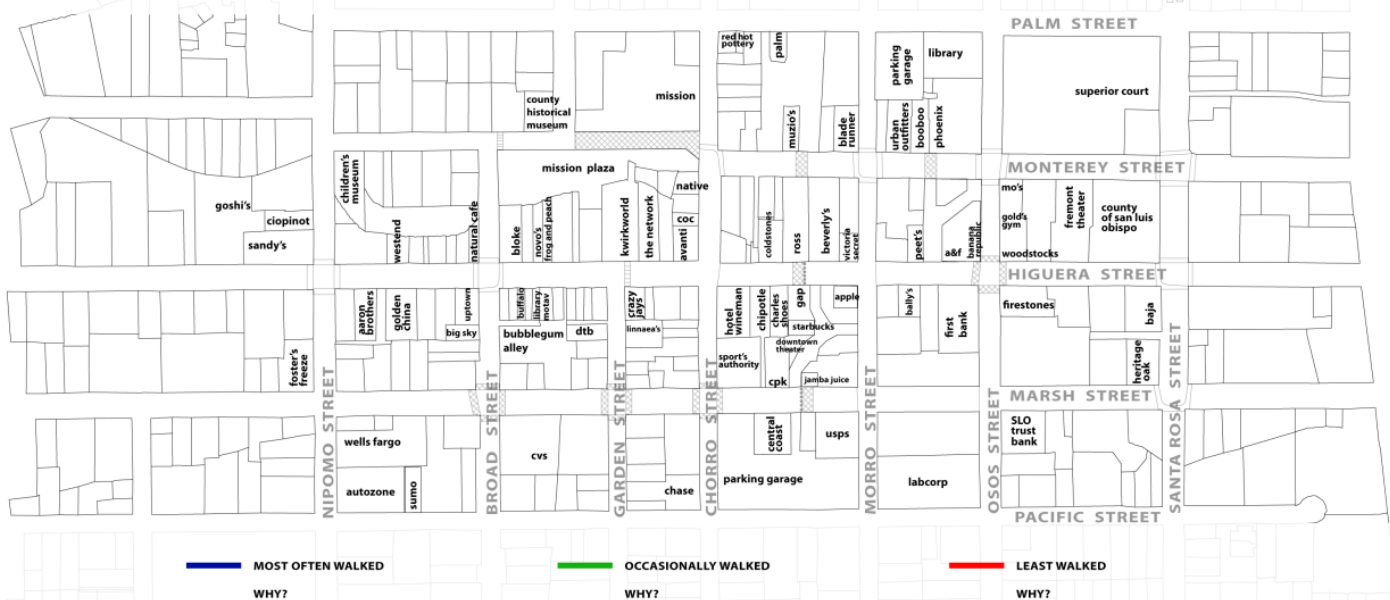

WHY?

COMFORT

PLEASE IDENTIFY YOUR PERSONAL COMFORT LEVEL OF THE STREETS AND INDICATE REASONS WHY BELOW

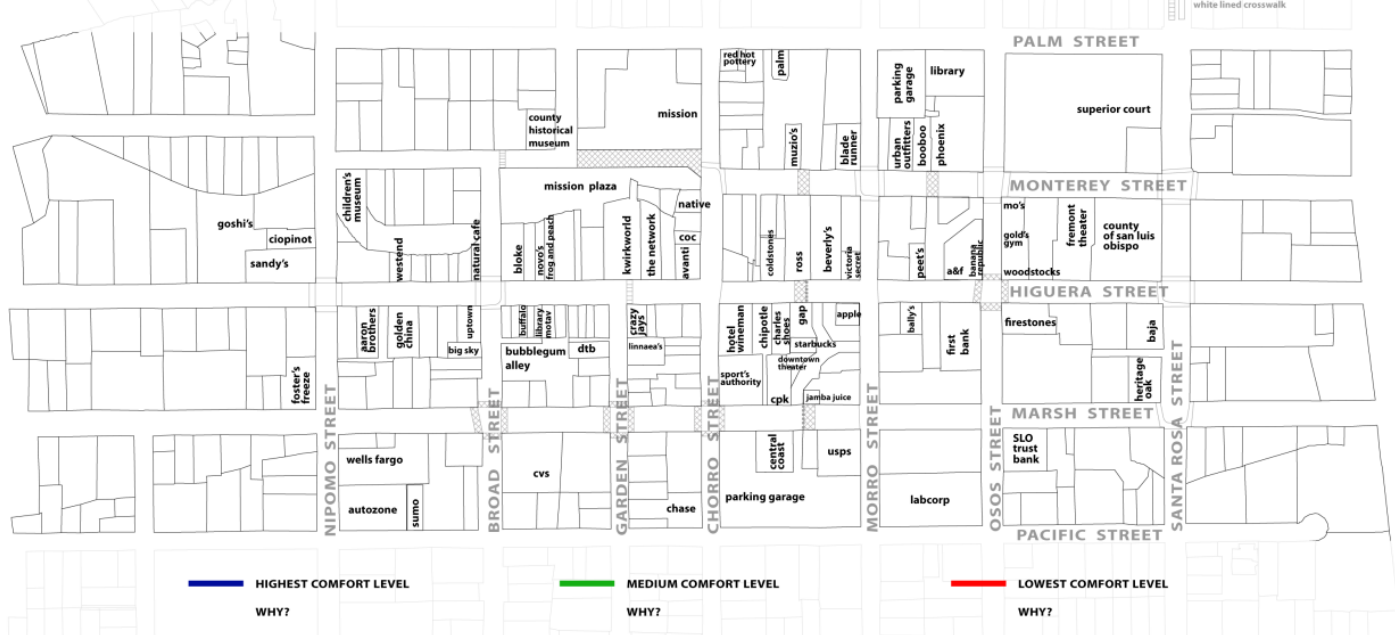




\section{Pedestrian Perception Survey - Page 3 to 4}
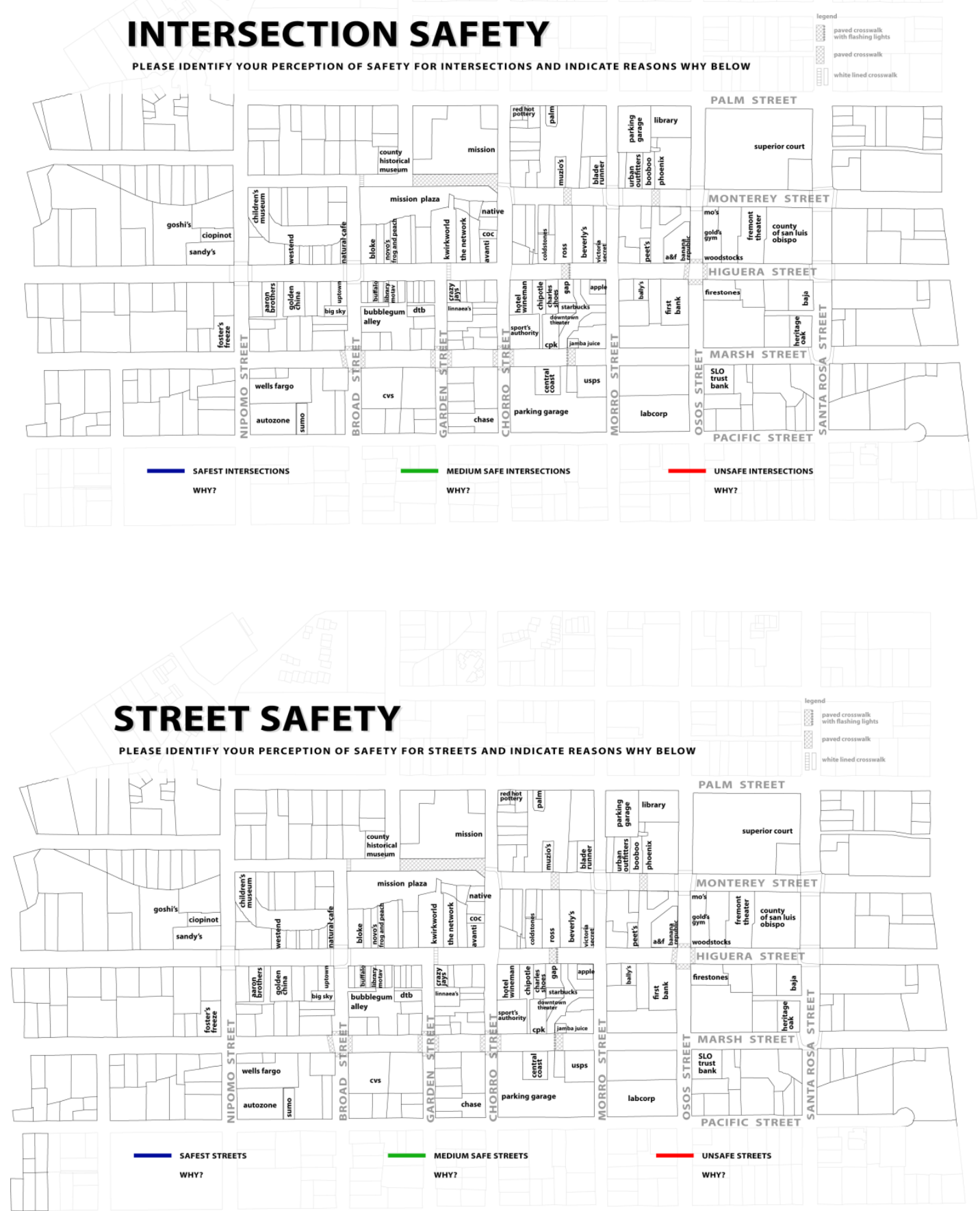
Pedestrian Perception Survey - Page 5 to 6
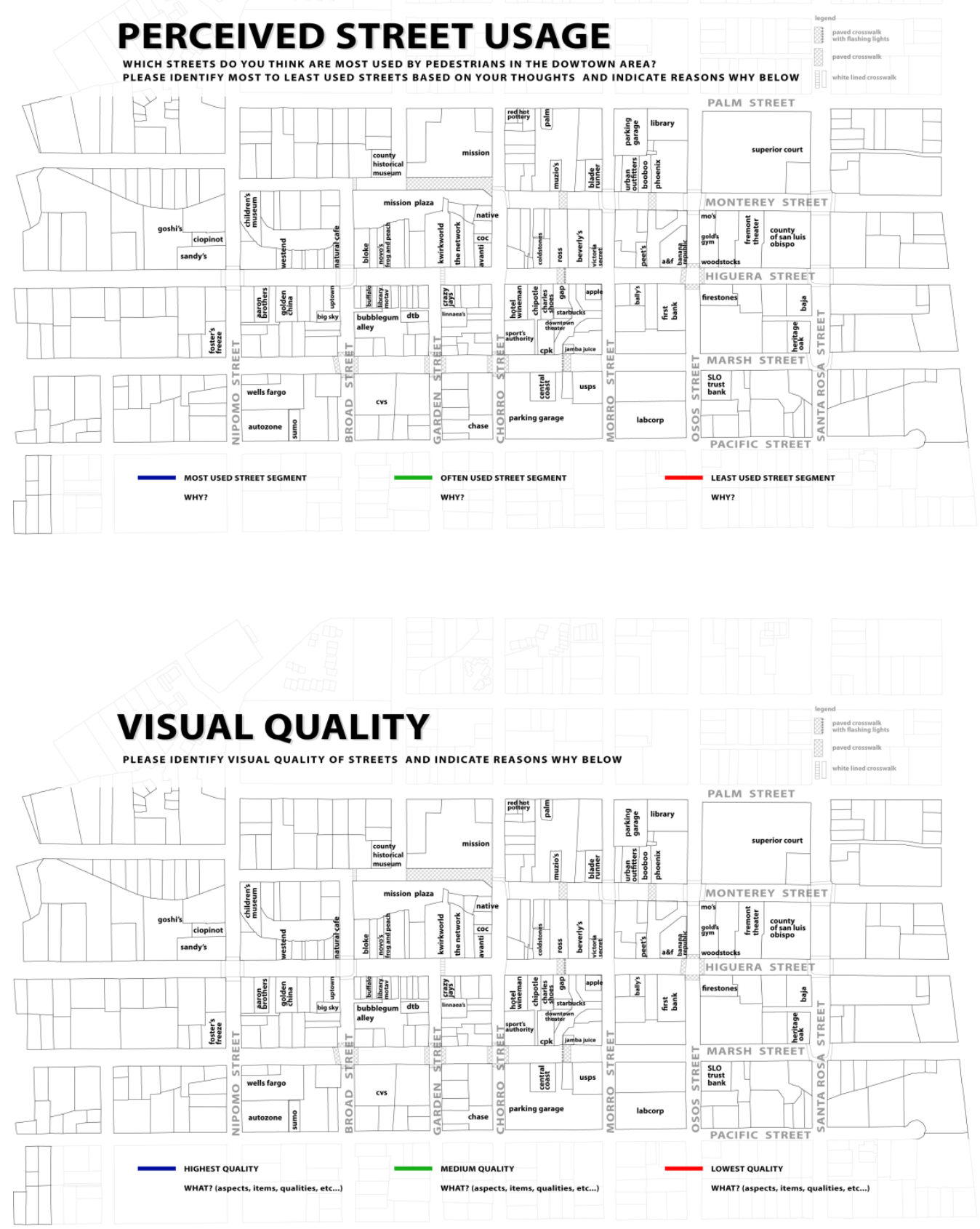


\section{Pedestrian Perception Survey - Page 7}

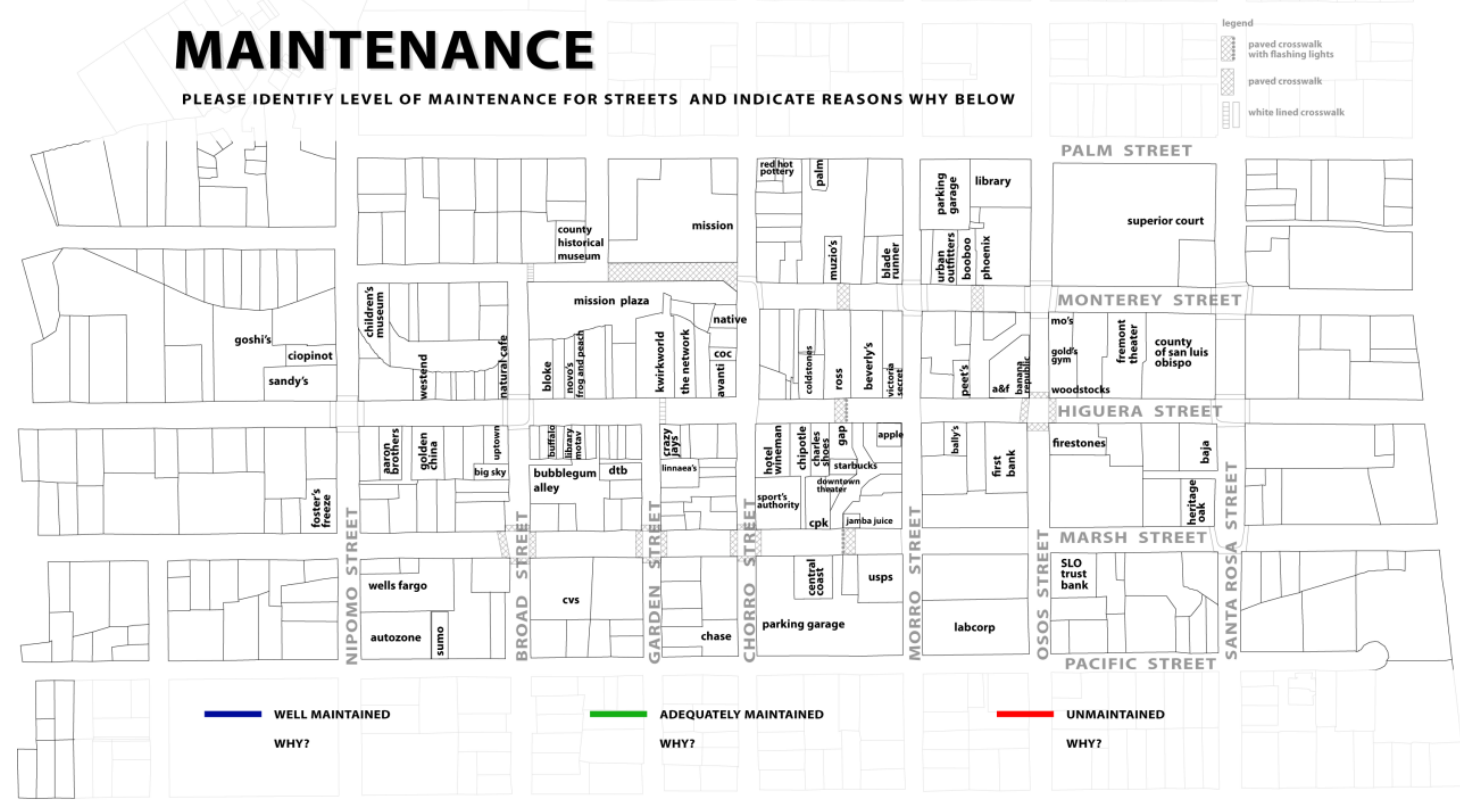


Appendix C: Pedestrian Perception Survey map results for most and least preferred areas for each category 


\section{LEISURE WALKS}

PLEASE IDENTIFY THE STREETS YOU PREFER FOR LEISURE WALKS AND INDICATE REASONS WHY BELOW

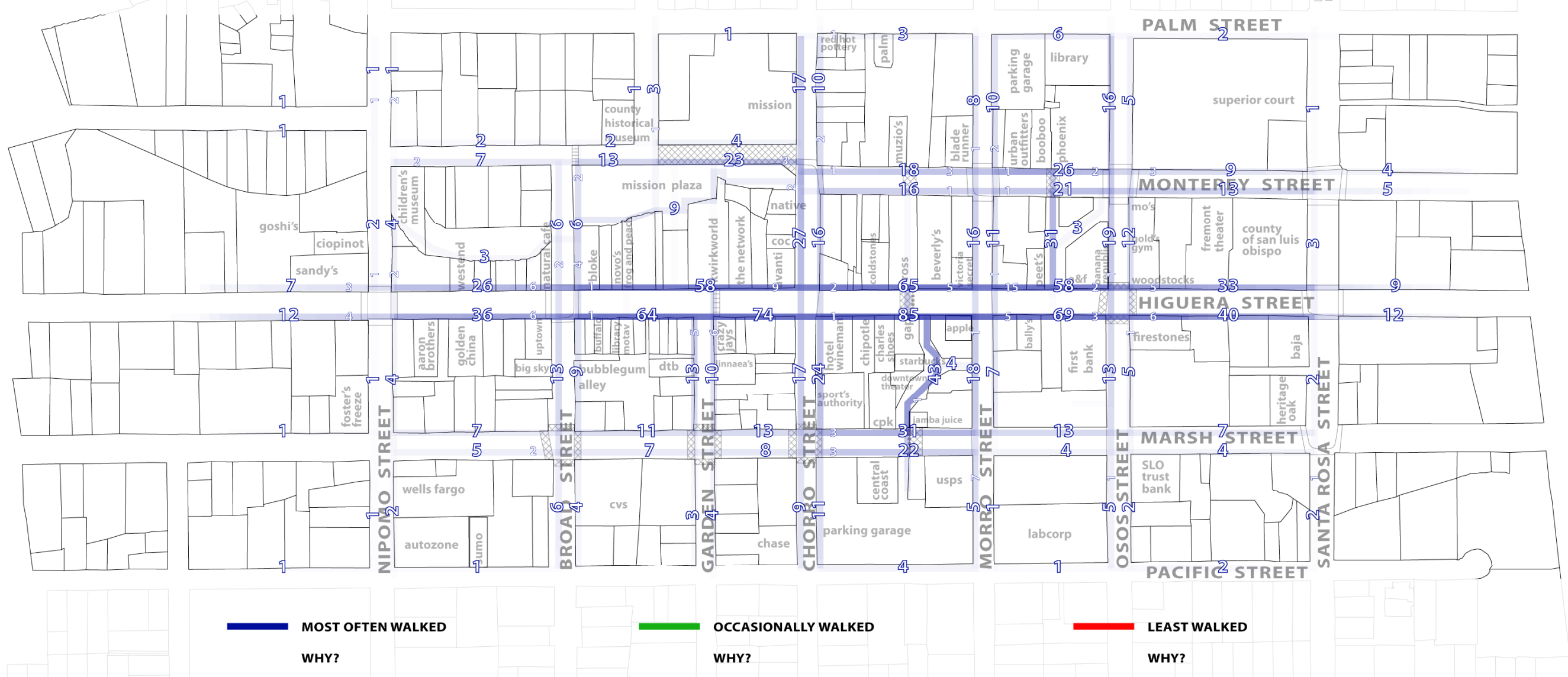

Pedestrian Perception Survey Map Results of most preferred areas for Leisure Walk 


\section{LEISURE WALKS}
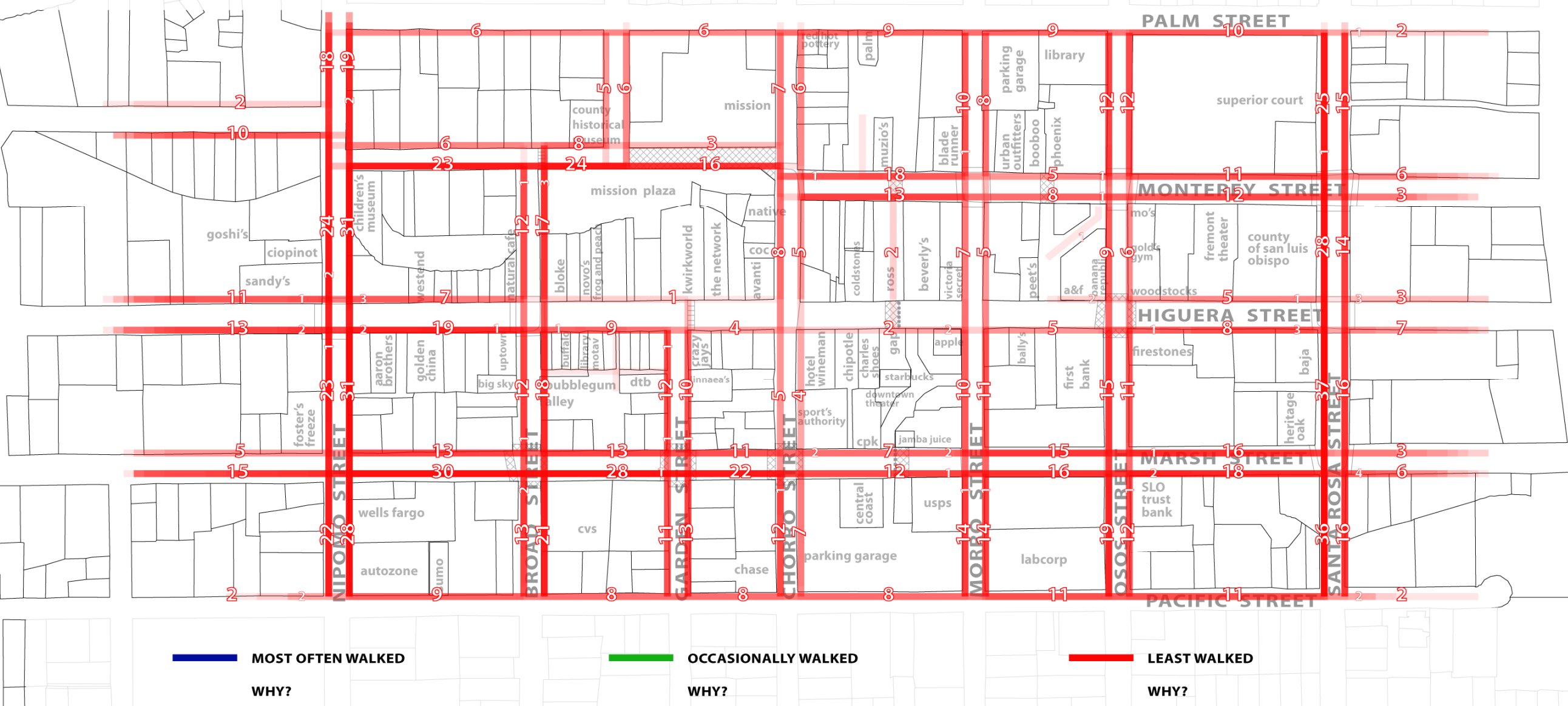

OCCASIONALLY WALKED

WHY?
LEAST WALKED
WHY?

Pedestrian Perception Survey Map Results of least preferred areas for Leisure Walk 


\section{COMFORT}

PLEASE IDENTIFY YOUR PERSONAL COMFORT LEVEL OF THE STREETS AND INDICATE REASONS WHY BELOW

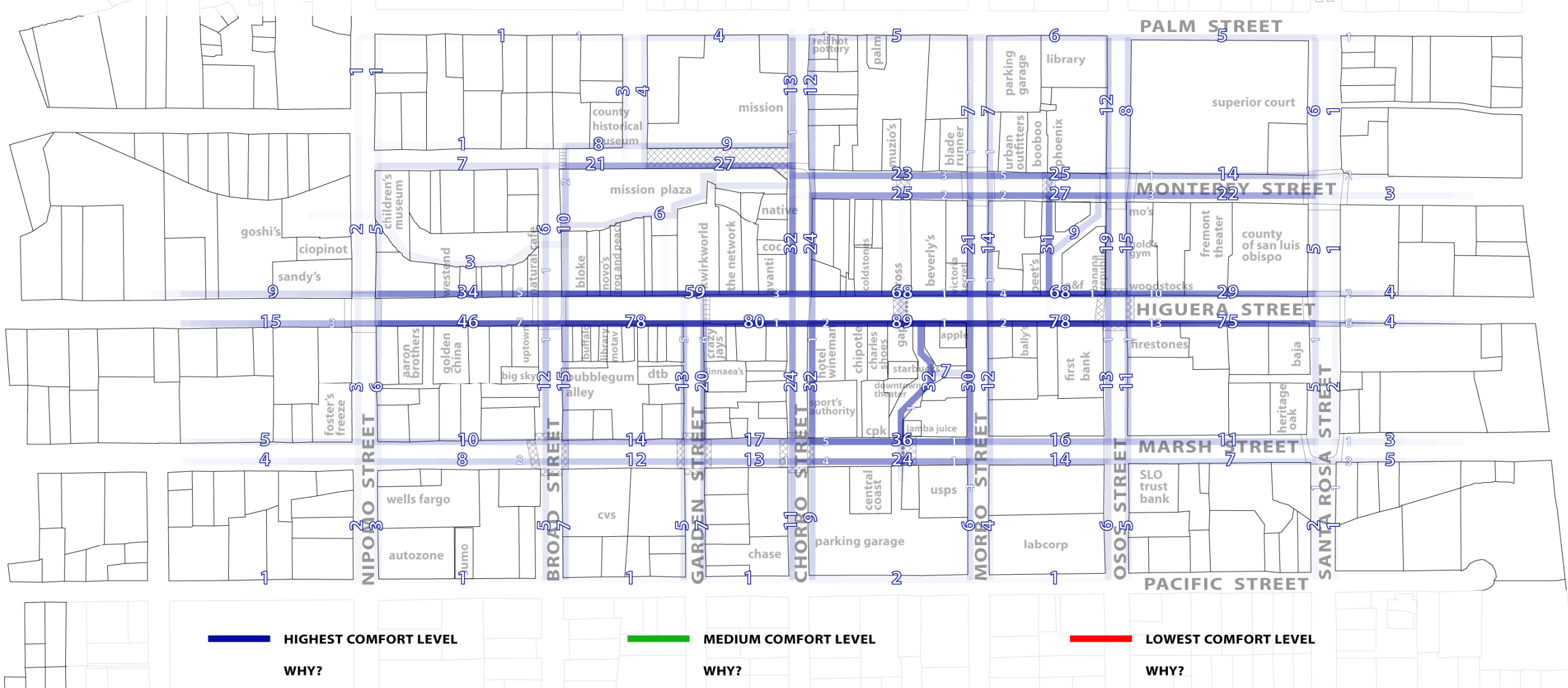

Pedestrian Perception Survey Map Results of most preferred areas for Comfort 


\section{COMFORT}

PLEASE IDENTIFY YOUR PERSONAL COMFORT LEVEL OF THE STREETS AND INDICATE REASONS WHY BELOW

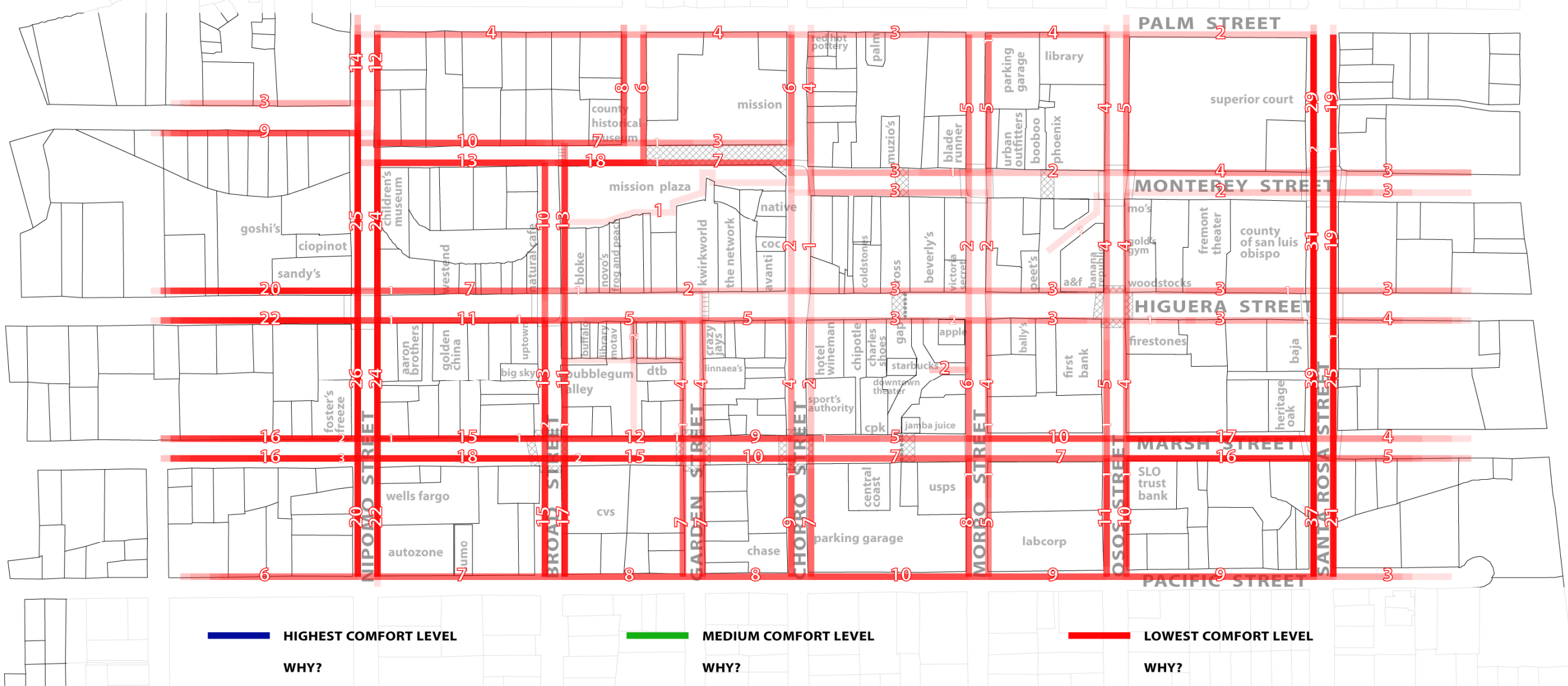

Pedestrian Perception Survey Map Results of least preferred areas for Comfort 


\section{INTERSECTION SAFETY}

PLEASE IDENTIFY YOUR PERCEPTION OF SAFETY FOR INTERSECTIONS AND INDICATE REASONS WHY BELOW

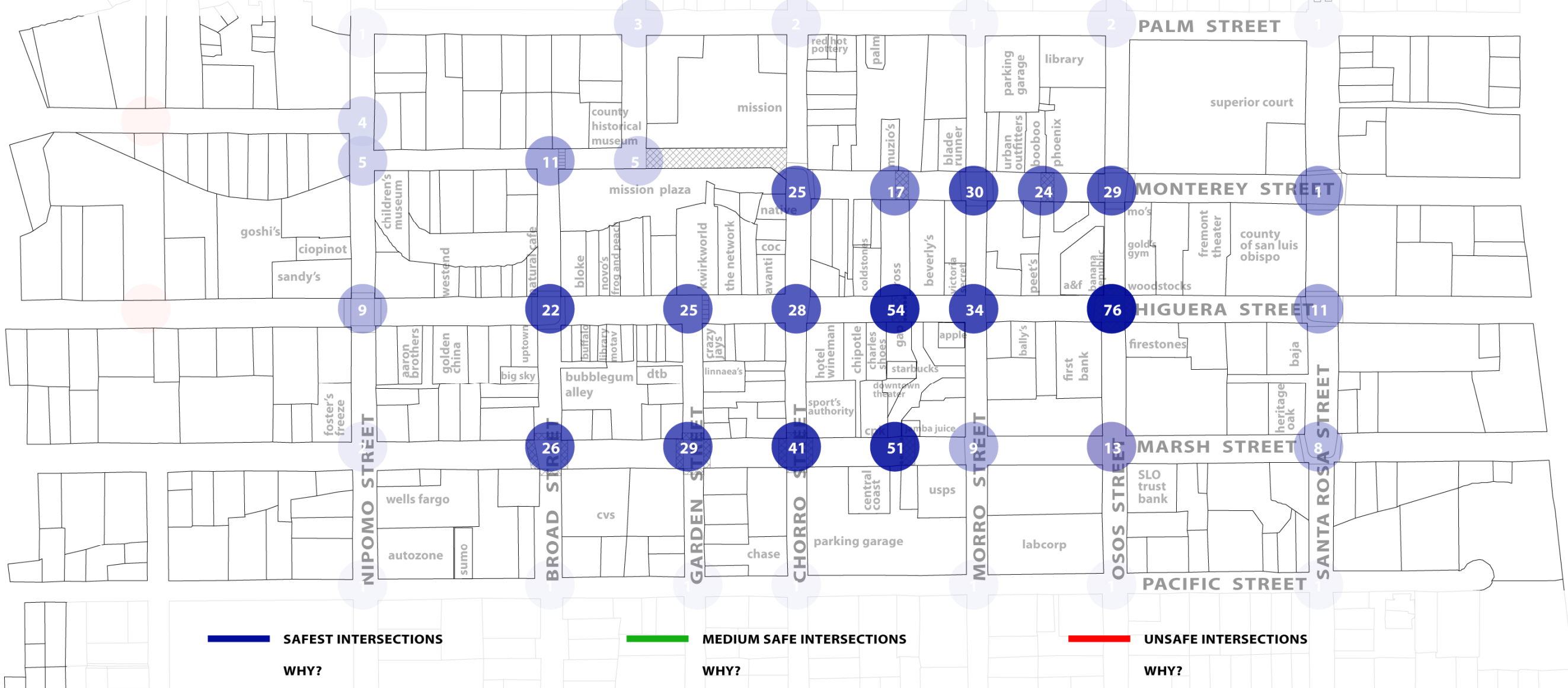

Pedestrian Perception Survey Map Results of most preferred areas for Intersection Safety 


\section{INTERSECTION SAFETY}

PLEASE IDENTIFY YOUR PERCEPTION OF SAFETY FOR INTERSECTIONS AND INDICATE REASONS WHY BELOW

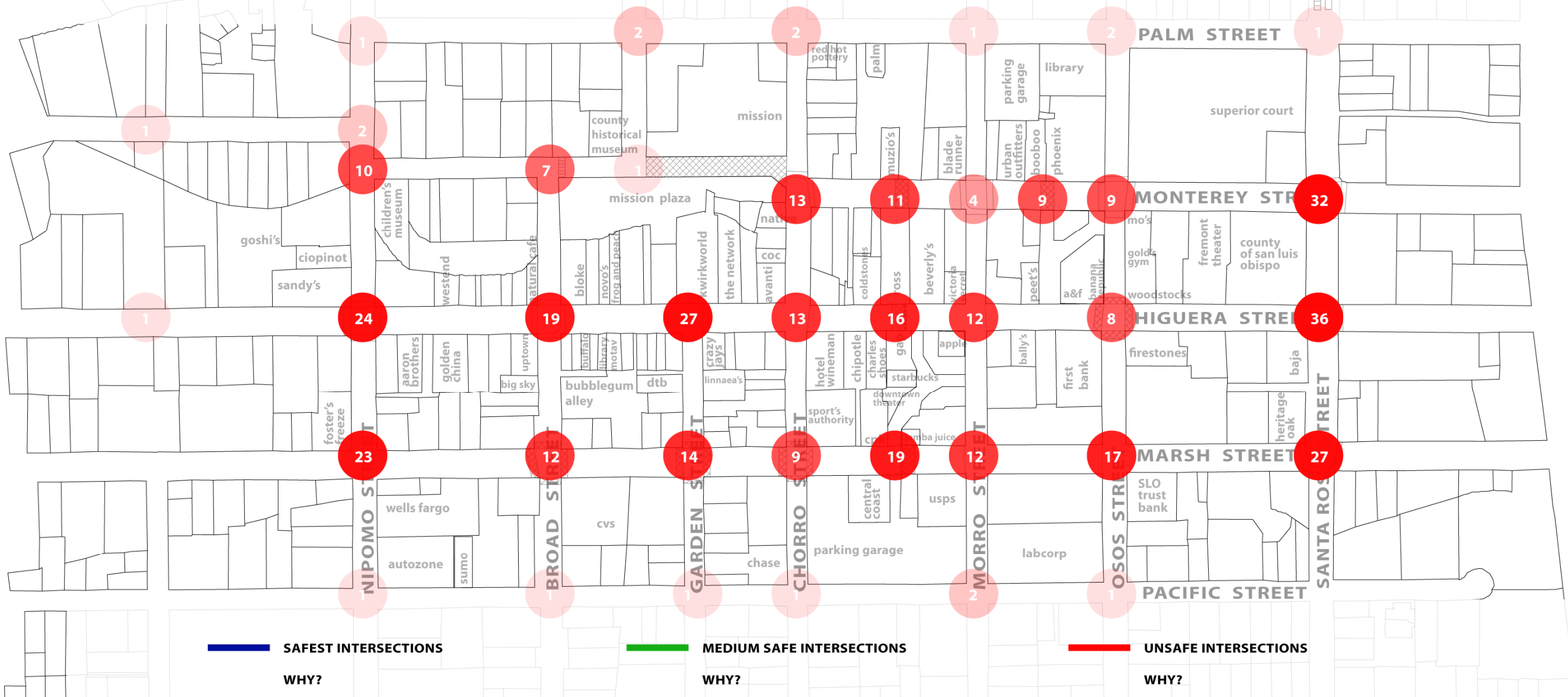

Pedestrian Perception Survey Map Results of least preferred areas for Intersection Safety 


\section{STREET SAFETY}

PLEASE IDENTIFY YOUR PERCEPTION OF SAFETY FOR STREETS AND INDICATE REASONS WHY BELOW

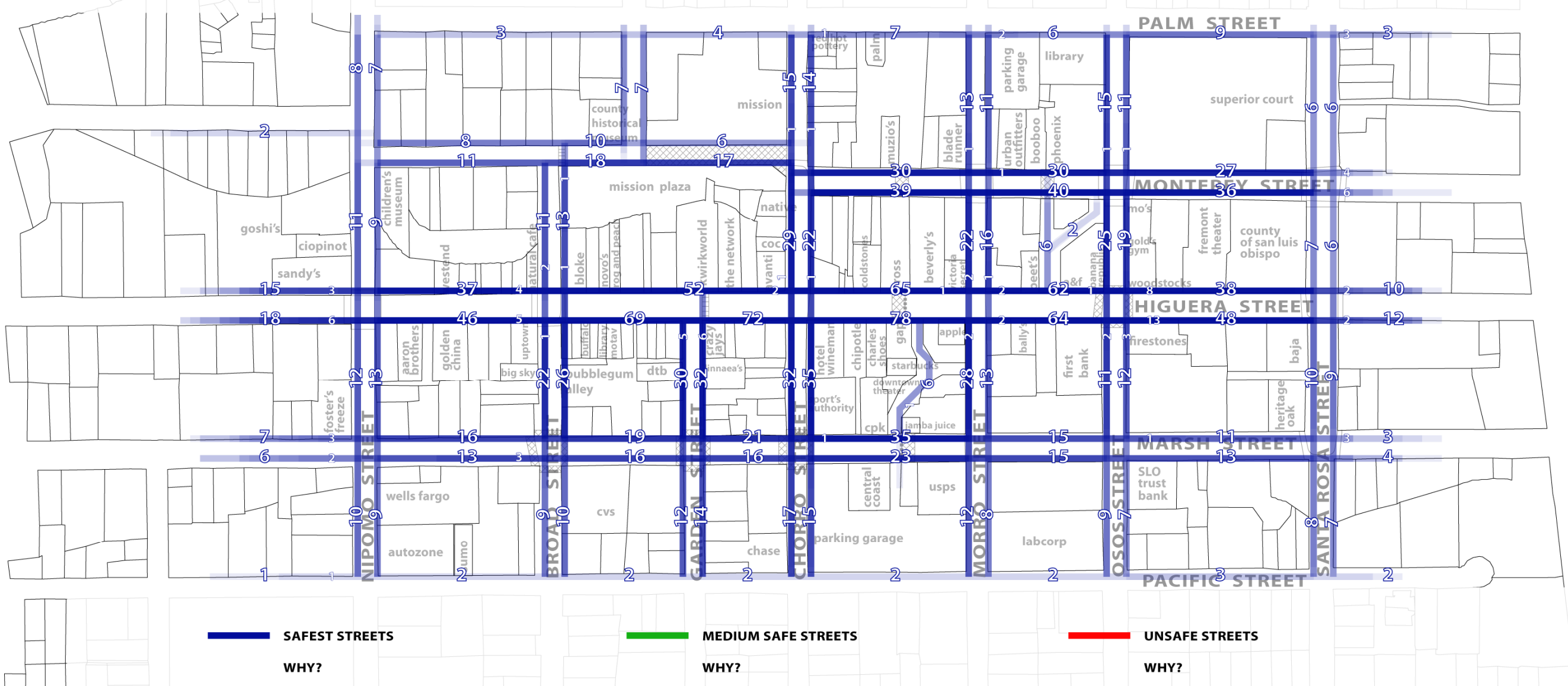

Pedestrian Perception Survey Map Results of most preferred areas for Street Safety 


\section{STREET SAFETY}

PLEASE IDENTIFY YOUR PERCEPTION OF SAFETY FOR STREETS AND INDICATE REASONS WHY BELOW

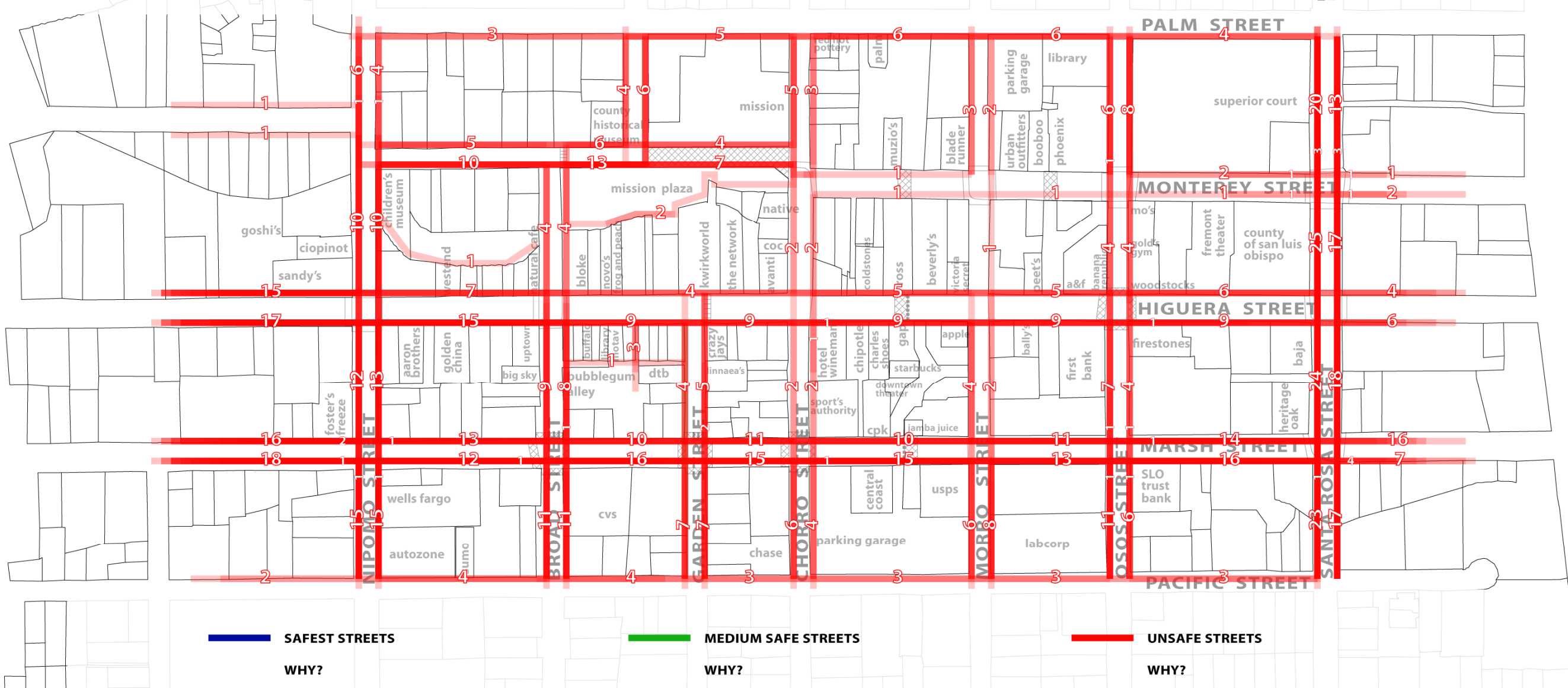

Pedestrian Perception Survey Map Results of least preferred areas for Street Safety 


\section{PERCEIVED STREET USAGE}

WHICH STREETS DO YOU THINK ARE MOST USED BY PEDESTRIANS IN THE DOWTOWN AREA?

PLEASE IDENTIFY MOST TO LEAST USED STREETS BASED ON YOUR THOUGHTS AND INDICATE REASONS WHY BELOW
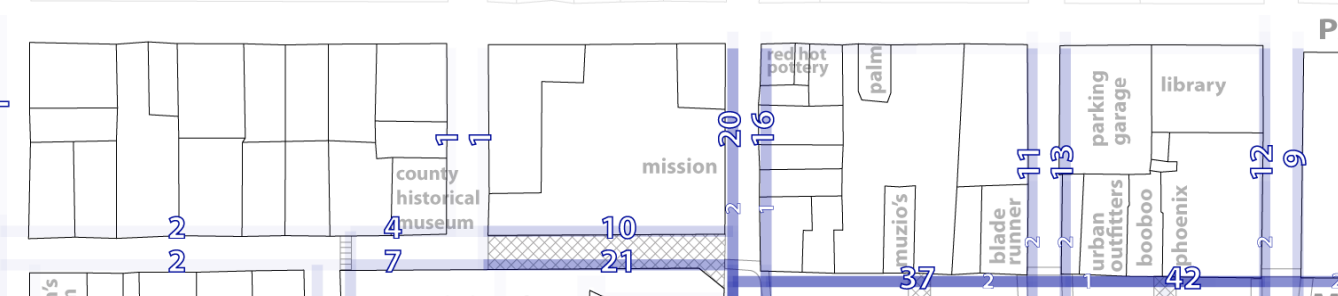

PALM STREET
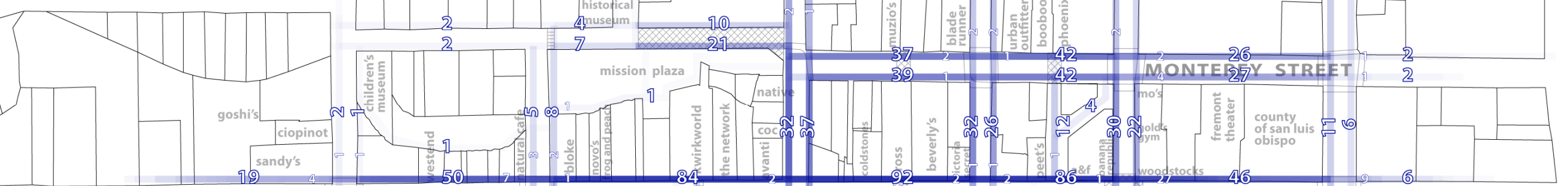

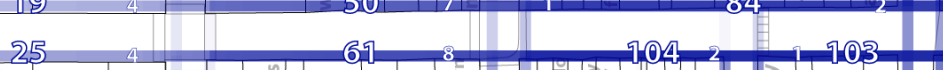
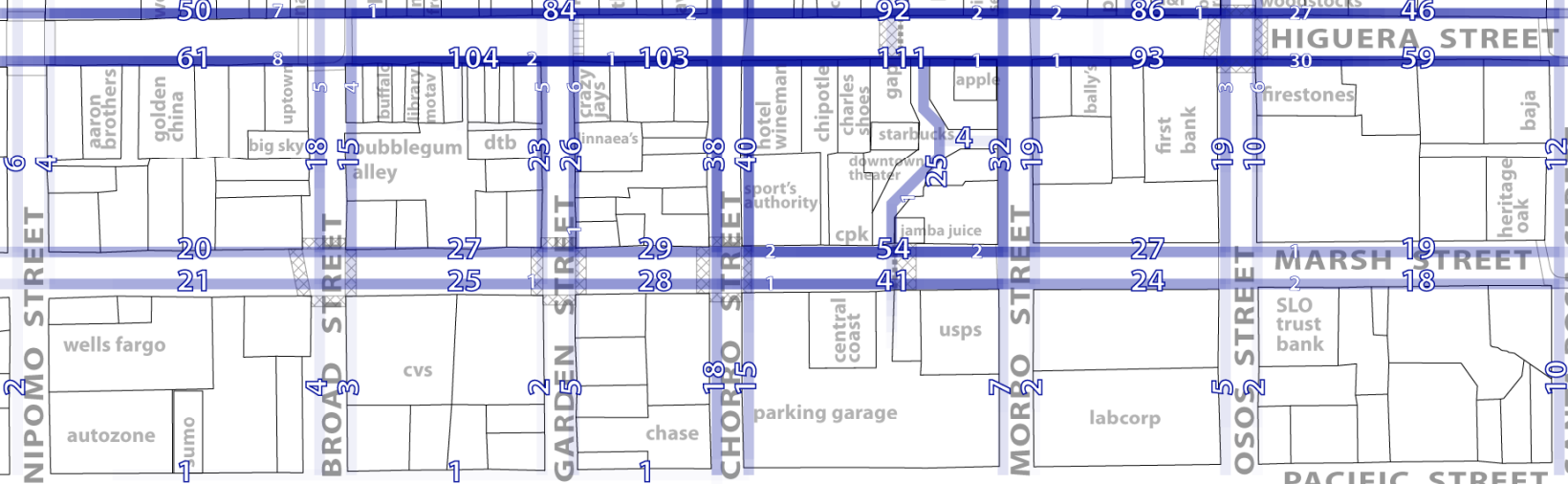

HIGUERA STREET
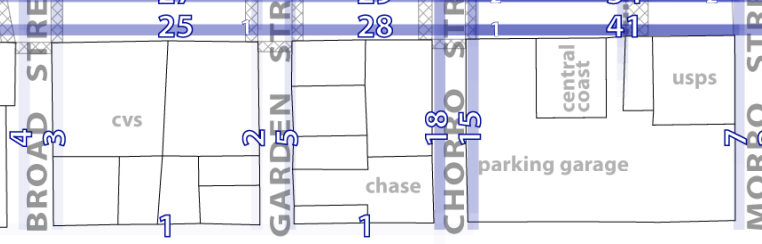

MOST USED STREET SEGMENT

OFTEN USED STREET SEGMENT WHY? WHY?

Pedestrian Perception Survey Map Results of most preferred areas for Perceived Street Usage 


\section{PERCEIVED STREET USAGE}

WHICH STREETS DO YOU THINK ARE MOST USED BY PEDESTRIANS IN THE DOWTOWN AREA?

PLEASE IDENTIFY MOST TO LEAST USED STREETS BASED ON YOUR THOUGHTS AND INDICATE REASONS WHY BELOW

Y 2 H PALM STRET
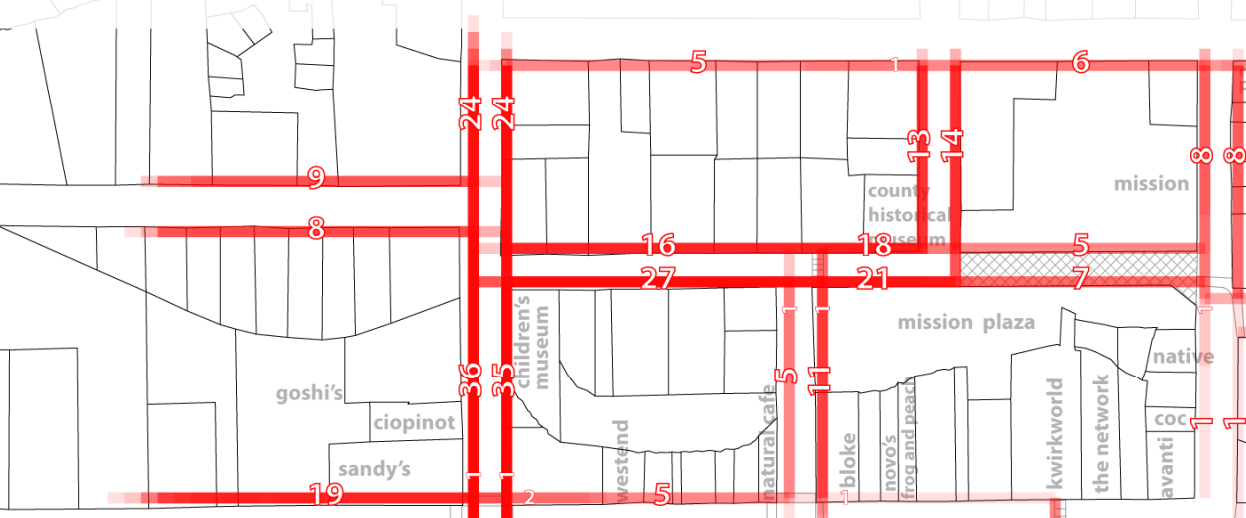

dy's
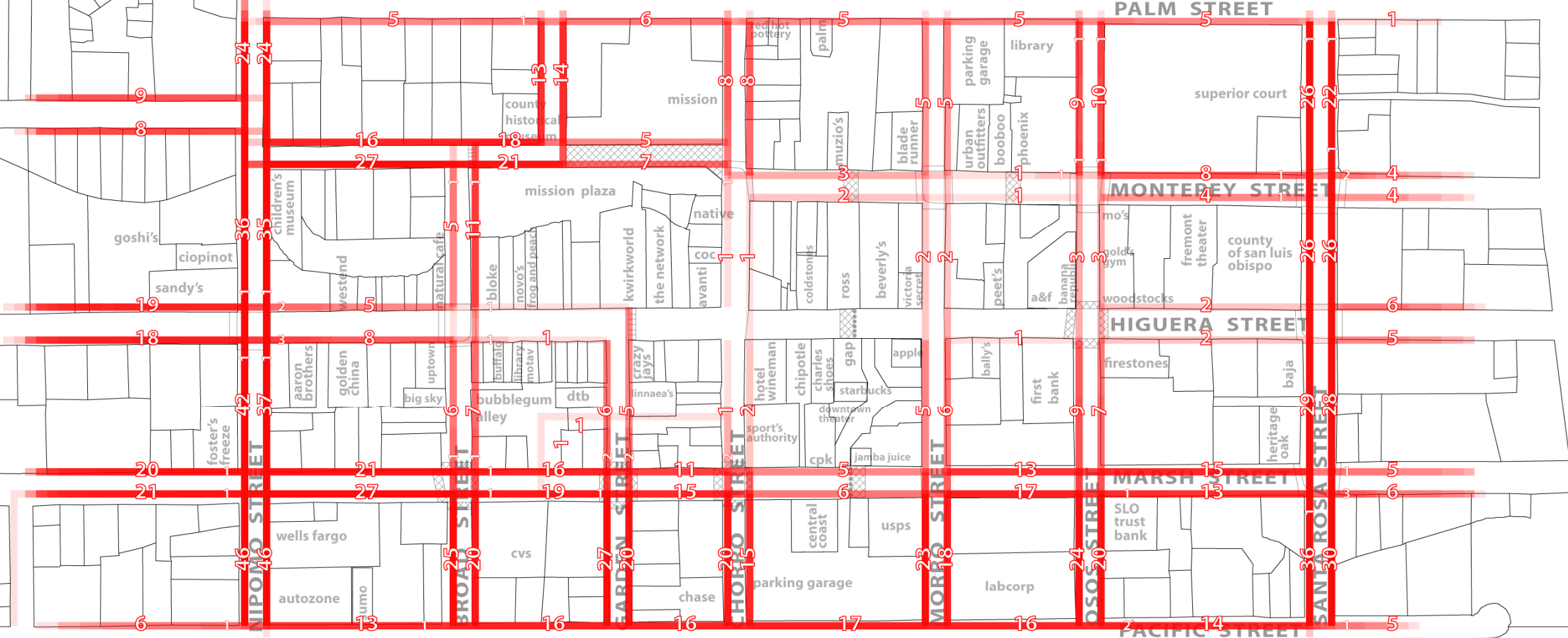

MOST USED STREET SEGMENT

OFTEN USED STREET SEGMENT

WHY?

LEAST USED STREET SEGMENT

WHY?

Pedestrian Perception Survey Map Results of least preferred areas for Perceived Street Usage 


\section{VISUAL QUALITY}

PLEASE IDENTIFY VISUAL QUALITY OF STREETS AND INDICATE REASONS WHY BELOW

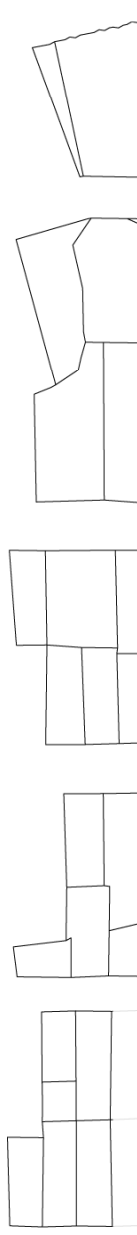

PLEASE IDENTIFY VISUAL QUALITY OF STREETS
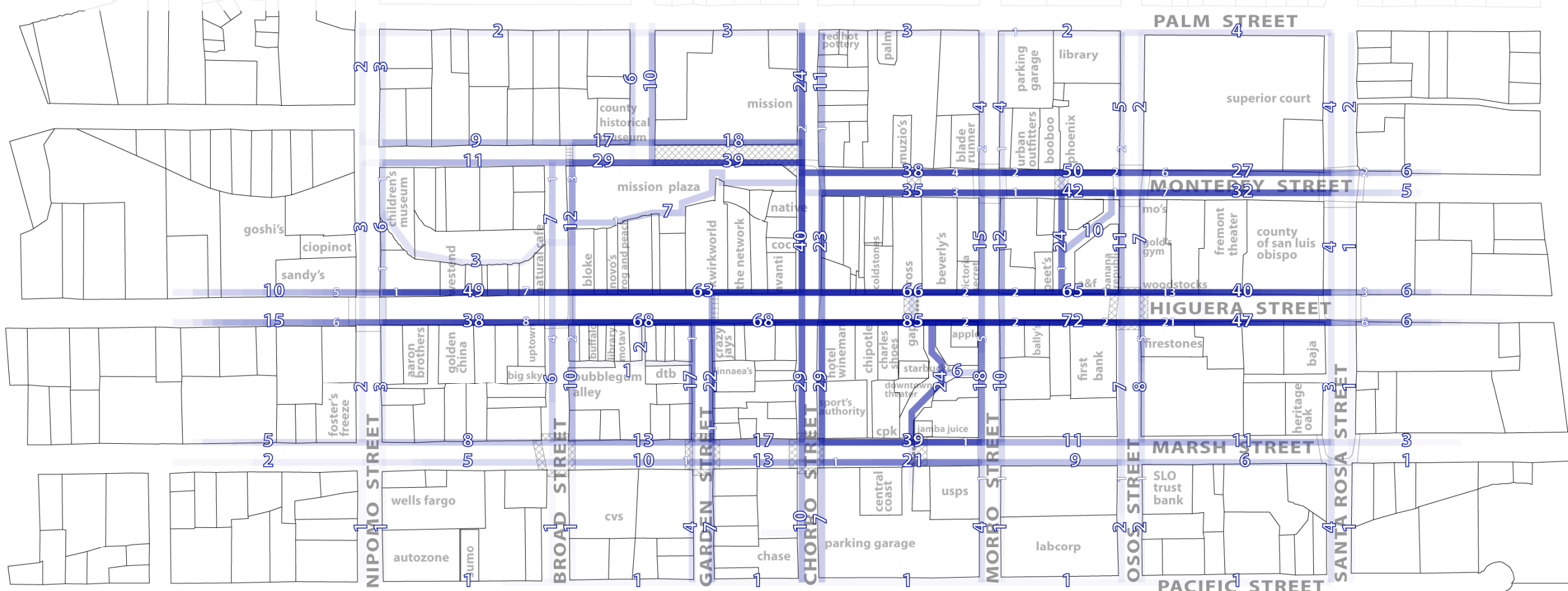

HIGUERA STREET
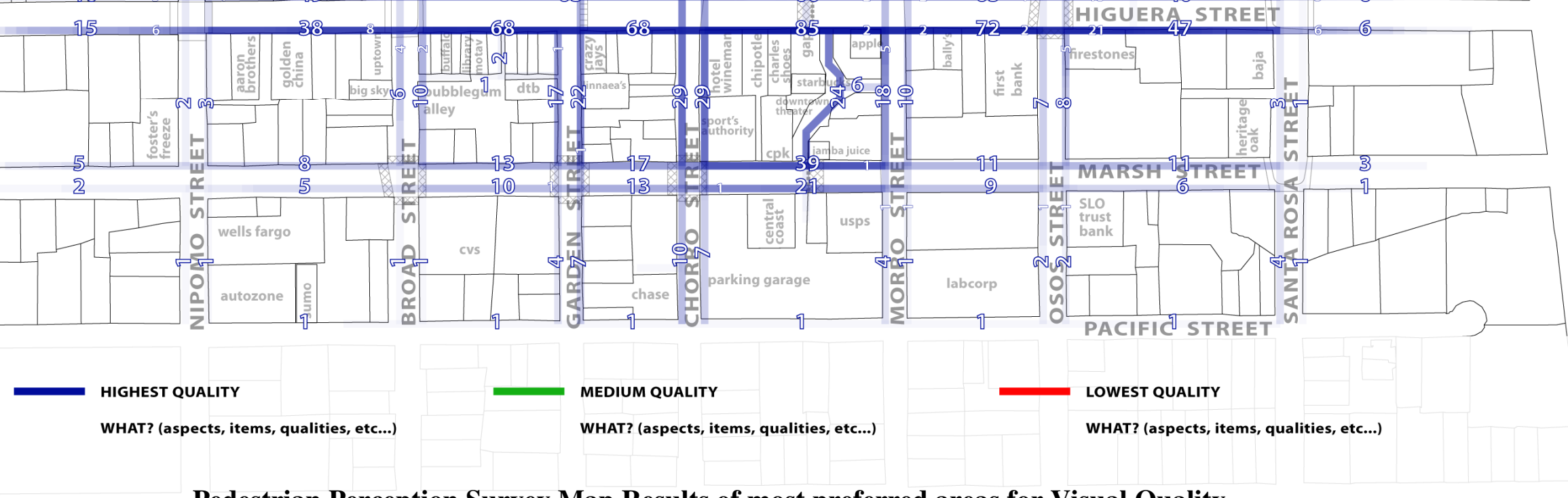

HIGHEST QUALITY

MEDIUM QUALITY

WHAT? (aspects, items, qualities, etc...)

LOWEST QUALITY

WHAT? (aspects, items, qualities, etc...)

Pedestrian Perception Survey Map Results of most preferred areas for Visual Quality 


\section{VISUAL QUALITY}

PLEASE IDENTIFY VISUAL QUALITY OF STREETS AND INDICATE REASONS WHY BELOW

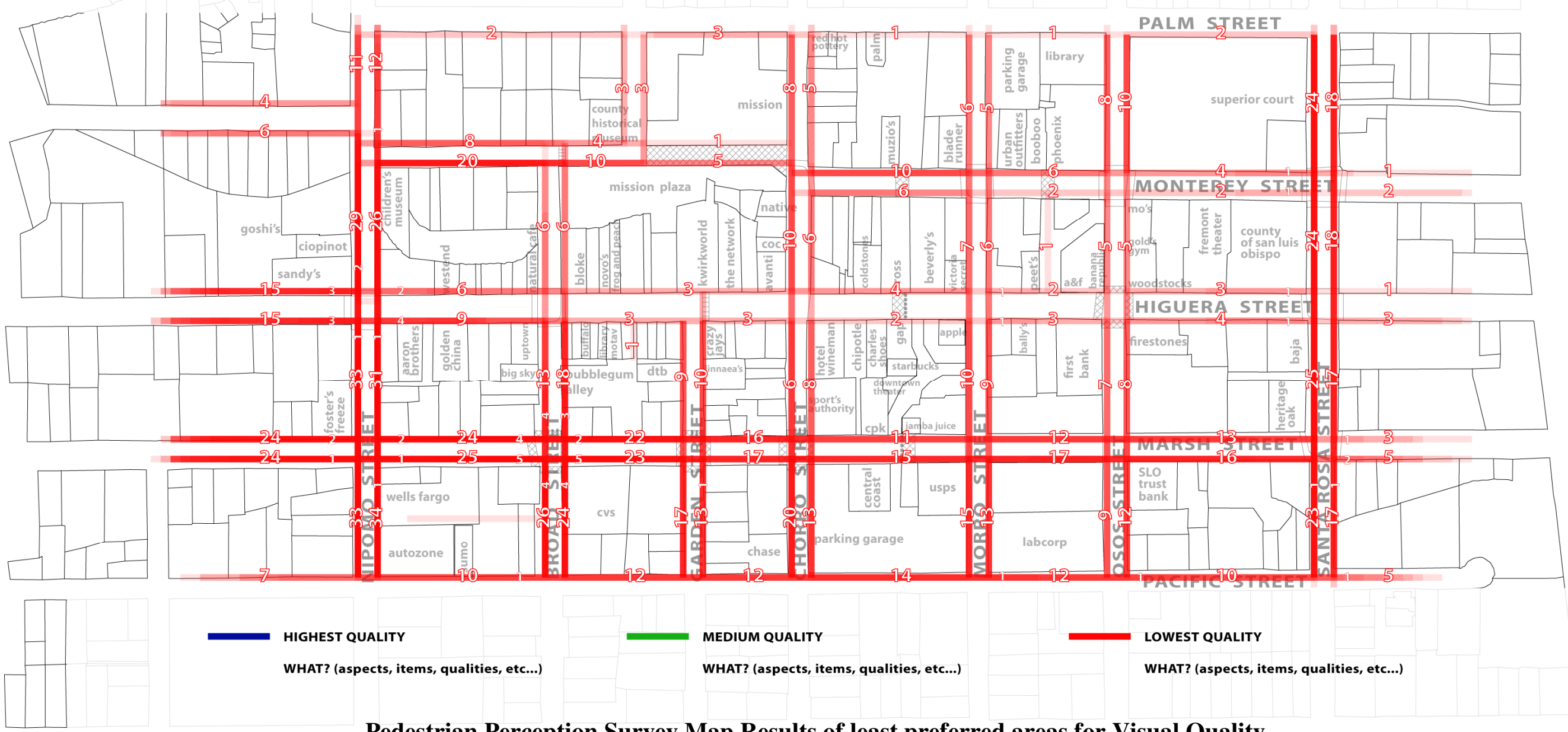

Pedestrian Perception Survey Map Results of least preferred areas for Visual Quality 


\section{MAINTENANCE}

PLEASE IDENTIFY LEVEL OF MAINTENANCE FOR STREETS AND INDICATE REASONS WHY BELOW

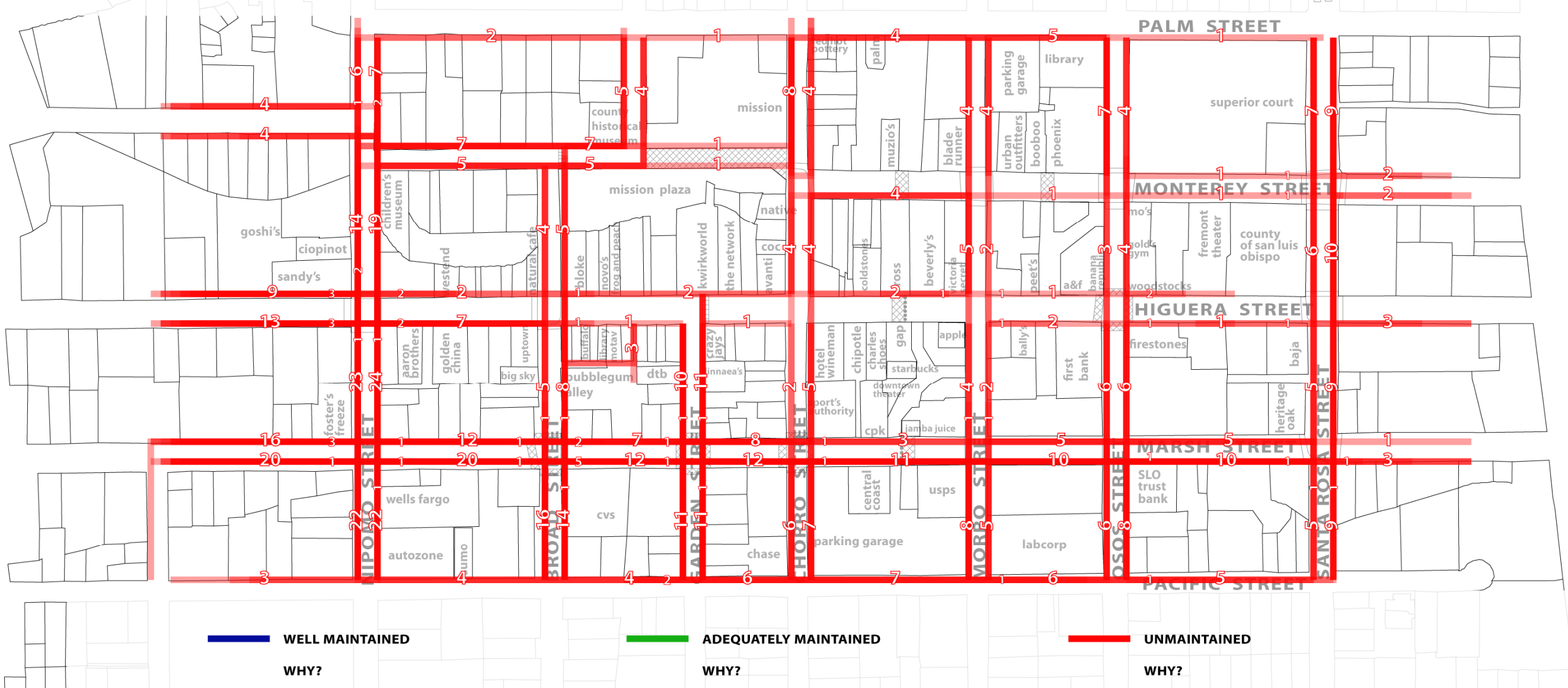

Pedestrian Perception Survey Map Results of least preferred areas for Maintenance 
Appendix D: PEQI indicators versus Survey respondents' identified indicators for each category 


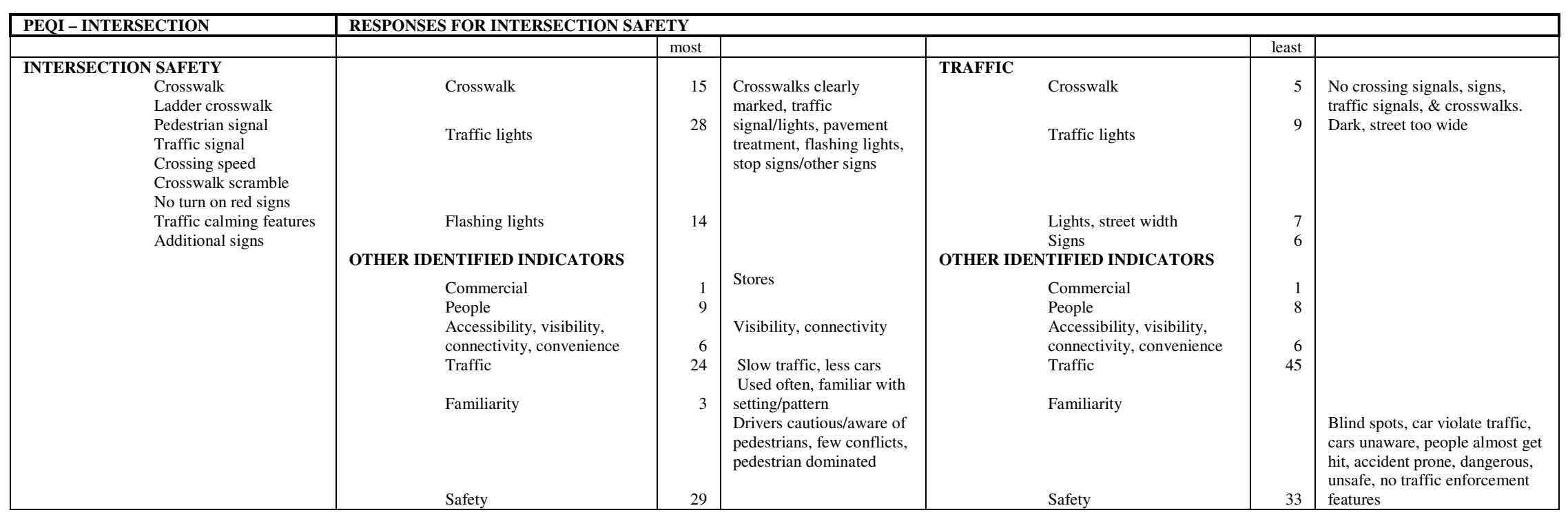

PEQI indicators versus Survey respondents' identified indicators for Intersection Safety 


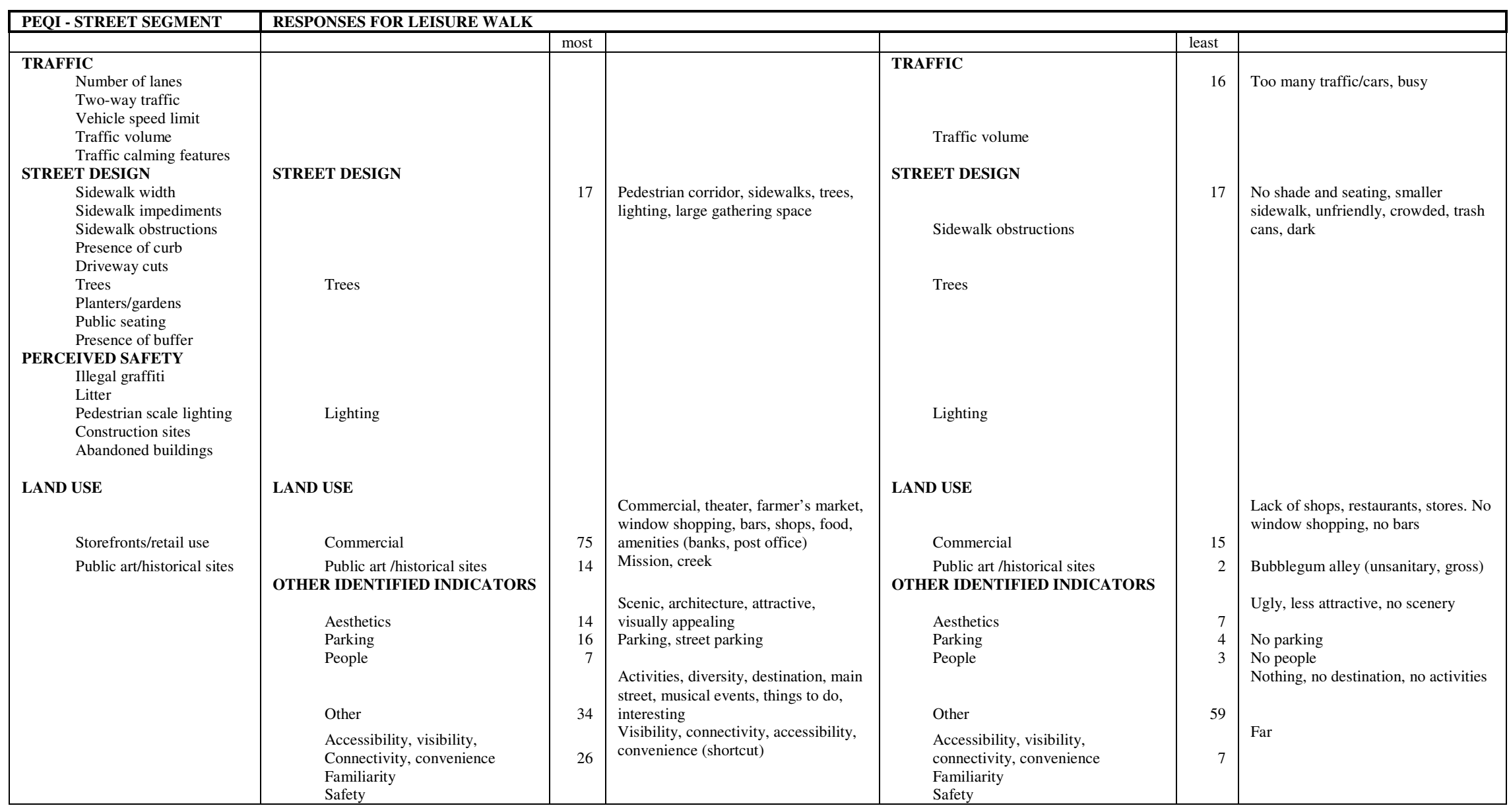

PEQI indicators versus Survey respondents' identified indicators for Leisure Walk 


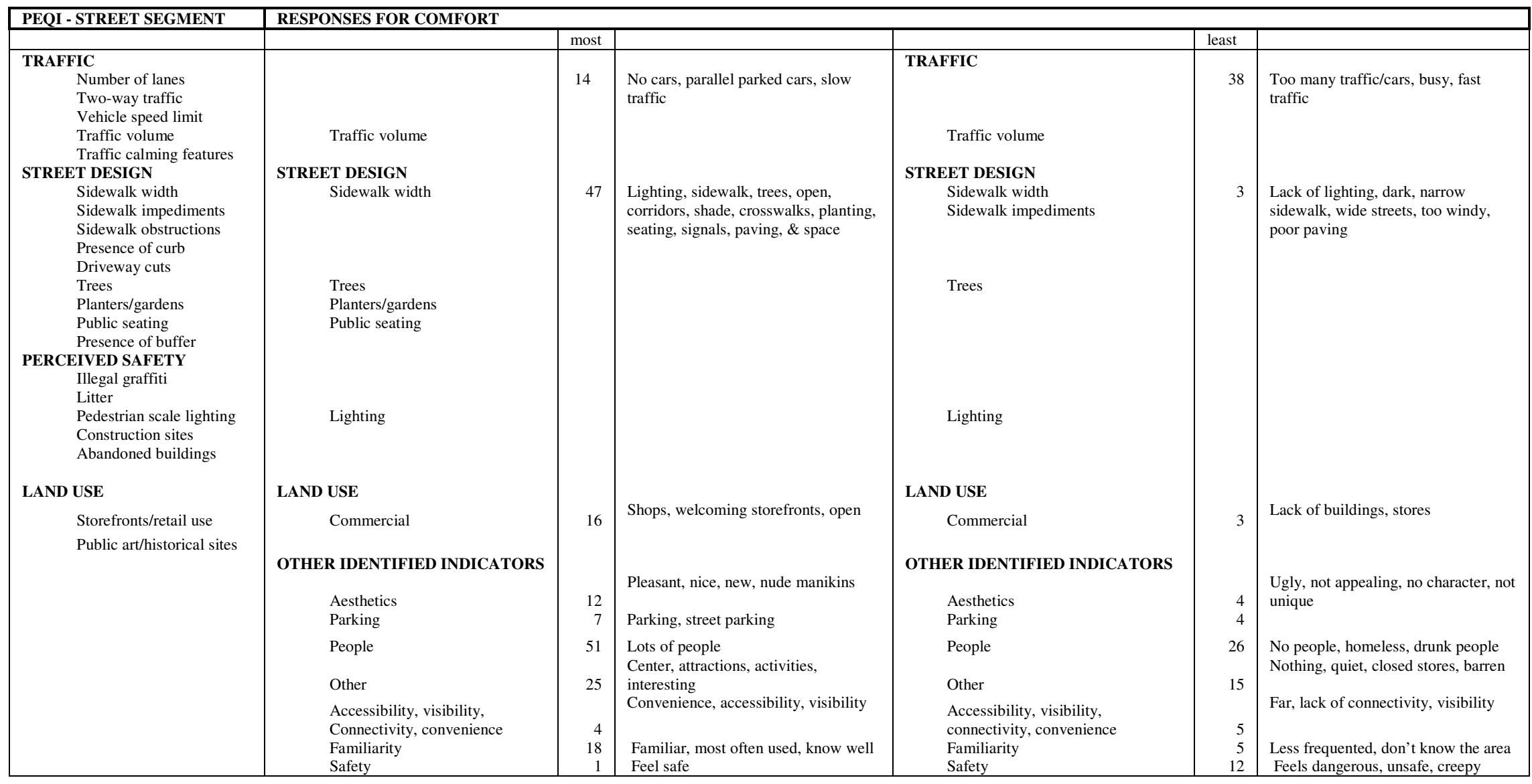

PEQI indicators versus Survey respondents' identified indicators for Comfort 


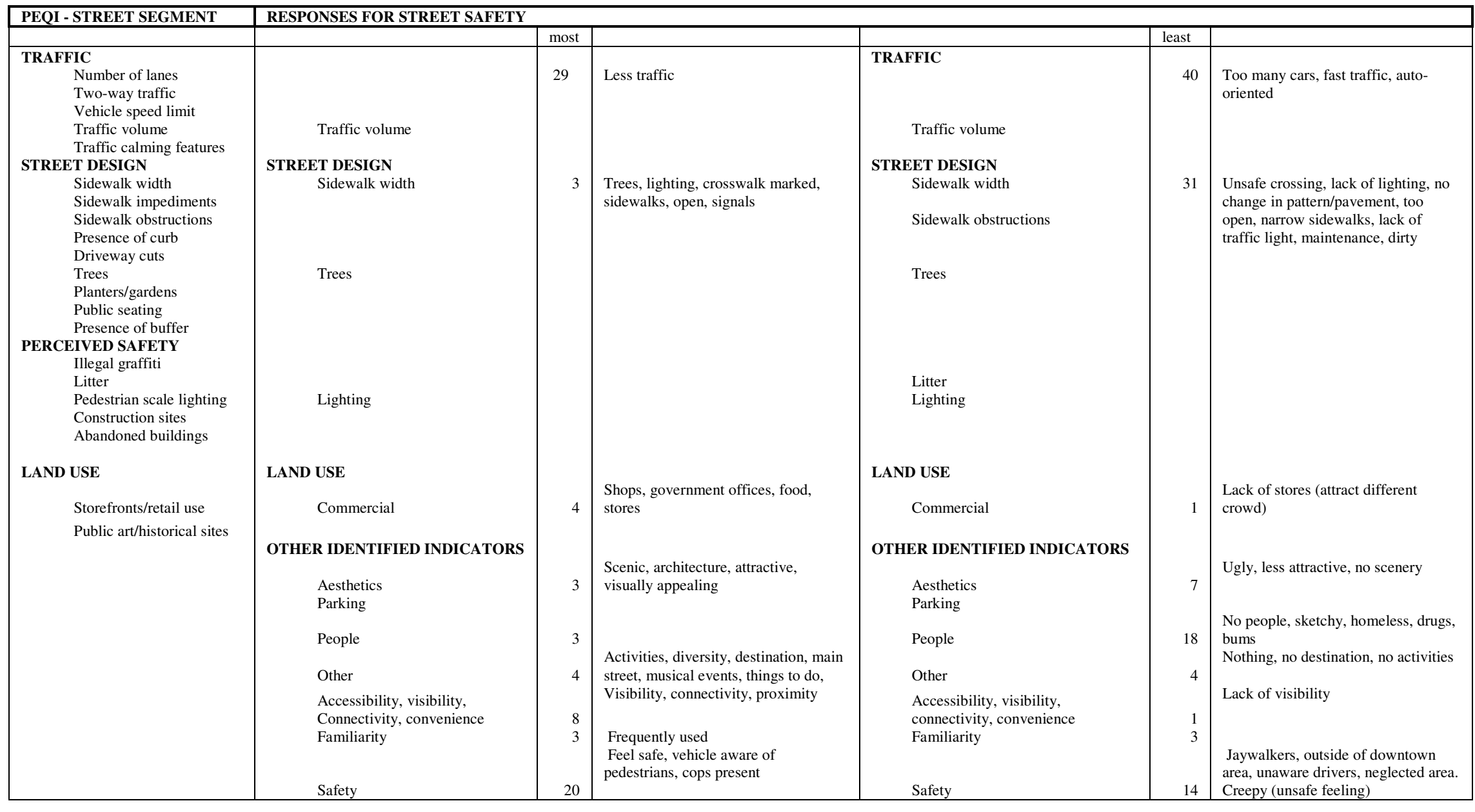

\section{PEQI indicators versus Survey respondents' identified indicators for Street Safety}




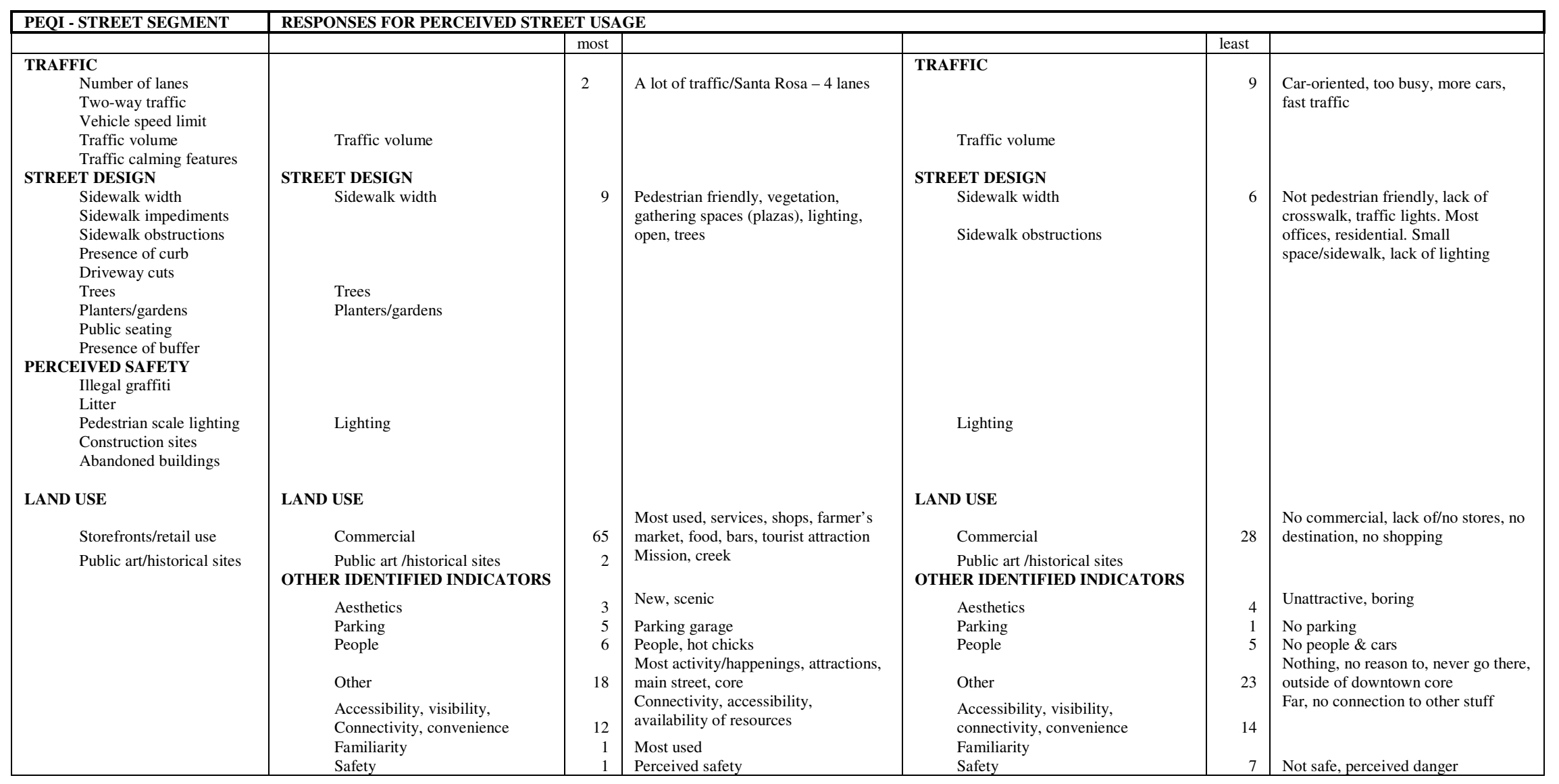

PEQI indicators versus Survey respondents' identified indicators for Perceived Street Usage 


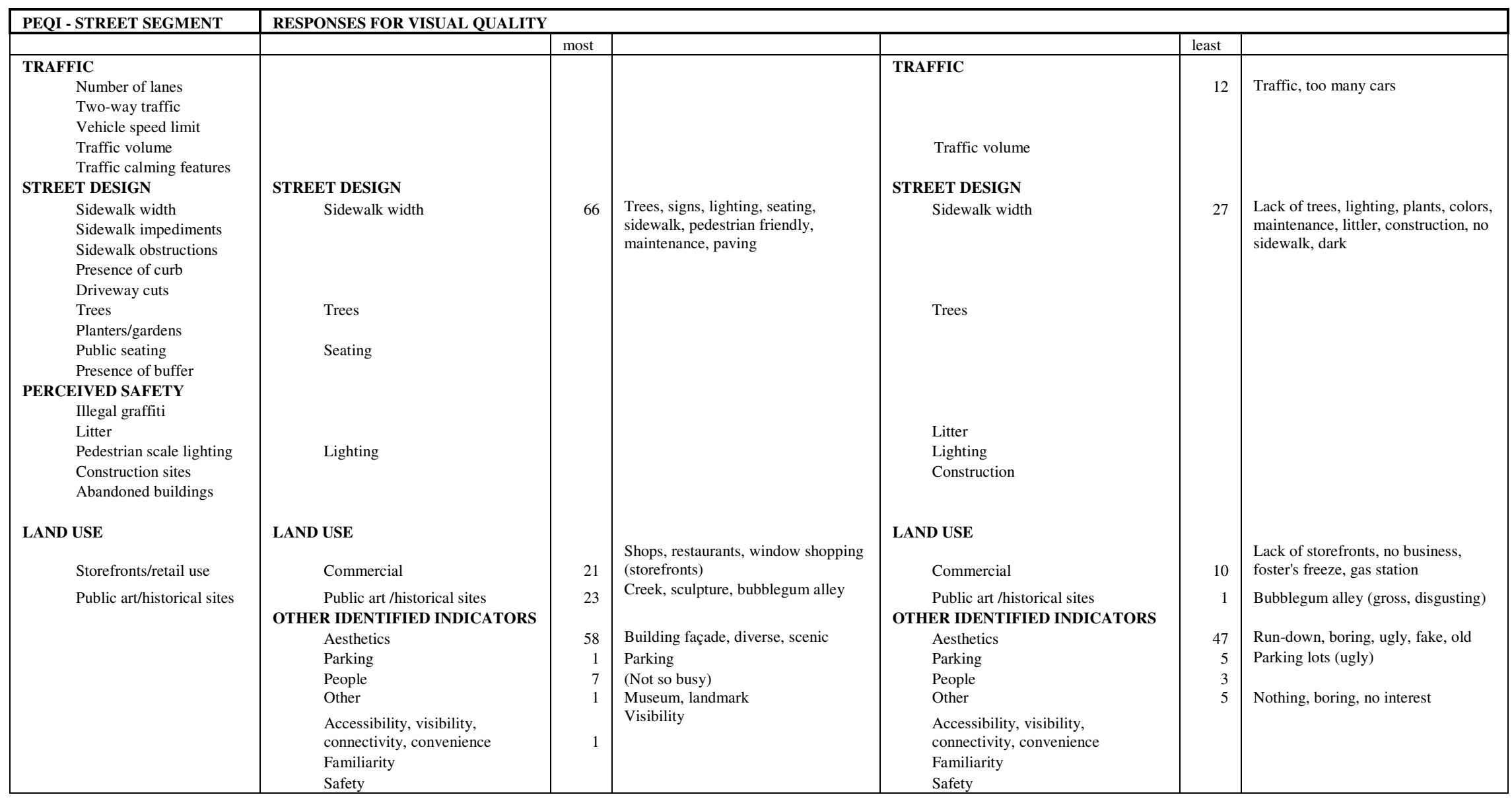

PEQI indicators versus Survey respondents' identified indicators for Visual Quality 


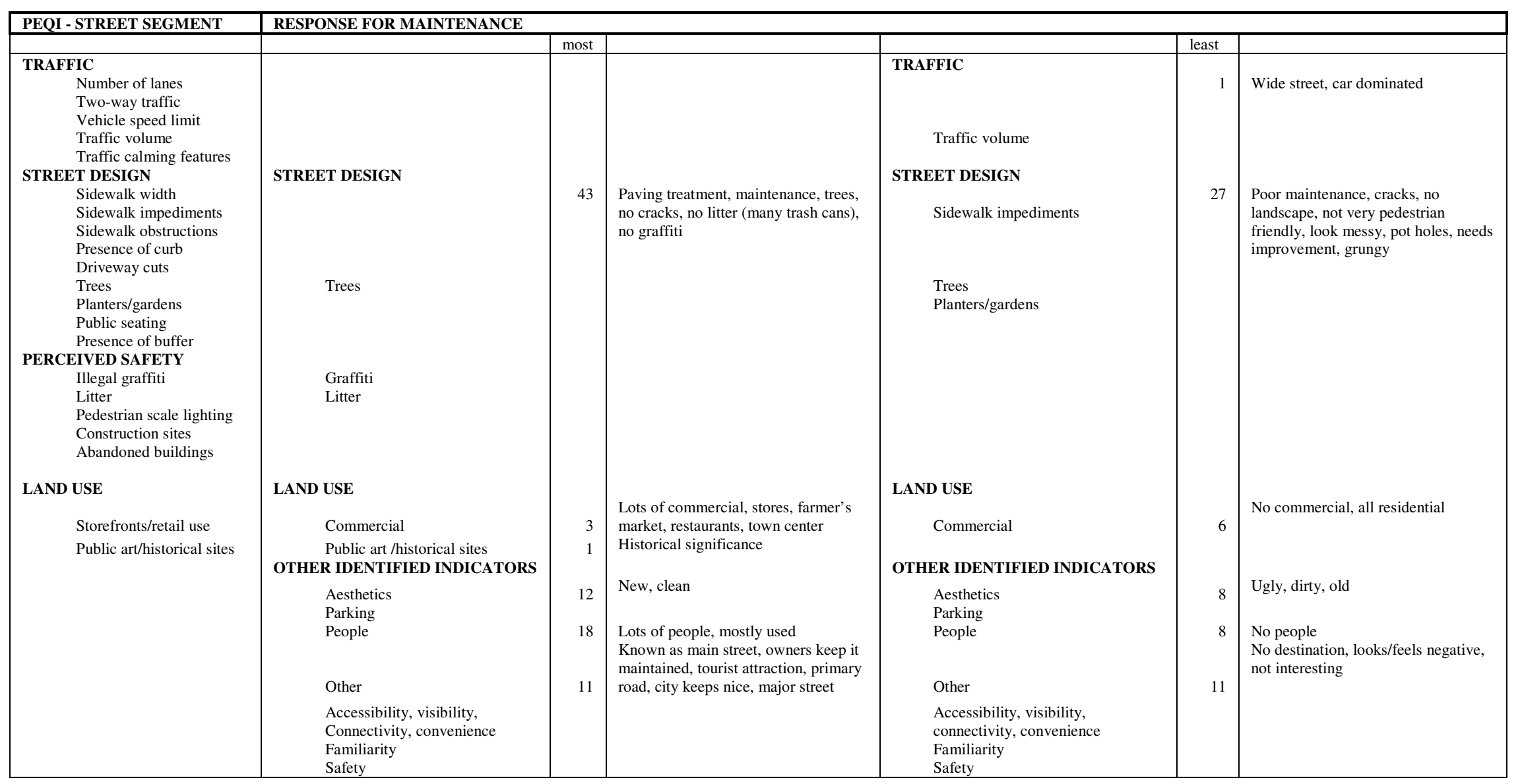

\section{PEQI indicators versus Survey respondents' identified indicators for Maintenance}




\title{
Appendix E: Aggregated Data from PEQI indicators versus Survey respondents'
}

\author{
identified indicators for each category table
}

\section{Leisure Walk Table}

\begin{tabular}{|l|l|l|}
\hline Most & Least & Total \\
\hline Commercial/other $75+34=109$ & Other/commercial 59+15=64 & Commercial/other 173 \\
Accessibility 26 & Street design 17 & Street Design 34 \\
Street design 17 & Traffic 16 & Accessibility 33 \\
Parking 16 & Aesthetics/accessibility 7/7 & Aesthetics 21 \\
Public art 14 & Parking 4 & Parking 20 \\
Aesthetics 14 & Public art 2 & Public art 16 \\
People 7 & People 1 & People 8 \\
\hline
\end{tabular}

\section{Comfort Table}

\begin{tabular}{|l|l|l|}
\hline Most & Least & Total \\
\hline People 51 & Traffic 38 & People 77 \\
Street design 47 & People 26 & Other/commercial 59 \\
Other/commercial $25+16=41$ & Other/commercial $15+3=18$ & Traffic 52 \\
Familiarity 18 & Safety 12 & Street design 50 \\
Traffic 14 & Accessibility 5 & Familiarity 23 \\
Aesthetics 12 & Familiarity 5 & Aesthetics 16 \\
Parking 7 & Aesthetics 4 & Safety 13 \\
Accessibility 4 & Parking 4 & Parking 11 \\
Safety 1 & Street design 3 & Accessibility 9 \\
\hline
\end{tabular}

\section{Intersection Saftey Table}

\begin{tabular}{|l|l|l|}
\hline Most & Least & Total \\
\hline Safety 29 & Traffic 45 & Traffic 69 \\
Traffic lights 28 & Safety 33 & Safety 62 \\
Traffic 24 & Traffic lights 9 & Traffic lights 37 \\
Crosswalk 15 & People 8 & Crosswalks 20 \\
Flashing lights 14 & Signs 6 & People 17 \\
People 9 & Accessibility 6 & Flashing lights 14 \\
Accessibility 6 & Crosswalk 5 & Accessibility 12 \\
Familiarity 3 & Commercial 1 & Signs 6 \\
Commercial 1 & & Familiarity 3 \\
& & Land use 2 \\
\hline
\end{tabular}




\section{Street Safety Table}

\begin{tabular}{|l|l|l|}
\hline Most & Least & Total \\
\hline Traffic 29 & Traffic 40 & Traffic 69 \\
Safety 20 & Street design 31 & Safety 34 \\
Accessibility 8 & People 18 & Street design 34 \\
Commercial/other 4+4=8 & Safety 14 & People 21 \\
Aesthetics 3 & Other/commercial 4+1=5 & Other/commercial 13 \\
Street design 3 & Familiarity 3 & Accessibility 9 \\
Familiarity 3 & Accessibility1 & Familiarity 6 \\
People 3 & & Aesthetics 3 \\
\hline
\end{tabular}

\section{Perceived Street Usage Table}

\begin{tabular}{|l|l|l|}
\hline Most & Least & Total \\
\hline Commercial/other $65+18=83$ & Commercial/other 28+23=51 & Commercial/other 134 \\
Accessibility 12 & Accessibility 14 & Accessibility 26 \\
Street design 9 & Traffic 9 & Street design 15 \\
People 6 & Safety 7 & Traffic 11 \\
Parking 5 & Street design 6 & People 11 \\
Aesthetics 3 & People 5 & Safety 8 \\
Traffic 2 & Aesthetics 4 & Aesthetics 7 \\
Public arts 2 & Parking 1 & Parking 6 \\
Familiarity 1 & & Public arts 2 \\
Safety 1 & & Familiarity 1 \\
\hline
\end{tabular}

\section{Visual Quality Table}

\begin{tabular}{|l|l|l|}
\hline Most & Least & Total \\
\hline Street design 66 & Aesthetics 47 & Aesthetics 105 \\
Aesthetics 58 & Street design 27 & Street design 93 \\
Public art 23 & Traffic 12 & Commercial/other 37 \\
Commercial/other 21+1=22 & Commercial/other 10+5=15 & Public art 24 \\
People 7 & Parking 5 & People 10 \\
Parking 1 & People 3 & Parking 6 \\
Accessibility 1 & Public art 1 & Accessibility 1 \\
\hline
\end{tabular}

\section{Maintenance Table}

\begin{tabular}{|l|l|l|}
\hline Most & Least & Total \\
\hline Street design 43 & Street design 27 & Street design 70 \\
People 18 & Other/commercial 11+6=17 & Other/commercial 31 \\
Aesthetics 12 & Aesthetics 8 & People 26 \\
Other/commercial $11+3=14$ & People 8 & Aesthetics 20 \\
Public art 1 & Traffic 1 & Public art 1 \\
& & Traffic 1 \\
\hline
\end{tabular}




\section{Bibliography}

Addy, C. L., Wilson, D., Kirtland, K. A., Ainsworth, B. E., Sharpe, P., \& Kimsey, D. (2004). Associations of Perceived Social and Physical Environmental Supports wth Physical Activity and Walking Behavior. American Journal of Public Health, 94 (3), 440-442.

Agrawal, A. W., Schlossberg, M., \& Irvin, K. (2008). How Far, by which Route and Why? A Spatial Analysis of Pedestrian Preference. Journal of Urban Design , 13 (1), 81-98.

Alfonzo, M., Boarnet, M. G., Day, K., McMillan, T., \& Anderson, C. L. (2008). The Relationship of Neighborhood Built Environment Features and Adult Parents' Walking. Journal of Urban Design , 13 (1), 29-51.

Ball, K., Bauman, A., Leslie, E., \& Owen, N. (2001). Perceived Environmental Aesthetics and Convenience and Company Are Associated with Walking for Exercise among Australian Adults. Preventive Medicine, 33, 434-440.

Baran, P. K., Rodriguez, D. A., \& Khattak, A. J. (2008). Space Syntax and Walking in a New Urbanist and Suburban Neighbourhoods. Journal of Urban Design, 13 (1), 5-28.

Bhatia, R., \& Wernham, A. (2008). Integrating Human Health into Environmental Impact Assessment: An Unrealized Opportunity for Environmental Health and Justice. Environmental Health Perspectives , 116 (8), 991-1000.

Booth, M. H., Owen, N., Bauman, A., Clavisi, O., \& Leslie, E. (2000). Social-Cognitive and Perceived Environmental Influences Associated with Physical Activity in Older Australians. Preventive Medicine , 31, 15-22.

Brown, B. B., Werner, C. M., Amburgey, J. W., \& Szalay, C. (2007). Walkable Route Perceptions and Physical Features: Converging Evidence for En Route Walking Experience. Environmental Design Research Association , 39 (1), 34-61.

Brownson, R. C., Baker, E. A., Housemann, R. A., Brennan, L. K., \& Bacak, S. J. (2001). Environmental and Policy Determinants of Physical Activity in the United States. American Journal of Public Health , 91 (2), 1995-2003.

Brownson, R. C., Hoehner, C. M., Day, K., Forsyth, A., \& Sallis, J. F. (2009). Measuring the Built Environment for Physical Activity. American Journal of Preventive Medicine, 36 (4S), S99-S123. 
Carver, A., Salmon, J., Campbell, K., Baur, L., Garnett, S., \& Crawford, D. (2005). How do perceptions of local neighborhood relate to adolescents' walking and cycling? The Science of Health Promotion, 20 (2), 139-147.

Centers for Disease Control and Prevention. (2003). Prevalence of Physical Activity, including Lifestyle Activities among Adults -- United States, 2000-2001. Morbidity and Mortality Weekly Reports , 52 (32), 764-769.

Clemente, O., Ewing, R., Handy, S., Brownson, R., \& Winston, E. (2005). Measuring Urban Design Qualities - An Illustrated Field Manual. Princeton: Robert Wood Johnson Foundation.

Creswell, J. W. (2009). Research Design. Los Angeles: Sage Publications, Inc.

Emery, J., Crump, C., \& Bors, P. (2003). Reliability and Validity of Two Instruments Designed to Assess the Walking and Bicycling Suitability of Sidewalks and Roads. American Journal of Health Promotion, 18 (1), 38-46.

Evans-Cowley, J. (2006). Sidewalk Planning and Policies in Small Cities. Journal of Urban Planning and Development, 132, 71-75.

Finnis, K. K., \& Walton, D. (2008). Field Observation to Determine the Influence of Population Size, Location, and Individual Factors on Pedestrian Walking Speeds. Ergonomics , 51 (6), 827-842.

Forsyth, A., Hearst, M., Oakes, J. M., \& Schmitz, K. H. (2008). Design and Destinations: Factors Influencing Walking and Total Physical Activity. Urban Studies Journal Limited, 45 (9), 1973-1996.

Foster, C., Hillsdon, M., \& Thorogood, M. (2004). Environmental perceptions and walking in English adults. Journal of Epidemiol Community Health, 58, 924-928.

Frank, L. D., Saelens, B. E., Powell, K. E., \& Chapman, J. E. (2007). Stepping towards causation: Do built environments or neighborhood and travel preferences explain physical activity, driving, and obesity? Social Science \& Medicine , 65, 1898-1914.

Giles-Corti, B., \& Donovan, R. J. (2002). Socioeconomic Status Differences in Recreational Physical Activity Levels and Real and Perceived Access to a Supportive Physical Environment. Preventive Medicine , 35, 601-611.

Graham, D. J., \& Glaister, S. (2003). Spatial Variation in Road Pedestrian Casualties: The Role of Urban Scale, Density and Land-use Mix. Urban Studies , 40 (8), 1591-1607.

Hoehner, C. M., Ivy, A., Ramirez, L. K., Handy, S., \& Brownson, R. C. (2007). Active Neighborhood Checklist: A User-Friendly and Reliable Tool for Assessing Activity Friendliness. American Journal of Health Promotion, 21 (6), 534-537. 
Humpel, N., Owen, N., Leslie, E., Marshall, A., Bauman, A. E., \& Sallis, J. F. (2004). Associations of Location and Perceived Environmental Attributes With Walking in Neighborhoods. The Science of Health Promotion , 18 (3), 239-242.

Isaacs, R. (2000). The Urban Picturesque: An Aesthetic Experience of Urban Pedestrian Places. Journal of Urban Design , 5 (2), 145-180.

Jackson, R. B., Carpenter, S. R., Dahm, C. N., McKnight, D. M., Naiman, R. J., Postel, S. L., et al. (2001). Water in a Changing World. Ecological Applications , 11, 1027-1045.

Jacobs, A. B. (1995). Great Streets. Cambridge: MIT Press.

Jervis, R. (2004). The Implications of Prospect Theory for Human Nature and Values. International Society of Political Pschology, 25 (2), 163-176.

King, W. C., Brach, J. S., Belle, S., Killingsworth, R., Fenton, M., \& Kriska, A. M. (2003). The Relationship Between Convenience of Destinations and Walking Levels in Older Women. Americal Journal of Health Promotion , 18 (1), 74-82.

Kirtland, K. A., Porter, D. E., Addy, C. L., Neet, M. J., Williams, J. E., Sharpe, P. A., et al. (2003). Environmental Measures of Physical Activity Supports Perception Versus Reality. American Journal of Preventive Medicine , 24 (4), 323-331.

Koplan, J. P., Lliverman, C. T., \& Kraak, V. I. (2005). Preventing Childhood Obesity: Health in the Balance Executive Summary. Journal of the American Dietetic Association, 105 (1), 131-138.

Kyle, A. D., Woodruff, T. J., \& Axelrad, D. A. (2006). Integrated Assessment of Environment and Health: America's Children and the Environment. Environmental Health Perspectives, 114 (3), 447-452.

Lin, J.-J., \& Yang, A.-T. (2009). Structural Analysis of How Urban Form Impacts Travel Demand: Evidence from Taipei. Urban Studies Journal Limited , 46 (9), 1951-1967.

Macera, C. A., Ham, S. A., Yore, M. M., Jones, D. A., Ainsworth, B. E., Kimsey, D., et al. (2005). Prevalence of Physical Activity in the United States: Behavioral Risk Factor Surveillance System, 2001. Preventing Chronic Disease: Public Health Research, Practice, and Policy, 2 (2), 1-10.

Rainham, D. G., \& McDowell, I. (2005). The Sustainability of Population Health. Population and Environment , 26 (4), 303-324.

Sallis, J. F., \& Glanz, K. (2006). The Role of Built Environments in Physical Activity, Eating, and Obesity in Childhood. The Future of Children , 16 (1), 89-108. 
San Francisco Department of Public Health. (2008). The Pedestrian Enviornmental Quality Index (PEQI): An assessment of the physcial condition of streets and intersections. Retrieved October 5, 2009, from Program on Health, Equity, and Sustainability: http://www.sfphes.org/HIA_Tools_PEQI.htm

San Luis Obispo Chamber of Commerce. (2010). San Luis Obispo - One of the country's Best Places. Retrieved August 8, 2010, from San Luis Obispo Champer of Commerce: http://visitslo.com/cm/About\%20SLO/accolades.html

San Luis Obispo Downtown Association. (2010). San Luis Obispo Downtown Association Home. Retrieved August 8, 2010, from San Luis Obispo Downtown Association: http://www.downtownslo.com/

Santana, P., Santos, R., \& Nogueira, H. (2009). The Link between Local Environment and Obesity: A Multilevel Analysis in the Lisbon Metropolitan Area, Portugal. Social Science and Medicine , 68, 601-609.

Southworth, M. (2005). Designing the Walkable City. Journal of Urban Planning and Development, 131 (4), 246-257.

Trasande, L., Cronk, C., Durkin, M., Weiss, M., Schoeller, D. A., Gall, E. A., et al. (2009). Environment and Obesity in the National Children's Study. Environmental Health Perspectives , 117 (2), 159-166.

Wen, M., \& Zhang, X. (2009). Contextual Effects of Built and Social Environments of Urban Neighborhoods on Exercise: A Multilevel Study in Chicago. American Journal of Health Promotion, 23 (4), 247-254.

Wilson, D. K., Kirtland, K. A., Ainsworth, B. E., \& Addy, C. L. (2004). Socioeconomic status and perceptions of access and safety for physical activity. The Society of Behavioral Medicine , 28 (1), 20-28. 